Opportunity \&

Inclusive Growth

T]

M

$\rightarrow$ is

FEDERAL RESERVE BANK OF MINNEAPOLIS

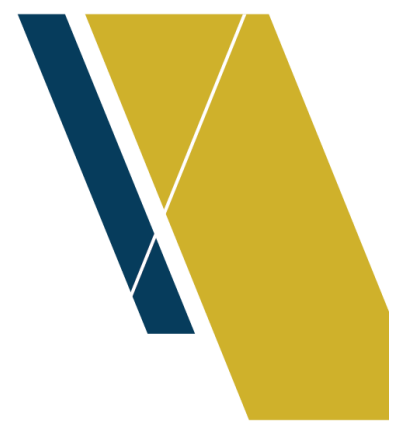

INSTITUTE WORKING PAPER

No. 54

\title{
Social Transfers and Spatial Distortions
}

November 2021

\section{Mark Colas \\ University of Oregon \\ Robert McDonough \\ University of Oregon}

DOI: https://doi.org/10.21034/iwp.54

Keywords: Social transfers; Local labor markets; Spatial equilibrium JEL classification: R13, I38, H21

The views expressed herein are those of the authors and not necessarily those of the Federal Reserve Bank of Minneapolis or the Federal Reserve System. 


\title{
Social Transfers and Spatial Distortions*
}

\author{
Mark Colas ${ }^{\dagger}$ \\ Robert McDonough ${ }^{\ddagger}$
}

November 8, 2021

\begin{abstract}
US social transfer programs vary substantially across states, incentivizing households to locate in states with more generous transfer programs. Further, transfer formulas often decrease in income, therefore rewarding low-income households for living in low-paying cities. We quantify these distortions by combining a spatial equilibrium model with a detailed model of transfer programs in the US. The current system leads to locational inefficiency of $4.38 \%$ of total transfer spending. A reform that both harmonizes transfer policies across states and indexes household income to local average earnings reduces this inefficiency by over 85 percent while still preserving the programs' means-tested nature.
\end{abstract}

JEL Classification: R13, I38, H21

Keywords: Social transfers, local labor markets, spatial equilibrium

${ }^{*}$ We would like to thank David Albouy, Shoya Ishimaru, Mike Kuhn, John M. Morehouse, Kegon Tan, Woan Foong Wong, and participants at the Rochester Applied Micro Conference. This work benefited from access to the University of Oregon high performance computer, Talapas.

†University of Oregon. Email: mcolas@uoregon.edu

$\ddagger$ University of Oregon. Email: rmcdono2@uoregon.edu 


\section{Introduction}

There is substantial variation in generosity of social transfers programs across states; a married household with two children and no income in 2017 could receive $\$ 1230$ in monthly Temporary Assistance for Needy Families (TANF) benefits in New Hampshire, while the same married household in Louisiana would be ineligible for TANF. ${ }^{1}$ Economists and policymakers have long debated whether these differences in transfer generosity lead poor households to migrate to locations with more generous transfer programs (so called "welfare magnets"), thereby distorting the distribution of households across space. ${ }^{2}$

Further, social transfers schedules are often decreasing in household income; household with lower income receive larger benefit payouts, all else equal. The means-tested nature of these programs helps to reduce inequality and target resources at households with the greatest need. However, this same feature also reduces the returns of living in highly productive locations, as moving to a city where a household will receive higher pay may also lead to a reduction in transfers received. ${ }^{3}$ Therefore, means-tested social transfers may distort the location decisions of poor households by rewarding locating in less productive cities.

To quantify these distortions, we build a quantitative spatial equilibrium model and embed within it a model of social transfer programs in the US. Locations vary in productivity levels, amenities, housing supply, and social transfer programs. Households choose the location which maximizes utility as a discrete choice. Wages and rents are determined in equilibrium. Transfer schedules vary across states, creating incentives for households to locate in states with more generous welfare programs. As in the models of Rosen (1979) and Roback (1982), households earn higher income in more productive cities, which creates an incentive to locate in these cities. However, these incentivizes are muted by the fact the social transfers schedules are decreasing in income; moving to a more productive city implies higher income but lower social transfers. Therefore, social transfers

\footnotetext{
${ }^{1}$ This applies to able-bodied households who meet the general eligibility criteria for TANF. We discuss the details of TANF eligibility in Appendix B.1.2.

${ }^{2}$ See e.g. Blank (1988), Borjas (1999), or Gelbach (2004).

${ }^{3}$ See Glaeser and Mare (2001) or Moretti (2011), for example, for evidence that differences in average income across cities reflect, at least partially, city-level productivity differences.
} 
can lead to both an earnings distortion - an incentive to locate in low-wage cities - and a generosity distortion - an incentive to locate in states with more generous social transfer programs. ${ }^{4}$

The model incorporates two social transfers programs, the Supplemental Nutrition Assistance Program (SNAP) and Temporary Assistance for Needy Families (TANF) programs, two of the largest social transfer programs in the US. ${ }^{5}$ SNAP is the highly progressive: in the phase-out region, a one dollar increase in earnings leads to a 24 cent decrease in SNAP benefits. Therefore, moving to a high-productivity location can lead to a large decrease in SNAP benefits. Further, while the SNAP benefits schedule is fixed across states, ${ }^{6}$ eligibility criteria and the ease at which households can apply for and receive benefits do vary across states. TANF, on the other hand, is administered at the state level and benefit schedules vary substantially across states in their overall generosity, their progressivity, and the extent to which benefits differ across various demographic groups. Our model incorporates these differences in TANF and SNAP programs across states, in addition to the non-linearities, kinks, and discontinuities present in the programs and the differences in eligibility and benefits allotment by household size and marital status. This allows us to capture the complex system of spatial incentives created by these programs and to understand how these incentives differ across households.

Households are heterogeneous and vary in their race, marital status, number of children, experience group and education level. These household demographic characteristics play an important role in determining the amount of transfers a

\footnotetext{
${ }^{4}$ Throughout, we focus on distortions to household location choice, and abstract away from distortions to labor force participation, hours worked, or household formation.

${ }^{5}$ Despite a decrease in TANF caseload over time, TANF and SNAP were the two largest sources of income besides earnings for families with children in extreme poverty in 2008, ahead of unemployment compensation, worker's compensation, and social security disability insurance income (Bitler and Hoynes, 2010). Besides these programs, other large programs in the US "safety-net" include tax credit programs, such as the Earned Income Tax Credit; social insurance programs, such as disability insurance and unemployment insurance; Supplemental Security Income; and Medicaid. Our analysis could be extended to include tax credits. In order to incorporate these into our model, we would also need to model the federal income tax program, which creates distortions of its own. Albouy (2009) and Colas and Hutchinson (2021) quantify the efficiency costs of federal income taxes in a spatial equilibrium setting.

${ }^{6}$ The exceptions are Hawaii and Alaska, which have different parameters in their SNAP formulas.
} 
household receives. First, demographic groups differ in their productivity and therefore their income levels. These income levels determine whether and where a household will be eligible for SNAP and TANF. Only relatively low-income households are eligible for transfers, ${ }^{7}$ implying that more productive demographic groups may be ineligible for social transfers regardless of where they live. Second, household demographics directly determine benefits through differences in demographic allotments in the social transfer functions. Finally, different demographics vary in their preferences over locations and thus their distribution across locations. Therefore, social transfers vary across demographic groups through differences productivity, differences in location choice, and through the dependence of social transfer functions on demographic characteristics directly.

We quantify the model by utilizing data from the American Community Survey (ACS), the Survey of Income and Program Participation (SIPP), locationspecific policy parameters of SNAP and TANF programs, and data on SNAP implementation across states. To quantify the parameters of household utility and therefore the household location choice, we combine data on household demographics, income, rent and location choice from the ACS with estimates of location choice elasticities from Colas and Hutchinson (2021). ${ }^{8}$ For our quantification of social transfer programs, we directly utilize location-specific formulas of TANF and SNAP. We use publications from the United States Department of Agriculture to quantify the SNAP benefit schedule. In cataloging the state variation in TANF programs, we rely heavily on the parameters and documentation collected by the Welfare Rules Database (The Urban Institute, 2019), in addition to state TANF manuals. ${ }^{9}$ We supplement this quantification of transfer programs with demographic specific take-up rates of TANF and SNAP that we estimate by combining SIPP data on program participation with data on SNAP application procedures and implementation across states from the SNAP Policy Database (Economic Research Service, 2019).

\footnotetext{
${ }^{7}$ For example, gross monthly income must generally be below 1.3 times the poverty line for a household to be eligible for SNAP.

${ }^{8}$ We also calculate our results using parameters from Notowidigdo (2020) in Section 6.1. The results are qualitatively similar to our main results but slightly larger in magnitude.

${ }^{9}$ See the Welfare Rules Databook (Heffernan et al., 2018) for additional documentation of state-level TANF programs.
} 
We then use the estimated model to quantify the spatial distortions caused by the current SNAP and TANF programs by comparing the equilibrium with the current programs to an equilibrium where social transfers are paid lump-sum. ${ }^{10}$ We find that these programs lead to a substantial increase in the number of high school dropouts living in low-income cities. This leads to an increase in earnings inequality; average earnings of high school dropout households decrease by $0.33 \%$ compared to the equilibrium with non-distortionary lump-sum transfers. The distortions are especially large for households with children and racial minorities. The distortion towards locations with more generous transfer programs is smaller, in part because low-education households strongly prefer to live near their places of birth, and therefore are unlikely to locate in distant places in order to take advantage of differences in transfer generosity across states. Concretely, high school dropout households from Louisiana are unlikely to locate in New Hampshire, despite the stark difference in social transfer generosity between the two states. Further, the generosity distortion is partially counteracted by the fact that states with more generous transfer programs also tend to have higher productivity levels. Overall, the distortions caused by the current transfer programs lead to a deadweight loss equal to $4.38 \%$ of total transfer payments. ${ }^{11}$

Next, we consider three alternative transfer programs aimed at reducing the inefficiencies of the current programs. As a first alternative transfer program, we attempt to eliminate the earnings distortion by indexing the earnings used to calculate transfer benefits to local average earnings levels, such that households do not receive larger benefit amounts for locating in low-productivity cities. ${ }^{12}$ This leads to a roughly $70 \%$ decrease in deadweight loss to $1.22 \%$ of total transfer spending, as the incentive to locate in low-productivity cities is effectively removed. However, the generosity distortion is exacerbated, as the number of high school dropout households in states with more generous transfer program increases markedly. As the second possible policy intervention, we simulate the

\footnotetext{
${ }^{10}$ Social transfers are the only source of inefficiency in the model, so all equilibria with lumpsum transfers are efficient. Specifically, we use the equilibrium where total transfers provided to each demographic group are the same as under the current transfer systems.

${ }^{11}$ A model based decomposition reveals that over $90 \%$ of this deadweight loss is generated by SNAP, with the remainder due to TANF.

${ }^{12}$ We also consider a cost-of-living adjustment in Appendix D.8.
} 
effects of harmonizing transfer schedules across states, thereby eliminating the generosity distortion. This reduces locational inefficiency by considerably less than the earning index: deadweight loss decreases by only $10 \%$ to $3.95 \%$ of total transfer spending. ${ }^{13}$ Taken together, the results from these two first two alternative transfer programs suggest that the earnings distortion, and not the generosity distortion, is responsible for the majority of the locational efficiency caused by the current transfer system.

Finally, we consider a combined program which both harmonizes transfer programs across locations and introduces an earnings index. We find that this combined policy intervention decreases deadweight loss by over $85 \%$. We show that this combined program leads to a decrease in earnings inequality and that the gains in efficiency from this program are larger than the sum of the gains from harmonizing transfers or the earnings index in isolation. Our results suggest that targeting both the earnings and generosity distortion caused by the current transfer programs can substantially reduce locational inefficiency while still preserving the fundamental means-tested nature of these programs.

This paper is related to a literature on "welfare migration" which analyzes the extent to which households move towards locations with more generous welfare programs (Blank, 1988; Walker, 1994; Enchautegui, 1997; Levine and Zimmerman, 1999; Meyer, 1998; Gelbach, 2004; Kennan and Walker, 2010). This paper incorporates differences in social transfer generosity across locations into a fully specified spatial equilibrium model and also highlights that the means-tested nature of welfare programs can disincentive households from moving to higher-paying locations. We show that in today's welfare environment, household location decisions are distorted predominately towards locations with low productivity, not towards so-called "welfare-magnet" states with generous transfer programs. To the best of our knowledge, ours is the first paper to quantify the locational inefficiency resulting from the progressivity of social transfers.

Notowidigdo (2020) estimates the extent to which low out-migration rates of low-skilled workers in response to local labor market shocks can be explained by increases in transfers paid when local economic conditions deteriorate. ${ }^{14}$ The paper

\footnotetext{
${ }^{13}$ We keep total spending on social transfers constant across counterfactuals. For this counterfactual, we make up for any differences in transfer spending by introducing lump-sum transfers.

${ }^{14}$ The paper also finds that decreases in housing costs when a city experiences a negative
} 
first provides reduced-form evidence for the role of transfers in reducing migration rates of low-skilled workers. The paper then estimates a spatial equilibrium model via GMM and finds that transfer payments mostly explain the difference in out-migration rates between low- and high-skilled workers. While Notowidigdo (2020) focuses on the effect of local welfare programs on out-migration of workers from a given location, this paper focuses on the effects of transfer programs on the equilibrium distribution of heterogeneous households across cities. ${ }^{15}$

A recent literature has quantified the distortionary effect of federal and state income taxes in spatial equilibrium (Albouy, 2009; Fajgelbaum et al., 2019; CoenPirani, 2021; Colas and Hutchinson, 2021). ${ }^{16}$ This paper instead uses a spatial equilibrium model to study the distortion caused by social transfer programs, which 1) can vary spatially and 2) are generally decreasing in income. Both these factors imply transfers can lead to spatial distortions. Further, while income taxes generally lead to larger distortions for high-skilled households (Colas and Hutchinson, 2021), the social transfers we highlight here almost exclusively affect low-income and low-skilled households. We are the first paper in this literature to quantify the locational inefficiency of social transfer programs.

Finally, this paper is related to a number of model-based papers quantifying the distortionary effects of social transfer programs on labor supply, household formation, and human capital accumulation; and quantifying the resulting welfare consequences (see e.g., Greenwood, Guner, and Knowles (2000), Keane and Wolpin (2010), Chan (2013), Blundell et al. (2016), Low et al. (2018), Guner, Kaygusuz, and Ventura (2020), or Ortigueira and Siassi (2021)). In order to focus on the effects of social transfers on location choice, we abstract away from these margins in our paper. ${ }^{17}$ We contribute to this literature by showing that the ef-

shock also leads to less out-migration of low-skilled workers.

${ }^{15}$ This paper also includes a richer formulation of social transfers functions than Notowidigdo (2020), who assumes social transfers are given by a constant elasticity function of wages. The welfare functions in this paper comes directly from the policy rules of SNAP and TANF, without assuming a particularly functional form, and take into account how these rules vary across locations and by household demographics.

${ }^{16}$ Relatedly, Fajgelbaum and Gaubert (2020) characterize the optimal system of location- and group-specific transfers in a model with heterogeneous workers and spillovers.

${ }^{17}$ Including these margins would likely increase the efficiency costs of social transfers. If labor supply were endogenous, for example, transfers would distort both location choice and labor supply. We discuss further the implications of assuming inelastic labor supply in Section 6.2. 
fect of social transfers on household location choice, previously absent from this literature, is responsible for a substantial efficiency cost.

The rest of the paper proceeds as follows. In Section 2 we introduce the SNAP and TANF programs and discuss how transfer benefits may vary based on where a household lives. Section 3 presents our spatial equilibrium model. Section 4 presents our data sources and describes how we quantify our spatial equilibrium model and social transfer programs. In Section 5 we present our main counterfactual results and in Section 6 we examine the robustness of these results. Section 7 concludes.

\section{Social Transfers Across Space}

The federal government has provided food assistance and direct cash assistance to needy families for nearly 100 years under a variety of programs. SNAP and TANF, which offer food and cash benefits respectively, are two of the largest transfer programs for vulnerable households in the United States. In 2017, SNAP provided 64 billion dollars in food benefits to roughly 42 million households. TANF provided basic cash assistance totaling 7 billion dollars during the same year.

Though SNAP and TANF are grounded in federal legislation, the amount of TANF or SNAP benefit a household receives is highly dependent on location choice. Indeed, whether or not a family is even eligible for SNAP or TANF is intimately tied to their place of residence. The dependence of social transfers on location is the consequence of two factors: (1) means testing and (2) policy variation between states. To see how these two factors influence transfer payments, first note that the formulas for SNAP benefits nationally and TANF benefits in most states follow the same basic structure. ${ }^{18}$ To start, family size determines the maximum potential benefit a household can receive. To determine the actual benefit payment, a weakly increasing function of the household's unearned and earned income is subtracted from this maximum. ${ }^{19}$

\footnotetext{
${ }^{18}$ We explain the SNAP and TANF formulas, including how the formulas vary across states, in Appendices B.1.1 and B.1.2.

${ }^{19}$ This formula mimics the formula for the Aid to Families with Dependent Children program, the predecessor of TANF.
} 


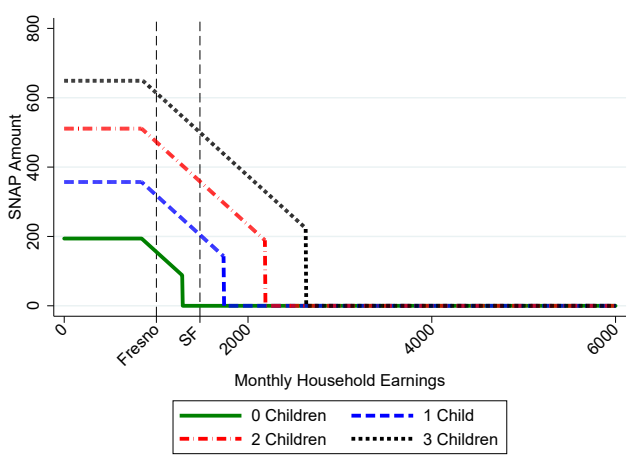

(a) Single

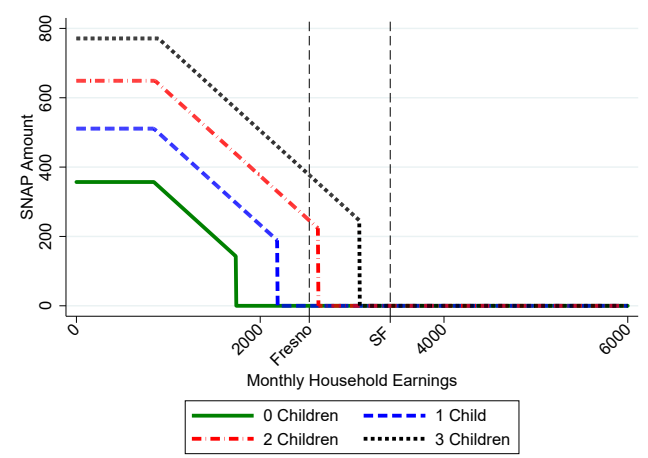

Married

Figure 1: Monthly SNAP benefits as a function of earnings in 2017 for (a) single households and (b) married households. For this graph, we assume that 1) households are not made ineligible by asset tests or term limits, 2) their only source of income is earned income, 3) the household takes the maximum allowed excess-shelter deduction, and 4) the household only takes the standard deduction and the excess-shelter deduction. The vertical lines give the average wage income of household head and spouse for high school dropout households living in either the Fresno CBSA or the San Francisco CBSA. Calculations are from the 2017 ACS.

Means Testing and the Earnings Distortion The amount of benefits a household receives based on this type of formula will vary with location due to means testing. Since household earnings enter into benefit calculation, differences in wage levels across US states and cities translate into differences in transfer payments. More concretely, Figure 1 displays the amount of monthly SNAP benefits as a function of monthly earnings for families with different numbers of children in 2017. ${ }^{20}$ The graph on the left shows the schedules for single households and the figure on the right shows the schedule for married households. ${ }^{21}$ The benefits formulas are highly progressive: in the phase-out region of the benefits formulas each additional dollar of earnings leads to a 24 cent decrease in SNAP benefits.

On this same figure we also plot the average household earnings for high school dropout households of the corresponding marital status who live in either Fresno,

\footnotetext{
${ }^{20}$ For this graph, we assume that 1) households are not made ineligible by asset tests or term limits, 2) their only source of income is earned income, 3) the household takes the maximum allowed excess-shelter deduction, and 4) the household only takes the standard deduction and the excess-shelter deduction.

${ }^{21}$ The schedules vary by household size; the graph shows the schedules for three and four family households. The benefits formulas for other family sizes share the same shape and the maximum allotment (the Y intercept of the formula) is strictly increasing in household size.
} 
California; or the San Francisco Bay Area. ${ }^{22}$ For both single and married households, the average household earning is considerably higher in San Francisco than in Fresno. These differences in earnings can lead to large differences in benefits. As an extreme example, consider two married households with three children, one who lives lives in San Francisco, one who lives in Fresno, and both who have earnings equal to the average earnings in their respective city. As a result of the differences in earnings, the household in Fresno would receive nearly $\$ 400$ in monthly SNAP benefits while the household in San Francisco would not receive any benefits. More generally, we can see that households with San Francisco's average earnings receive less transfers than households with Fresno's average earnings; however, the magnitude of the disparity depends on marital status and number of children. Furthermore, we can also imagine that higher-income households, such as households with higher education levels, may be ineligible for SNAP regardless of where they live.

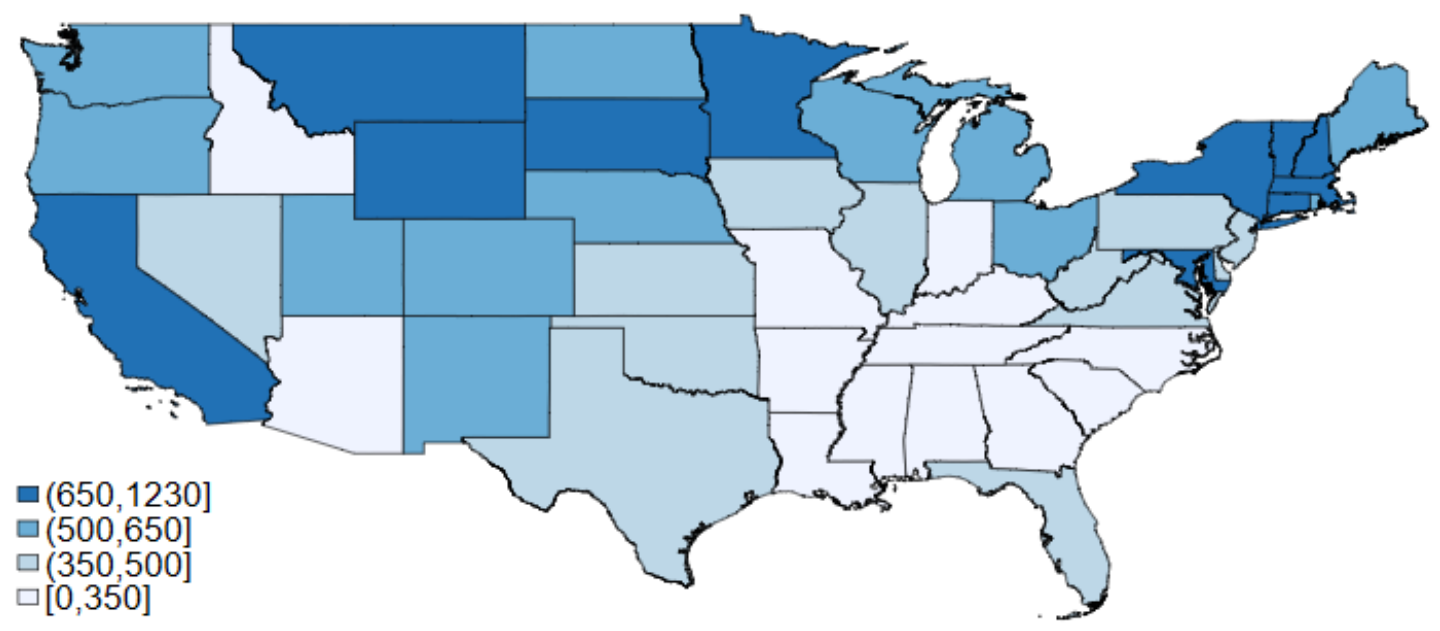

Figure 2: Maximum possible TANF benefits (in dollars) for married households with able-bodied parents and two children in each state in 2017.

Policy Variation and the Generosity Distortion Due to differences in state policy, though, holding earnings constant across location does not lead to equal benefit payments across space. Since the reform efforts of the 1990s, states have

\footnotetext{
${ }^{22}$ This is average wage income of household head and spouse for households who's head is a high school dropout living in either the Fresno CBSA or the San Francisco CBSA. Calculations are from the 2017 ACS.
} 
had substantial freedom - of which most states have taken advantage - to change their implementation of TANF, and to a lesser extent SNAP. First, states have wide latitude to alter the eligibility and accessibility parameters of both programs. Imagining that income is constant across location, a given family might be eligible for SNAP or TANF in one state but ineligible in another. Moreover, states also have considerable latitude to implement policies which do not alter a family's de jure eligibility for SNAP or TANF, but which nevertheless make it much less likely that a family can actually claim TANF or SNAP consistently. Substantial differences in SNAP take-up among eligible households attributable to such policies have been widely discussed. ${ }^{23}$ For instance, Kabbani and Wilde (2003) find that frequency of re-certification requirements are associated with lower SNAP take-up among eligible households.

Specifically with regard to TANF, states also have broad authority to experiment with different maximum benefits and levels of progressivity. In short, holding both income and also eligibility constant, TANF benefits still vary with location. As mentioned above, TANF in most states is calculated as a maximum benefit level minus some function of household income. However, both the maximum benefit levels and the progressivity of their benefit schedules differ massively across states. ${ }^{24}$ Beyond simply altering the numbers in this traditional "welfare" formula, many states have experimented more drastically. Some have simplified their TANF payments, such as Wisconsin's implementation of a single, flat TANF payment for all eligible households. Other states have created more complex TANF systems. ${ }^{25}$

To get a sense for how these differences in TANF policies translate into differences in benefits, Figure 2 presents the maximum possible benefits for a married, able-bodied household with two children in 2017. There is large variation in

\footnotetext{
${ }^{23}$ See e.g. Currie and Grogger (2001), Bitler and Hoynes (2010), or Ganong and Liebman (2018).

${ }^{24}$ In New Hampshire, for example, $100 \%$ of earned income can be deducted from a household's total income. Therefore, so long as a household remains eligible for TANF, increases in earnings do not lead to decreases in benefits. In Tennessee, on the other hand, a household can deduct a maximum of $\$ 250$ in earned income each month, after which increases in earnings lead to dollar-for-dollar decreases in TANF benefits.

${ }^{25}$ For example, Virginia's present system effectively calculates TANF payments using three different formulas, then pays an eligible family the minimum of those three results.
} 
these benefits. In Louisiana, for example, two-parent households with able-bodied adults are categorically ineligible from receive TANF, and therefore the maximum benefit a family could receive is 0 dollars. On the other end of the spectrum, a married household with two children in New Hampshire with zero income would receive $\$ 1230$ each month. These differences create strong incentives to locate in states with generous TANF programs.

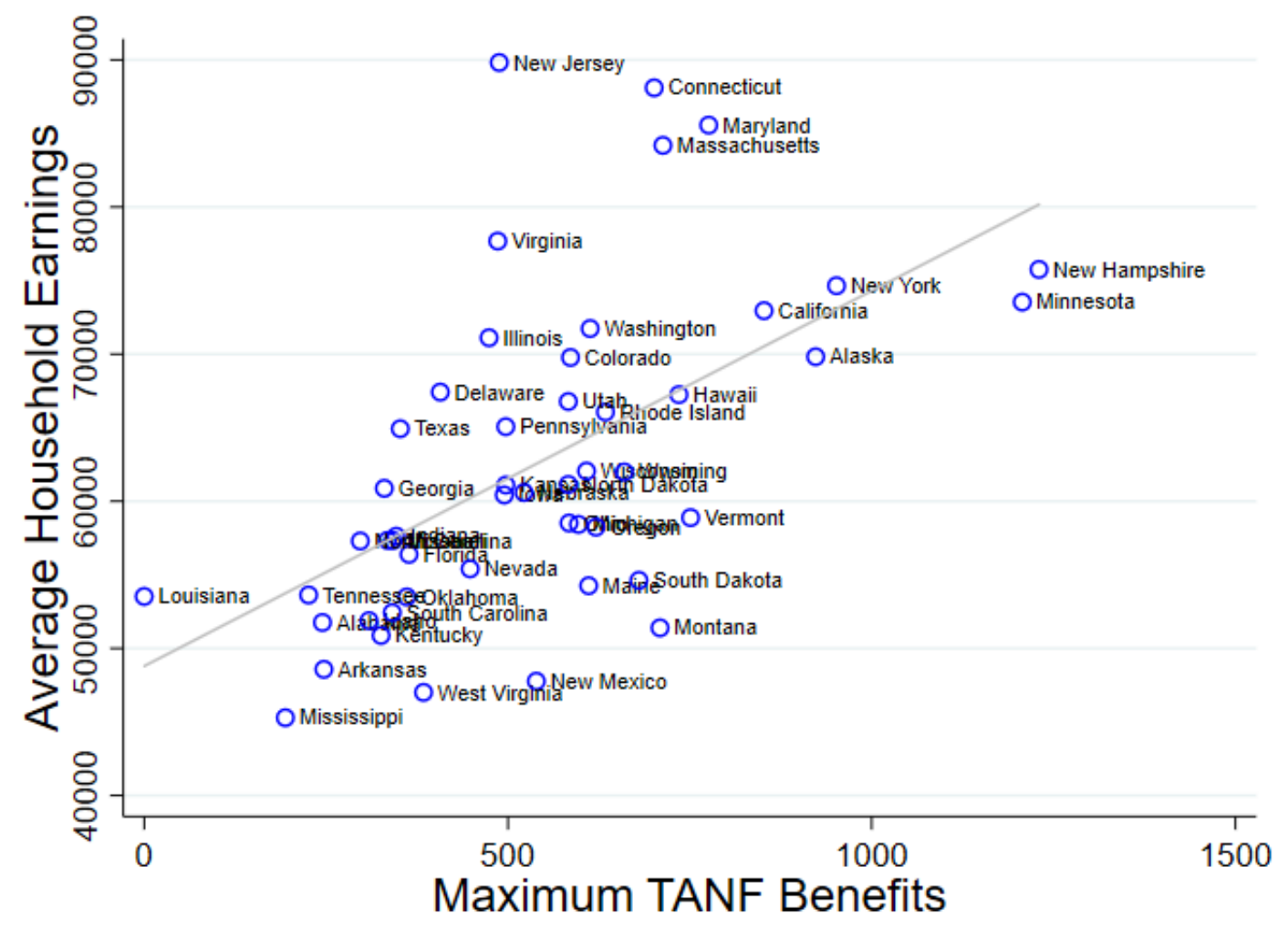

Figure 3: Scatterplot between state-level average household earnings and maximum possible TANF benefits for married households with able-bodied parents and two children in each state. Earnings are calculated as average wage income for the household head and spouse in the 2017 ACS. The two variables have a correlation coefficient of .56.

Interaction Between Generosity and Earnings Thus far, we have suggested that the social transfers system creates incentives to live in states with more generous transfer programs, and in locations where a given household will receive lower earnings. How do these incentives interact? First, note that since TANF schedules are generally set at the state level, the generosity distortion will 
mostly affect interstate location choice, while the earnings distortion can also affect intrastate location choice. Second, to get a sense of how these distortions jointly affect interstate location choices, in Figure 3 we present a scatterplot of these maximum possible TANF benefits for married households with two children (X Axis) and average household earnings in each state (Y Axis). We can see there is a strong positive relationship: higher state-level earnings are generally associated with more generous TANF benefits. ${ }^{26}$ Therefore, these two incentives will generally work in opposite directions; the means-tested nature of these programs will encourage households to locate in states in which they receive lower earnings and therefore generally higher transfers, while differences in transfer generosity across states will incentive households to live in states with more generous benefits, which tend to have higher earnings.

Taken together, the evidence presented here suggests that social transfers differ substantially across space. The amount of transfers a household receives can therefore vary based on where a household chooses to live, potentially distorting the distribution of households across space. However, the magnitude of these distortions and what they imply for economic efficiency are open questions. To answer these questions, we now turn to our quantitative spatial equilibrium model.

\section{Model}

We build and estimate a spatial equilibrium model, in the tradition of Rosen (1979) and Roback (1982) and related to the recent models by Diamond (2016), Piyapromdee (2019), and Colas and Hutchinson (2021). Cities vary by wages, rents, amenities and social transfer programs. Households choose the city that maximizes utility as a discrete choice. Differences in wages and social transfer generosity across cities imply the amount of social transfers a household receives directly depend on a household's location choice. Wages and rents are determined in equilibrium.

Households in the model are heterogeneous in their productivity levels, preferences, and their household composition. The generosity of transfer programs varies substantially depending on household composition, with the highest bene-

\footnotetext{
${ }^{26}$ The two variables have a correlation coefficient of 0.57 .
} 
fits generally paid to households with children. Further, differences in household productivity levels, and therefore income levels, lead to differences in the transfers available to the household across locations. High-productivity households, for example, may have earnings which make them ineligible for benefits regardless of where they live. For such families, transfer programs do not directly affect location choice at all. ${ }^{27}$ The upshot for our model is that differences in productivity and household composition imply that households vary in the menu of transfers they face. Therefore, the extent to which transfers distort location choice will also vary across households; the distortions may be large for some households, such as low-productivity households or households with children, but small or nonexistent for others, such as high-productivity households without children.

Wages and rents are determined in equilibrium by equalizing supply and demand in the labor and housing markets. General equilibrium changes in wages and rents play two roles in the model. First, the equilibrium nature of these markets may limit the extent to which social transfers can lead to distortions. For example, if housing supply is highly inelastic in a given city, small increases in population will lead to large increases in rent, thereby discouraging further population flows into the city. Second, groups that do not receive social transfers themselves can also potentially be affected by general equilibrium effects. For example, highly educated households may themselves not receive transfers. However, if transfer programs discourage low-skilled households from living in high-paying cities, this will lower rents in those cities, potentially making it more attractive for high-skilled households to locate in these cities.

\subsection{Household Location Choice}

Individual households are indexed by $i$. Each household is endowed with a demographic group $d \in D$, which includes a household's education, experience group, marital status, number of children, and race. Additionally, households are separated by their skill level, either skilled or unskilled. We define skilled households as households whose head has at least some college education and denote a household's skill level as $e \in\{U, S\}$.

\footnotetext{
${ }^{27}$ Such a household can still be affected indirectly through general equilibrium changes in rents and wages.
} 
Households choose a location $j$, and conditional on location, choose consumption of a tradeable good $c$ and a housing level $h_{j}$. We assume household labor supply is inelastic, conditional on location. ${ }^{28}$ Utility is Cobb-Douglas in the consumption good and housing and is given by

$$
U_{i j}=c^{1-\alpha_{e}} h_{j}^{\alpha_{e}} \Gamma_{i j}
$$

where $\alpha_{e}$ is a skill level specific utility parameter and $\Gamma_{i j}$ represents the amenity utility household $i$ receives when they live in location $j$. This includes all nonpecuniary benefits the household receives for living in city $j$, including for example, the weather, restaurants, and idiosyncratic preference for living in a city. ${ }^{29}$

Households face the following budget constraint

$$
I_{d j}+U_{d}+\tau_{d j}\left(I_{d j}, U_{d}, r_{j} h_{j}\right)=c+r_{j} h_{j}
$$

where $I_{d j}$ is the earned income of households of demographic $d$ who live in city $j, U_{d}$ is unearned income for demographic group $d$, and $r_{j}$ is the location-specific cost of housing. The price of the consumption good $c$ is normalized to one and we assume unearned income, $U_{d}$, does not depend on the household's location. The function $\tau_{d j}(\cdot)$ represents SNAP and TANF transfers received by a household with demographic $d$ in location $j$, and is written as a function of earnings $I_{d j}$, unearned income $U_{d}$, and housing costs $r_{j} h_{j} .{ }^{30}$ We allow the transfer function to vary with $j$ to allow for state-level differences in social transfer functions and by $d$ to allow for differences in social transfer allotment by demographic groups, for example by number of children or marital status.

\footnotetext{
${ }^{28}$ This is a relatively common assumption in the literature (see e.g. Albouy (2009), Moretti (2013), or Diamond (2016)). We discuss the implications of assuming inelastic labor supply in Section 6.2. Allowing for elastic labor supply would imply a larger efficiency cost of social transfers, as social transfers would distort both location choices and labor supply decisions.

${ }^{29} \mathrm{We}$ assume amenities are exogenously given. See Diamond (2016) or Almagro and Dominguez-Iino (2019), for example, for spatial equilibrium models with endogenous amenities. By assuming that amenities are exogenous, we ensure that equilibria with lump-sum transfers are efficient and therefore it is straightforward to measure the deadweight loss of current transfer programs. If amenities are endogenous, equilibria with lump-sum transfers are generally not efficient (Fajgelbaum and Gaubert, 2020).

${ }^{30} \mathrm{We}$ think of the food coupons provided by SNAP as equivalent to cash transfers, as is common in the literature (See e.g. Ortigueira and Siassi (2021)).
} 
Importantly, the transfer function depends on a household's location through earnings, $I_{d j}$, through location $j$ directly, and through the housing costs $r_{j} h_{j}$. The dependence on earnings allows for an earnings distortion: households can choose locations where their earnings lead to larger transfer receipts. As transfer programs are generally deceasing in earnings, this implies that households are rewarded for locating in areas where they earn lower income. Second, the dependence on $j$ implies location choices may be subject to a generosity distortion: households are rewarded for choosing locations with more generous transfer programs overall. Finally, the dependence on housing cost allows for a housing-cost deduction, a feature of the SNAP formula. ${ }^{31}$

We can think of the household's constrained optimization problem as a twostep problem. First, the household calculates optimal housing and consumption conditional on choosing each location, and then chooses the location which maximizes utility, given optimal housing and consumption choices. We illustrate this by first rewriting a household's indirect utility conditional on choosing location $j$ as a function of optimal housing $h_{d j}^{\star}$ and optimal consumption $c_{d j}^{\star}$

$$
V_{i j}=\left(1-\alpha_{e}\right) \log c_{d j}^{\star}+\alpha_{e} \log h_{d j}^{\star}+\log \left(\Gamma_{i j}\right)
$$

Appendix B.2 gives the analytical expressions for optimal housing $h_{d j}^{\star}$ and optimal consumption $c_{d j}^{\star}$, both of which are implicitly functions of rents, earned and unearned income, and social transfers. The households problem can now be thought of as a simple discrete-choice problem: the household chooses the location $j$ that maximizes (1).

Amenities, $\log \left(\Gamma_{i j}\right)$, consist of a term that is common to all households of a given group, a term which measures how close the location is to an individual's birth state, and a idiosyncratic term which is unique to the individual household. ${ }^{32}$ We therefore write a household's amenity utility for living in location $j$ as

$$
\log \left(\Gamma_{i j}\right)=\underbrace{\xi_{d j}}_{\text {Common term }}+\underbrace{f_{d}\left(j, \text { Bstate }_{i}\right)}_{\text {Distance from Birth State }}+\underbrace{\sigma_{e} \epsilon_{i j}}_{\text {Idiosyncratic }} .
$$

\footnotetext{
${ }^{31}$ Several states' TANF formulas also include a housing-cost deduction. We discuss our specification of the transfer function in Section 4.2.

${ }^{32}$ This is the same parameterization as used in Colas and Hutchinson (2021).
} 
The first term $\xi_{d j}$ is the component of amenity in location $j$ that is common to all households of demographic $d$. The next term $f_{d}\left(j\right.$, Bstate $\left._{i}\right)$ gives the utility from living from a location near the household head's state of birth, Bstate . We parameterize $f(\cdot)$ as

$$
f_{d}\left(j, \text { Bstate }_{i}\right)=\gamma_{d}^{h p} \mathbb{I}\left(j \in \text { Bstate }_{i}\right)+\gamma_{d}^{\text {dist }} \phi\left(j, \text { Bstate }_{i}\right)+\gamma_{d}^{\text {dist2 }} \phi^{2}\left(j, \text { Bstate }_{i}\right),
$$

where $\mathbb{I}\left(j \in\right.$ Bstate $\left._{i}\right)$ indicates that location $j$ in within the households head's birth state, $\phi\left(j\right.$, Bstate $\left._{i}\right)$ gives the distance between the household head's birth state and location $j$, and $\phi^{2}\left(j\right.$, Bstate $\left._{i}\right)$ gives this distance squared. These parameters play an important role in our analysis as they dictate how far a household is willing to locate from their birth place to take advantage of differences in social transfers across locations. For example, if the disutility from living far away from one's birth place is large, then households from Texas may be unwilling to locate in New Hampshire to take advantage of their generous TANF program. They may, however, be willing to locate in relatively low-productivity San Antonio instead of high-productivity Houston in order to receive higher social transfers as a result of living in the lower-productivity city. Therefore, a larger disutility associated with living far from one's birth state will diminish the influence of the generosity distortion relative to the earnings distortion. The term $\epsilon_{i j}$ is the idiosyncratic utility the household $i$ receives for living in city $j$. We assume that $\epsilon_{i j}$ is distributed as Type 1 Extreme Value.

The parameter $\sigma_{e}$ is skill-specific and dictates the dispersion of this idiosyncratic preference draw. A larger value of $\sigma_{e}$ implies idiosyncratic preferences play a more important role in determining location choice relative to differences in income, transfers and rent across cities. As such, small differences in transfer generosity across cities are unlikely to significantly effect location choices. However, if $\sigma_{e}$ is small, then idiosyncratic factors only play a small role in dictating location choices and households will be more responsive to changes in transfers, income and rent. 


\subsection{Housing Supply}

Absentee landowners own plots of land which may be developed for housing. These plots of land vary in their marginal costs of development and therefore generate an upward sloping housing supply curve in each city. Let $r_{j}\left(H_{j}\right)$ be the marginal cost of producing an additional unit of housing as a function of the total amount of housing supplied in city $j, H_{j}$. We parameterize this following Kline and Moretti (2014) as

$$
r_{j}=z_{j} H_{j}^{k_{j}} .
$$

The parameter $z_{j}$ is a parameter which shifts the level of housing costs in city $j$. A higher value of $z_{j}$ implies higher costs of developing housing in city $j$, all else equal. The parameter $k_{j}$ dictates the elasticity of the housing supply curve: a higher value of $k_{j}$ implies that housing costs increase more rapidly with housing supply. We allow $k_{j}$ to vary across cities to allow for differences in housing supply elasticities across cities. In particular, we let $\frac{k_{j}}{1+k_{j}}=\left(\nu_{1}+\nu_{2} \psi_{j}^{W R I}\right)$ where $\psi_{j}^{W R I}$ gives a measure of the strictness of local land-use restrictions (Gyourko, Saiz, and Summers, 2008). ${ }^{33}$ The parameter $\nu_{1}$ dictates the overall level of the housing supply elasticity across cities while $\nu_{2}$ dictates the extent to which a city's housing supply curve increases in local land-use restrictions. We expect both $\nu_{1}$ and $\nu_{2}$ to be positive to reflect that the cost of developing housing is increasing in housing supply and more so in cities with stricter land use restrictions.

Landowners profits in city $j$ are given by rental rate of housing minus the marginal cost of housing, integrated up to the quantify of housing produced

$$
\Pi_{j}=\left[\int_{0}^{H_{j}}\left(r_{j}-z_{j} x^{k_{j}}\right) d x\right] .
$$

Total landowner profits are the sum of landowner profits across all cities $\Pi=$ $\sum_{j} \Pi_{j}$. We assume these landowner profits are distributed lump-sum back to households. Letting $s_{d}$ denote the share of total landowner profits that are owned by a household of demographic $d$, a household's unearned income is given total

\footnotetext{
${ }^{33}$ These measures are created by aggregating the measures of local land use restriction provided by Gyourko, Saiz, and Summers (2008) to the core-based statistical area (CBSA). Similar parameterizations of the housing supply curve are also used in Diamond (2016), Piyapromdee (2019), Colas and Hutchinson (2021), and Colas and Morehouse (2021).
} 
landowner profits multiplied by their share of profits as $U_{d}=s_{d} \Pi .^{34}$

\subsection{Labor Demand}

In each city, perfectly competitive firms use the following CES production function combining skilled and unskilled labor

$$
Y_{j}=A_{j}\left[\left(1-\theta_{j}\right) L_{U j}^{\frac{\varsigma-1}{\varsigma}}+\theta_{j} L_{S j}^{\frac{\varsigma-1}{\varsigma}}\right]^{\frac{\varsigma}{\varsigma-1}} .
$$

$L_{U j}$ and $L_{S j}$ give the total efficiency units of labor supplied by unskilled and skilled workers in city $j$, respectively. ${ }^{35}$ The parameter $A_{j}$ gives the city's total factor productivity and $\theta_{j}$ gives the skill intensity of skilled labor. ${ }^{36}$ These technology parameters are allowed to differ across cities, reflecting exogenous differences in production technology across cities. All else equal, households living in cities with higher values of $A_{j}$ will have higher wages and therefore receive less social transfers. The parameter $\varsigma$ dictates how much relative wages change in response to changes in the ratio of skilled to unskilled workers; if increases in social transfers lead to large influx of unskilled workers, the parameter $\varsigma$ dictates how much the relative wages of skilled workers would increase in response and therefore the extent to which social transfers can lead to general equilibrium wage changes. Further, a lower value of $\varsigma$ will limit the extent to which social transfers can shift the distortion of households across space. If $\varsigma$ is low, an influx of lowskilled households into a city will lead to a large drop in unskilled wages, thereby discouraging more low-skilled households from coming to the city.

Within skill levels, demographic groups are perfect substitutes but vary in their productivity levels. Let $\ell_{d}$ give the efficiency units of labor inelastically

\footnotetext{
${ }^{34}$ We estimate share of landowner profit owned as the share of total interest, dividend, and rental income owned by each demographic group.

${ }^{35}$ One could easily introduce capital into this model by modeling a Cobb-Douglas production function in capital and the labor aggregate, as in Colas and Hutchinson (2021). With perfectly elastic capital supply, the wage equations implied by a model with capital are equivalent to those here.

${ }^{36} \mathrm{We}$ do not allow for the possibility of agglomeration affects. See Glaeser and Gottlieb (2009) for a review of agglomeration effects in spatial equilibrium models. See Baum-Snow, Freedman, and Pavan (2018) for estimates of skill-biased agglomeration effects. By allowing for agglomeration effects, we ensure that equilibria with lump-sum transfers are efficient. This allows for straightforward quantification of the deadweight loss of current programs.
} 
supplied by a household of demographic $d$, reflecting the productivity level, hours worked, and propensity to be employed of the demographic group. ${ }^{37}$ Total labor supply of each skill level in each city is then given by sum of these efficiency units of labor. In particular, letting $D_{S}$ and $D_{U}$ give the sets of demographic group that classify as skilled and unskilled, respectively, total skilled labor in city $j$ is given by $L_{S j}=\sum_{d \in D_{S}} N_{d} \ell_{d}$ and total unskilled labor in city $j$ is given by $L_{U j}=\sum_{d \in D_{U}} N_{d} \ell_{d}$.

Differences in $\ell_{d}$ play an important role in determining how much social transfers a household can receive. For example, households with very high levels of $\ell_{d}$ will receive high income and therefore may be ineligible for social transfers, regardless of where they live. As a result, their location choice decisions will not be directly affected by social transfers. ${ }^{38}$ Households with lower levels of $\ell_{d}$ will be more affected by phase-out of social transfers and by differences in social transfer generosity across cities.

Labor markets are competitive and therefore households are paid the marginal products of their labor. Solving the firm's problem yields the inverse labor demand curves

$$
I_{d j}=\ell_{d} A_{j}^{\frac{\varsigma-1}{\varsigma}} Y_{j}^{\frac{1}{\varsigma}} \theta_{j} L_{S j}^{-\frac{1}{\varsigma}}
$$

for skilled demographic groups $\left(d \in D_{S}\right)$ and

$$
I_{d j}=\ell_{d} A_{j}^{\frac{\varsigma-1}{\varsigma}} Y_{j}^{\frac{1}{\varsigma}}\left(1-\theta_{j}\right) L_{U j}^{-\frac{1}{\varsigma}}
$$

for unskilled demographic groups $\left(d \in D_{U}\right)$.

\section{Data and Quantification}

In this section, we first describe the data we use. We then describe how we estimate the social transfer functions, the demographic-specific productivity levels, and

\footnotetext{
${ }^{37}$ Importantly, we do not assume that households work full time. This is a departure from many papers using similar models, (see Colas and Hutchinson (2021), for example) who only use data on full-time workers. Full-time household receive higher income and therefore are more likely to be ineligible for transfers.

${ }^{38}$ However, their locations choices may be affected through general equilibrium price changes if social transfers affect the choices of other agents.
} 
the household sorting component of the model. Details on how the production function and housing supply curves are taken to the data are included in Appendix C.2 and Appendix C.3, respectively.

\subsection{Data}

We use the 5-year aggregated 2017 American Community Survey as our main data source (Ruggles et al., 2010). This dataset provides household-level data on respondents' location, state of birth, demographics, earned and unearned income, and housing costs. We define locations as Core Based Statistical Areas (CBSAs). Specifically, we chose the 70 CBSAs with the largest population in $1980 .{ }^{39}$ We aggregate the remainder of locations to the nine census divisions. This gives us a total of 79 locations in our quantitative version of the model.

As discussed above, the extent to which social transfer affect a household's decisions depends on the household's demographics. In our quantification, we divide households into 128 demographic groups, differentiated by four education groups, two experience groups, marital status, number of children $(0,1,2$, and 3 or more), and race (non-minority vs. minority). ${ }^{40}$ As we describe in Section 4.3, we allow household productivity levels to vary across marital status (reflecting more working adults), race, education, and experience. Conditional on income and location, transfer functions $\tau_{d j}$ depend on marriage and number of children, reflecting the dependence of TANF and SNAP programs on these characteristics. All demographic groups vary in their preferences over locations, which is captured by differences in amenity values across cities.

We supplement this ACS data with data from the SIPP. In addition to data on household income and demographics, the SIPP contains detailed information on participation and transfers received from TANF, SNAP, and other programs. As we describe below, we use these data combined with the SNAP Policy Database (Economic Research Service, 2019) to estimate take-up and accessibility of social transfer programs across demographic groups and states.

\footnotetext{
${ }^{39}$ These 70 locations make up approximately $60 \%$ of the entire US population.

${ }^{40}$ We define minority households as households in which the household head is white, nonHispanic, and not an immigrant.
} 


\subsection{Social Transfer Programs}

The function $\tau_{d j}\left(I_{d j}, U_{d}, r_{j} h_{j}\right)$ gives transfers as a function of earnings, unearned income, housing costs, household demographics, and location. We assume $\tau_{d j}$ consists of transfers from TANF and SNAP: ${ }^{41}$

$$
\tau_{d j}\left(I_{d j}, U_{d}, r_{j} h_{j}\right)=\tau_{d j}^{T}\left(I_{d j}, U_{d}\right)+\tau_{d j}^{F}\left(I_{d j}, U_{d}, \tau_{d j}^{T}, r_{j} h_{j}\right)
$$

The functions $\tau_{d j}^{T}$ and $\tau_{d j}^{F}$ give TANF and SNAP transfers received, respectively, taking into account a household's demographics, location, earned and unearned income, and, in the case of SNAP, housing costs. ${ }^{42}$

To quantify these social transfer functions, we mostly rely on the administrative formulas for TANF and SNAP. However, there are several details of the data and of social transfer programs that are not modeled directly and need to be accounted for. First, even conditional on being eligible for transfers, take-up rates of social transfer programs in the data are often less than $100 \%{ }^{43}$ Second, we are not able to directly model some eligibility criteria, such as asset tests or time limits. ${ }^{44}$ To account for incomplete take-up rates and unmodeled eligibility criteria, we therefore supplement the administrative formulas with reduced-form estimates of the expected fraction of time a household will take-up transfers and meet the unmodeled criteria. Specifically, we model our transfer functions as the product of 1) "benefit amounts", the amount of transfers received conditional on taking up social transfers and meeting unmodeled eligibility criteria; and 2)

\footnotetext{
${ }^{41}$ It would be relatively straightforward to incorporate tax credit programs, such as the EITC. However, incorporating tax credits would necessitate modeling the federal income tax program, which also leads to distortions. See Albouy (2009) or Colas and Hutchinson (2021) for a quantification of the efficiency costs of federal income taxes in spatial equilibrium.

${ }^{42}$ TANF benefits are counted as unearned income for the sake of determining SNAP benefits, which is why TANF transfers $\tau_{d j}^{T}$ are an argument in the SNAP function. In contrast to SNAP benefits, housing costs do not usually impact TANF benefits directly. However, a small number of states do allow for housing cost deductions in their TANF formulas. These deductions are not accounted for in our model.

${ }^{43}$ Low take-up rates are typically attributed to stigma costs, administrative costs, and lack of information (Currie, 2004).

${ }^{44}$ Assets and time limits are difficult to incorporate into our model, given that our model is static. Most TANF recipients are subject to a 60 month time limit. Only able bodied adults without dependents face time limits for SNAP. These time limits are waived for households who meet certain work requirements and are waived completely in some states.
} 
transfer "accessibility", the reduced-form representation of the expected fraction of time a household will meet the unmodeled criteria and take up social transfers. We write this as

$$
\tau_{d j}^{T}=\tilde{\tau}_{d j}^{T} \times o_{d j}^{T} \quad \text { and } \quad \tau_{d j}^{F}=\tilde{\tau}_{d j}^{F} \times o_{d j}^{F},
$$

where $\tilde{\tau}_{d j}^{T}$ and $\tilde{\tau}_{d j}^{F}$ denote the TANF and SNAP benefit amounts, and $o_{d j}^{T}$ and $o_{d j}^{F}$ denote transfer accessibility. This formulation allows us to account for the fact that some eligibility criteria are not directly modeled and that take-up rates of social transfer programs may be less than $100 \%$.

In what follows, we first describe how we model $\tilde{\tau}_{d j}^{T}$ and $\tilde{\tau}_{d j}^{F}$, and then describe how we estimate $o_{d j}^{T}$ and $o_{d j}^{F}$, the TANF and SNAP accessibility measures.

Benefit Amounts The amount of transfers received are modeled using the institutional formulas of TANF and SNAP. The SNAP benefits formula is set federally and therefore all states in the continental US share the same benefits formula. ${ }^{45}$ We give a brief overview of this formula here, with a detailed description in Appendix B.1.1. Generally speaking, SNAP benefits are equal to a "maximum allotment" minus .3 times "net income", given by income minus deductions. ${ }^{46}$ Both the maximum allotment and many of the deductions are increasing in family size. An important deduction for our purposes is the "excess-shelter" deduction which allows households to deduct a portion of their housing costs from their net income. Our SNAP benefits function $\tilde{\tau}_{d j}^{F}$ follows the institutional SNAP benefits formula closely, accounting for this excess-shelter deduction and differences in program parameters across household sizes. ${ }^{47}$

While the formulas determining SNAP benefits are largely a matter of federal policy, the welfare reform underpinning current TANF programs gave states wide latitude to change how TANF benefits are calculated. Conditional on eligibility, TANF benefit in most states are calculated as a benefit standard minus household

\footnotetext{
${ }^{45}$ The formula is slightly different in Hawaii and Alaska. Our model accounts for this.

${ }^{46}$ These deductions include a deduction for a portion of earned income, a standard deduction, an excess-shelter deduction, and deductions for dependent care, medical expenses, and child support.

${ }^{47}$ The income eligibility tests can create discontinuities in the SNAP formula as a function of earnings. These discontinuities can prevent the model from converging. To deal with this, we replace the SNAP formula with a linear basis function in earnings in a small interval around these discontinuities.
} 
income less deductions. As is the case under SNAP, benefit standards for TANF are normally increasing with household size; however in contrast to SNAP, each state sets its own benefit standard and chooses the number and size of deductions they offer. Importantly, states differ in the extent to which earned income can be deducted from total income, and how the parameters of their benefits formulas vary with household size and marital status. We collect data on these state- and demographic-specific parameters from the Welfare Rules Database (The Urban Institute, 2019). Further, as mentioned in Section 2, many states have experimented more drastically with their TANF formulas and do not follow this same basic structure. For these state we supplement the information from the Welfare Rules Database with information from the individual state TANF manuals. Details are in Appendix B.1.2. ${ }^{48}$

Accessibility While SNAP benefits formulas are set federally, ease of use and access and some eligibility criteria vary across states, and can lead to substantial differences in SNAP enrollment rates (Currie and Grogger, 2001; Kabbani and Wilde, 2003; Ratcliffe, McKernan, and Finegold, 2008; Bitler and Hoynes, 2010; Dickert-Conlin et al., 2010; Ganong and Liebman, 2018). To estimate SNAP accessibility taking account these state-level differences in SNAP implementation, we combine household-level SIPP data on program participation, demographics and income with data on SNAP implementation across states from the USDA's SNAP Policy Database (Economic Research Service), which contains state-level data on eligibility criteria and application and certification procedures. In particular, we estimate via ordinary least squares the fraction of all months a given household in the SIPP receives SNAP benefits as a function of their demographic characteristics, the SNAP policy characteristics of the state in which they live in, and their earnings as a fraction of the federal poverty level. Letting $o_{i}^{F}$ be the fraction of months a given household receives SNAP benefits, we write our

\footnotetext{
${ }^{48}$ Overall, we have tried to preserve as much of the state variation in TANF policy as our data allows. In situations where we cannot model a state's TANF formula exactly, we have opted to be general, using the policies which would apply to most TANF recipients most of the time. E.g.: In several states, the formula for net income changes based on how long a family has received TANF benefits. For these states, we use the modal formula for net income that would apply in a majority of months.
} 
reduced-form estimating equation as

$o_{i}^{F}=\beta^{F 1}$ Policy $_{s}+\beta^{F 2} \frac{I_{i}}{F P L_{d(i)}}+\beta^{F 3} \mathrm{ABAWDWaiver}_{s} \times \mathrm{ABAWD}_{i}+\beta^{F 4} X_{i}^{\mathrm{Rec}}+\varepsilon_{i}^{F}$,

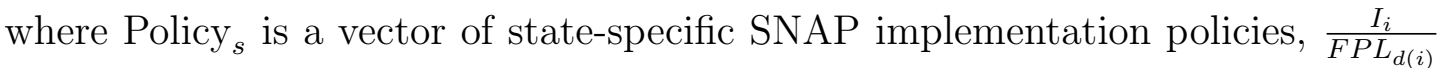
is household earnings as a fraction of the poverty line, ABAWDWaiver indicates that state $s$ has time-limit waivers for able-bodied adults without dependents, $\mathrm{ABAWD}_{i}$ indicates household $i$ is an able-bodied adult without children, and $X_{i}^{\mathrm{Rec}}$ is a vector of demographic control variables, containing a household head's education level, race, and the household's marital status interacted with number

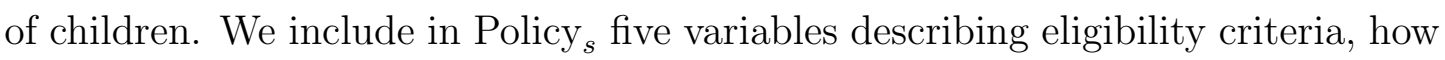
often a household is required to re-certify their SNAP eligibility, and details on the application process. ${ }^{49}$

The estimates of (7) are displayed in Appendix D.1. ${ }^{50}$ We find that all the policy variables have the expected sign and are quite predictive of state-level takeup rates. In particular, and consistent with Kabbani and Wilde (2003), we find that frequent re-certification requirements have a large negative effect on SNAP take-up. Using these estimates, we then calculate the SNAP accessibility measures $o_{d j}^{F}$ as the predicted values of (7) for each demographic group and location.

We use a similar technique to estimate $o_{d j}^{T}$, our TANF accessibility measure. In particular, we estimate the fraction of months a given household in the SIPP receives TANF as a function of their demographic characteristics, the state in which they live in, and their income as a fraction of the poverty line:

$$
o_{i}^{T}=\beta_{s}^{T 1}+\beta^{T 2} \frac{I_{i}}{F P L_{d(i)}}+\beta^{T 3} X_{i}^{\mathrm{Rec}}+\varepsilon_{i}^{T},
$$

\footnotetext{
${ }^{49}$ We use the following 5 variables, which have been previously shown to be predictive of SNAP caseload (Dickert-Conlin et al., 2010): (i) whether the state uses broad-based categorical eligibility, (ii) whether one vehicle can be excluded from asset test, (iii) whether all vehicles can be excluded from the asset test, (iv) whether the state has an online application, and (v) how often a household must re-certify their SNAP eligibility. We use SNAP Policy Database from October of 2015, the latest date with no missing data on all variables.

${ }^{50}$ Transfer receipts are often under-reporting in survey data (Meyer, Mok, and Sullivan, 2009). We therefore multiply our estimated accessibility measures by the inverse of the reporting rates calculated in Meyer, Mok, and Sullivan (2009), which calculates the ratio of the number individuals who report received SNAP and TANF in survey data divided by the number of individuals who receive these benefits according to administrative data sources.
} 
where $\beta_{s}^{T 1}$ is a state-specific intercept, and, as before, $\frac{I_{i}}{F P L_{d}}$ is household earnings as a fraction of the poverty line and $X_{i}^{\mathrm{Rec}}$ is a vector of demographic variables. Note that, unlike our estimation procedure for $o_{d j}^{F}$, we do not use data on statelevel TANF accessibility, and instead rely on state-level fixed effects to capture differences in TANF accessibility across states. ${ }^{51}$ We then set the TANF accessibility as the predicted values from (8) for each demographic group and location.

\subsection{Productivity and Wages}

Note that (5) and (6), which give demographic specific income levels can be rewritten as:

$$
I_{d j}=\ell_{d} W_{S j}
$$

and

$$
I_{d j}=\ell_{d} W_{U j}
$$

where $W_{S j}$ and $W_{U j}$ represent the wage levels in city $j$ paid for one unit of skilled and unskilled labor, respectively. Recall that demographic-specific efficiency units of labor, $\ell_{d}$ captures both differences in the probability of working and productivity and hours worked conditional on working. We therefore specify $\ell_{d}$ as the product of the probability of working and productivity conditional on working. Specifically, let $\ell_{d}=E_{d} \tilde{\ell}_{d}$, where $E_{d}$ is the probability of working for agents of demographic group $d$, and $\tilde{\ell}_{d}$ represents the productivity conditional on working. ${ }^{52}$ Further, we parameterize $\tilde{\ell}_{d}$, the productivity level conditional on working as

$$
\log \tilde{\ell}_{d}=\beta_{S} X_{d}^{\text {Prod }}
$$

for skilled demographic groups and

$$
\log \tilde{\ell}_{d}=\beta_{U} X_{d}^{\text {Prod }}
$$

\footnotetext{
${ }^{51}$ It would also be possible to estimate TANF accessibility using state-specific TANF implementation policies, such as details on asset tests and time limits across states. Data on asset tests and time limits are included in the Welfare Rules Database.

${ }^{52}$ We assume probability of employment doesn't depend on location.
} 
for unskilled demographic groups, where $\beta_{u}$ and $\beta_{S}$ are vectors of parameters and $X_{d}^{\text {Prod }}$ is a vector of demographic variables indicating the marital status, experience level, minority status, and specific education level of demographic group $d$.

Note that log income levels for agents conditional on working can now be written as

$$
\log I_{d j}=\beta_{S} X_{d}^{\text {Prod }}+\log W_{S j}
$$

and

$$
\log I_{d j}=\beta_{U} X_{d}^{\text {Prod }}+\log W_{U j}
$$

We estimate $\ell_{d}$ is two steps. In the first step we estimate $E_{d}$, the demographic specific employment probability, for each demographic group as the proportion of households of this group who are employed. ${ }^{53}$ In the second step, we estimate the productivity levels conditional on working, $\tilde{\ell}_{d}$, and the skill specific wage levels. Let $i$ index individual households, and let $X_{i}^{\text {Prod }}$ be a vector of household-specific demographic variables for the same characteristics included in the vector $X_{d}^{\text {Prod }}$. Using data on household income with at least one employed spouse from the ACS, we estimate the following two equations via ordinary least squares using household-level earnings:

$$
\log I_{i j}=\hat{\beta}_{S} X_{i}^{\text {Prod }}+\gamma_{S j}+\varepsilon_{i}
$$

and

$$
\log I_{i j}=\hat{\beta}_{U} X_{i}^{\text {Prod }}+\gamma_{U j}+\varepsilon_{i}
$$

for unskilled households, where $I_{i j}$ gives household $i$ 's earnings, $\varepsilon_{i}$ represents household level measurement error and $\gamma_{U j}$ and $\gamma_{S j}$, our estimates of $\log W_{U j}$ and $\log W_{S j}$, are estimated as CBSA fixed effects. The underlying assumption is that there is no selection on unobservables which affect income after controlling for the vector of household demographics, $X_{i}^{\text {Prod }}$. Baum-Snow and Pavan

\footnotetext{
${ }^{53}$ For married households, $\ell_{d}$ represents the efficiency units supplied by the household head and spouse. We therefore estimate $\ell_{d}$ for married demographic groups as the proportion of households with at least one married spouse. Importantly, we assume that the employment probabilities, $E_{d}$, do not depend on the household's location. See Bilal (2020) for a discussion of how unemployment rates vary across cities.
} 
(2012) and Roca and Puga (2017) find that, conditional on education, selection on unobservables which affect wages across locations is small.

The above regression provides us with estimates of the $\beta$ 's, which we can use to calculate productivity conditional on working, $\tilde{\ell}_{d}$. We can then combine this with our estimates of employment probabilities $E_{d}$ to calculate demographic specific productivity levels, $\ell_{d}$. The estimates of equations 5" and 6" are displayed in Appendix D.2.

\subsection{Household Sorting}

We estimate the parameters of the household utility function using a two-step procedure in which we estimate most parameters via maximum likelihood and calibrate several parameters using estimates from the literature. ${ }^{54}$ It will helpful to refer to the portion of the indirect utility function that is common for all households of a given demographic group as the "mean utility". The mean utility of demographic $d$ for living in location $j$ is given by

$$
\delta_{j}^{d}=\left(1-\alpha_{e}\right) \log c_{d j}^{\star}+\alpha_{e} \log h_{d j}^{\star}+\xi_{d j}
$$

Further, let the "standardized indirect utility" denote the indirect utility divided by $\sigma_{e}$ :

$$
\begin{aligned}
& \hat{V}_{i j}=\frac{V_{i j}}{\sigma_{e}}= \\
& \hat{\delta}_{d j}+\hat{\gamma}_{d}^{h p} \mathbb{I}\left(j \in \text { Bstate }_{i}\right)+\hat{\gamma}_{d}^{\text {dist }} \phi\left(j, \text { Bstate }_{i}\right)+\hat{\gamma}_{d}^{\text {dist2 }} \phi^{2}\left(j, \text { Bstate }_{i}\right)+\epsilon_{i j}
\end{aligned}
$$

where hatted values represent a value divided by $\sigma_{e}$ (e.g. $\left.\hat{\delta}_{i j}=\frac{\delta_{i j}}{\sigma_{e}}\right) .{ }^{55}$

In the first step of estimation, we estimate these mean utility terms $\hat{\delta}_{d j}$ and

\footnotetext{
${ }^{54}$ This procedure is similar to the two-step estimation technique commonly used in the industrial organization literature to estimate demand systems (Berry, Levinsohn, and Pakes, 2004) and employed with increasing frequency in the urban economics literature (see e.g. Diamond (2016)). The key difference is that we calibrate two parameters rather than estimating them using instrumental variables.

${ }^{55}$ Because of the large amount of heterogeneity we assume, there are some demographic groups which we do not observe in each location. To deal with these, we assume that there is one household of each demographic group in locations in which we do not observe any observations of a given demographic group. This allows the estimation procedure to run.
} 
$\hat{\gamma}_{d}^{h p}, \hat{\gamma}_{d}^{\text {dist }}$ and $\hat{\gamma}_{d}^{\text {dist2}}$, the parameters which dictate the preference for living near ones' state of birth, for each demographic group via maximum likelihood. ${ }^{56}$ The log-likelihood function for households of demographic group $d$ can be written as

$$
\mathcal{L}_{d}\left(\gamma_{d}^{h p}, \gamma_{d}^{\text {dist }}, \gamma_{d}^{\text {dist2 }}, \boldsymbol{\delta}^{\boldsymbol{d}}\right)=\sum_{i=1}^{N_{d}} \sum_{j=1}^{J} \mathbb{I}_{i j} \log \left(P_{i j}\right)
$$

where $\boldsymbol{\delta}_{\boldsymbol{d}}$ give the vector of mean utility across locations for households of demographic group $d, \mathbb{I}_{i j}$ is an indicator equal to one if individual $i$ lives in location $j$ and zero otherwise, and $P_{i j}$ is given by the logit-choice probability formula

$$
\begin{aligned}
& P_{i j}= \\
& \frac{\exp \left(\hat{\delta}_{d j}+\hat{\gamma}_{d}^{h p} \mathbb{I}\left(j \in \text { Bstate }_{i}\right)+\hat{\gamma}_{d}^{\text {dist }} \phi\left(j, \text { Bstate }_{i}\right)+\hat{\gamma}_{d}^{\text {dist2 }} \phi^{2}\left(j, \text { Bstate }_{i}\right)\right)}{\sum_{j^{\prime} \in J} \exp \left(\hat{\delta}_{d j^{\prime}}+\hat{\gamma}_{d}^{h p} \mathbb{I}\left(j^{\prime} \in \text { Bstate }_{i}\right)+\hat{\gamma}_{d}^{\text {dist }} \phi\left(j^{\prime}, \text { Bstate }_{i}\right)+\hat{\gamma}_{d}^{\text {dist2 }} \phi^{2}\left(j^{\prime}, \text { Bstate }_{i}\right)\right)} .
\end{aligned}
$$

In the second step of estimation, we decompose the estimated mean utility into utility from consumption of housing and the consumption good, and from amenities. We begin by setting the parameters $\sigma_{e}$ and $\alpha_{e}$ based on estimates from previous studies. As explained in Section 3.1, the parameter $\sigma_{e}$ dictates the importance of idiosyncratic factors in explaining location choice relative to income, rents and social transfers. Therefore, a smaller value of $\sigma_{e}$ implies that differences in social transfers across cities will lead to larger distortions in agents choices. We set $\sigma_{e}=\frac{1}{7.15}$ for unskilled households and $\sigma_{e}=\frac{1}{12.54}$ based on the estimates of Colas and Hutchinson (2021), who estimate location choice elasticities by creating synthetic tax instruments which generate variation in after-tax wages across cities. The parameter $\alpha_{e}$ determines the importance of housing prices in determining location choices. We calibrate these parameters based on the estimates in Colas and Hutchinson (2021). We examine the robustness of our findings to alternative values of these parameters in Section $6 .^{57}$

\footnotetext{
${ }^{56}$ In practice, we utilize the contraction mapping developed by Berry (1994).

${ }^{57}$ One issue is that these estimates of household mobility generally do not take into account social transfers and therefore may underestimate the elasticity of location choice with respect to income. We therefore re-simulate our model using estimates based on Notowidigdo (2020) in
} 
Unobserved common amenities, $\xi_{d j}$, can then be calculated given information on income, rents and the estimates of mean utility. First, let $\tilde{V}_{d j}\left(I_{d j}, r_{j}\right)=$ $\left(1-\alpha_{e}\right) \log c_{d j}^{\star}+\alpha_{e} \log h_{d j}^{\star}$ denote maximal utility from goods consumption, written as a function of the endogenous income and rents. Note that $\tilde{V}_{d j}(\cdot)$ is increasing in earnings $I_{d j}$ and decreasing in rent, $r_{j} .{ }^{58}$ Given estimates of $\alpha_{e}$ and information on wages and rents, we can calculate $\tilde{V}_{j}^{d}\left(I_{d j}, r_{j}\right)$ analytically using the expressions from Appendix B.2. We can then back out the unobserved common amenities using

$$
\xi_{d j}=\delta_{d j}-\tilde{V}_{d j}\left(I_{d j}, r_{j}\right)
$$

Essentially, we use the classic intuition from Rosen-Roback to infer $\xi_{d j}$ : in spatial equilibrium, all else equal, cities with higher income levels, and therefore higher values of $\tilde{V}_{d j}\left(I_{d j}, r_{j}\right)$, must be offset by lower amenities. Similarly, cities with higher rents, and thus lower values of $\tilde{V}_{d j}\left(I_{d j}, r_{j}\right)$, must be compensated by higher amenities. One key distinction between the model here is that, in the RosenRoback model, households in equilibrium are indifferent between all cities. In our model, because of the presence of the idiosyncratic preference draw $\epsilon_{i j}$, households can be inframarginal in regards to their optimal location choices. Therefore, the mean utility $\delta_{d j}$, which reflects the number of households of group $d$ controlling for household birth states, also contain information on amenities. Cities with higher population and therefore higher $\delta_{d j}$, all else equal, are inferred to have higher amenities.

The estimates of the birth state premium parameters are presented in Appendix D.3. We find that the disutility associated with locating far from one's birth place is largest for households with low education, indicating that loweducation households need to pay a large utility premium to take advantage of generous welfare programs in states far from their birth place. ${ }^{59}$ For example,

Section 6. Notowidigdo (2020) estimates these parameters via GMM in a model which accounts for social transfers. Our results are qualitatively similar to our main results but slightly larger in magnitude when we use these alternative estimates.

${ }^{58} \tilde{V}_{d j}$ is an indirect utility function minus a constant. As utility is always increasing in both consumption goods, $\tilde{V}_{d j}$ must be increasing in income and decreasing in rents.

${ }^{59}$ For example, the average utility premium of locating within one's birth state, $\gamma_{d}^{h p}$, is 2.93 for households with no college experience, compared to 2.37 for those with some college and above. 
low-education households from Texas are unlikely to locate in New Hampshire even though New Hampshire offers drastically more generous TANF benefits. On the other hand, these same households may be on the margin between Houston and lower-productivity San Antonio and therefore may still have their location decisions affected by the earnings distortion.

The model fit is given in Appendix D.4. In Appendix D.5, we simulate general equilibrium elasticities of location choice with respect to transfers and compare our elasticities with the literature. The average elasticity for high school dropout households is 0.02 - a one percent increase in local transfers leads to a 0.02 percent increase in the population of high school dropout households. The elasticity is strongly increasing in number of children and is larger for single households than married households; single, high school dropout households with children have an elasticity of 0.086 . This is consistent with the elasticities in Kennan and Walker (2010), who find that a $20 \%$ increase in benefits is associated with a $1 \%$ to $2 \%$ increase in state population of single women with dependents after 10 years, implying an elasticity of .05 to .1.

\section{Results}

In this section, we use the estimated model to measure the spatial distortions caused by the US social transfer system and to consider alternative systems. To visualize and quantify spatial distortions, we compare the equilibria generated by the various transfer schemes to the equilibrium when all transfers are lumpsum. As transfers are the only source of inefficiency in the model, the equilibrium allocation with lump-sum transfers is Pareto efficient. ${ }^{60}$ In particular, we consider an equilibrium in which all households of a given demographic group receive the same lump-sum amount, and the total amount of transfers received by each demographic group is the same as under the current transfer system. ${ }^{61}$

\footnotetext{
${ }^{60}$ This relies on the assumptions that 1) all markets are competitive, and 2) there are no externalities (e.g. no agglomeration effects or endogenous amenities). See Colas and Hutchinson (2021) or Fajgelbaum and Gaubert (2020) for a proof.

${ }^{61}$ All equilibria with lump-sum transfers are Pareto efficient. We chose this lump-sum transfer system as it does not directly transfer income across demographic groups relative to the current transfer system.
} 


\subsection{The Current US Social Transfer System}

First, we quantify the distortions associated with the current TANF and SNAP programs. ${ }^{62}$ In what follows, we describe how the current transfer programs create both an earnings distortion - a distortion towards cities where they receive lower earnings - and a generosity distortion - a distortion towards states with more generous transfer programs. We then quantify general equilibrium effects and measure the efficiency costs of these distortions in terms of deadweight loss.

\begin{tabular}{lcccc}
\hline & $\begin{array}{c}\mathrm{A} \\
\text { Baseline }\end{array}$ & $\begin{array}{c}\mathrm{B} \\
\text { Earnings } \\
\text { Adjustments }\end{array}$ & $\begin{array}{c}\mathrm{C} \\
\text { Harmonize }\end{array}$ & $\begin{array}{c}\mathrm{D} \\
\text { Earn Adj+ } \\
\text { Harmonize }\end{array}$ \\
\hline I. \% $\Delta$ Low-Earning Locations & & & \\
HS Dropout & 3.37 & 1.46 & 2.26 & 0.01 \\
HS Grad & 0.49 & 0.01 & 0.64 & 0.15 \\
College & 0.45 & 0.26 & 0.44 & 0.37 \\
Post College & -0.36 & -0.13 & -0.37 & -0.19 \\
II. \% $\Delta$ Generous-Benefit Locations & & & \\
HS Dropout & 2.42 & 6.56 & -2.08 & 1.08 \\
HS Grad & -0.96 & 0.41 & -0.87 & 0.09 \\
College & -0.83 & -0.64 & -0.74 & -0.94 \\
Post College & 0.07 & -0.01 & 0.11 & 0.16 \\
III. Deadweight Loss & 4.38 & 1.22 & 3.95 & 0.60 \\
\hline
\end{tabular}

Table 1: Spatial distortions caused by current transfer programs and by alternative transfer programs. Panel I gives the percentage difference the number of households location in lowearnings cities compared to the equilibrium with lump-sum transfers. Low-earning locations are defined as the ten cities with the lowest average income in the data. Panel II gives the percentage difference the number of households locating in generous-benefit locations compared to the equilibrium with lump-sum transfers. Generous-benefit locations are defined as the ten cities which provide the highest transfers to households with zero income. Deadweight loss is measured as a percent of total spending on transfer programs. See text for details on each counterfactual. Transfer spending is held constant across counterfactuals.

Earnings Distortion As argued above, the current US transfer system incentivizes low-income households to locate in low-productivity cities.To quantify this distortion, Column A in Panel I of of Table 1 gives the percentage difference in the number of households of various education levels choosing low-earnings cities

\footnotetext{
${ }^{62}$ In Section 5.3 we quantify the distortions caused by each of these programs individually.
} 


\begin{tabular}{|c|c|c|c|c|}
\hline & $\begin{array}{c}\text { A } \\
\text { Baseline }\end{array}$ & $\begin{array}{c}\text { B } \\
\text { Earnings } \\
\text { Adjustments }\end{array}$ & $\begin{array}{c}\mathrm{C} \\
\text { Harmonize }\end{array}$ & \begin{tabular}{c}
\multicolumn{1}{c}{ D } \\
Earn Adj+ \\
Harmonize
\end{tabular} \\
\hline \multicolumn{5}{|c|}{ I. $\% \Delta$ Low-Earning Locations (HS Dropouts Only) } \\
\hline \multicolumn{5}{|l|}{ By Race: } \\
\hline Non-Minority & 2.62 & -0.73 & 2.76 & -0.55 \\
\hline Minority & 3.60 & 2.10 & 2.11 & 0.18 \\
\hline \multicolumn{5}{|l|}{ Single: } \\
\hline No Children & 3.76 & -0.65 & 2.49 & -1.49 \\
\hline With Children & 8.41 & 5.86 & 5.69 & 1.65 \\
\hline \multicolumn{5}{|l|}{ Married: } \\
\hline No Children & -1.32 & -0.48 & -1.13 & -0.24 \\
\hline With Children & 0.68 & 0.35 & 0.54 & 0.01 \\
\hline \multicolumn{5}{|c|}{ II. \% $\Delta$ Generous-Benefit Locations (HS Dropouts Only) } \\
\hline \multicolumn{5}{|l|}{ By Race: } \\
\hline Non-Minority & -1.81 & 4.28 & -3.92 & 2.14 \\
\hline Minority & 2.65 & 6.69 & -1.98 & 1.02 \\
\hline \multicolumn{5}{|l|}{ Single: } \\
\hline No Children & -0.22 & 6.10 & -3.89 & 2.21 \\
\hline With Children & 16.23 & 21.81 & 0.26 & 4.37 \\
\hline \multicolumn{5}{|l|}{ Married: } \\
\hline No Children & -0.12 & -1.92 & 0.79 & -0.36 \\
\hline With Children & -3.61 & -0.30 & -3.00 & -0.86 \\
\hline
\end{tabular}

Table 2: Spatial distortions for high school dropouts with various demographic characteristics. See Table 1 for details.

in the equilibrium with the current SNAP and TANF programs relative to the efficient equilibrium with lump-sum transfers. Low-earning locations are defined as the ten cities with the lowest average earnings in the data.

We can see that the current transfer system leads to an increase in the proportion of high school dropout households living in these cities. The first row ("HS Dropout") indicates that the number of high school dropout households who choose to locate in these low-income cities increases by $3.37 \%$ when we move from the efficient equilibrium to the equilibrium with the current transfer programs. Households with higher education, however, are mostly unaffected, as their income levels make them less likely to be eligible to receive these transfers.

We analyze heterogeneity in this distortion within high school dropout house- 


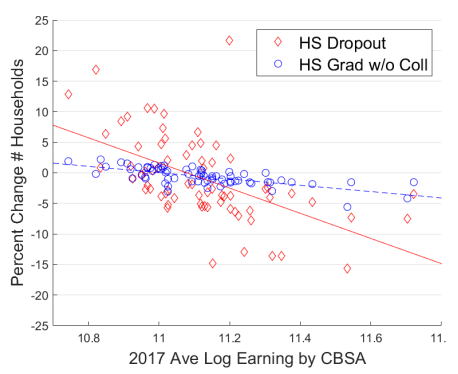

(a) Education Groups

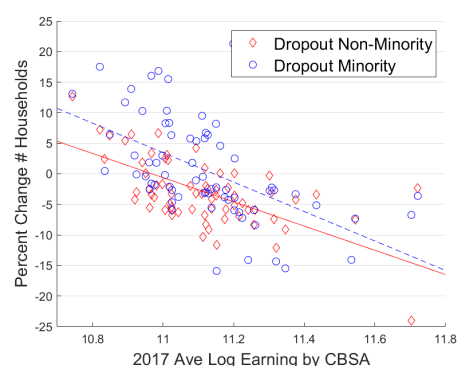

(b) Minority vs. Non-Minority

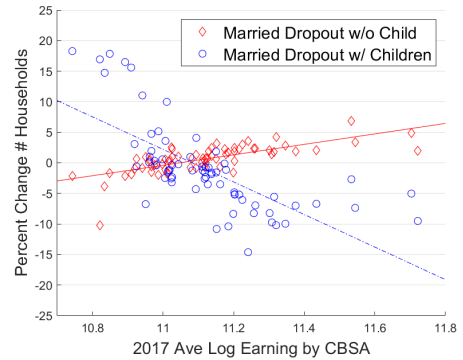

(c) Children vs. Without

Figure 4: Earnings Distortion with Baseline Transfer Programs: Counterfactual population relative to lump-sum taxes for harmonizing transfer programs across cities. Each dot represents a CBSA. The horizontal axis is the 2017 log mean earnings for all households. Panel (a) presents results for high school graduates (without college) and high school dropouts, Panel (b) presents results for non-minority high school dropout households compared to minority dropout households, and Panel (c) presents results for married high school dropouts with children and without children,.

holds in Table 2. Panel I describes the distribution of high school dropout households divided by marital status, the presence of children and minority status. The magnitude of the distortions are highly heterogeneous across demographic groups. Distortions are larger for minority relative to non-minority households because minority households generally have lower income levels and therefore are more likely to be receive transfers. The distortions are larger for households with children than those without, as transfers are generally more generous for households with children. The number of single dropout households without children in low-earning locations, for example, increases by over $8 \%$. There is also evidence of general-equilibrium effects at play: the number of married dropout households without children decreases in low-earning cities, as these households are effectively "crowded out" by households more likely to receive transfers.

These patterns are echoed in Figure 4, which shows the change in CBSA population relative to the efficient lump-sum equilibrium for various demographic groups. Across the panels, we can see an increase in the number of high school dropout households living in low-earning cities, with minority and households with children showing the largest changes. Overall, there are many outliers from these trends, reflecting differences in transfer generosity across states. ${ }^{63}$

Table 3 explores the consequences of the earnings distortion on average earn-

\footnotetext{
${ }^{63}$ The largest outlier in Honolulu, as Hawaii offers more SNAP benefits than the continental US.
} 


\begin{tabular}{lcccc}
\hline Earnings & $\begin{array}{c}\mathrm{A} \\
\text { Baseline }\end{array}$ & $\begin{array}{c}\mathrm{B} \\
\text { Earnings } \\
\text { Adjustments }\end{array}$ & $\begin{array}{c}\mathrm{C} \\
\text { Harmonize }\end{array}$ & $\begin{array}{c}\mathrm{D} \\
\text { Earn Adj+ } \\
\text { Harmonize }\end{array}$ \\
\hline HS Dropout & -0.33 & 0.05 & -0.37 & 0.02 \\
HS Grad & 0.04 & 0.00 & 0.04 & 0.00 \\
College & -0.06 & -0.05 & -0.05 & -0.05 \\
Post College & 0.01 & 0.04 & 0.01 & 0.04 \\
\hline
\end{tabular}

Table 3: Percentage change in average earnings. Each row shows the percent change in average earnings of a given education group across all cities relative to the lump-sum equilibrium.

ings across education groups. Each row shows the percent change in average earnings of a given group across all cities compared to the lump-sum equilibrium. We can see that the current program leads to an increase in earnings inequality: earnings of high school dropouts decrease by $0.33 \%$ relative to the equilibrium with lump-sum transfers as high school dropouts are more likely to locate in lower-productivity cities. Earnings of other education groups are mostly unchanged from the lump-sum equilibrium.

Generosity Distortion The current system also incentives household to locate in states with generous transfer programs, either in the form of more generous TANF benefits or more accessible SNAP programs. We quantify this distortions in Panel II of Tables 1 and 2, where we show the percentage change in the number of households living in the cities with the most generous transfer programs. To measure the transfer generosity of a location, we calculate how much transfers a household of each demographic type with zero income would receive in this location. We then calculate the average of these zero-income transfers over demographic types. The "Generous-Benefit Locations" are defined as the ten locations with the highest average zero-income transfers across demographic groups.

The current transfer system leads to a $2.42 \%$ increase in the number of highschool dropout households living in generous-benefit locations. Table 2 reveals considerable heterogeneity in the size of distortions within high dropout households: the population of single dropout households with children increases by over $16 \%$ in these locations. The populations of other groups, such as married households and single households with children, decrease in these locations, as these groups are crowded out by the households more likely to receive transfers. 


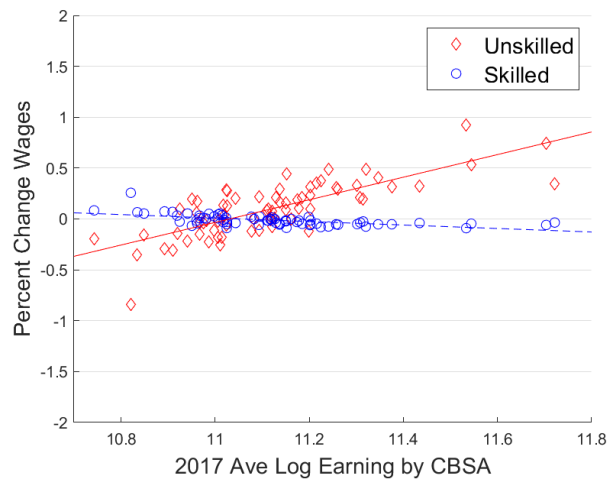

(a) Wage Changes

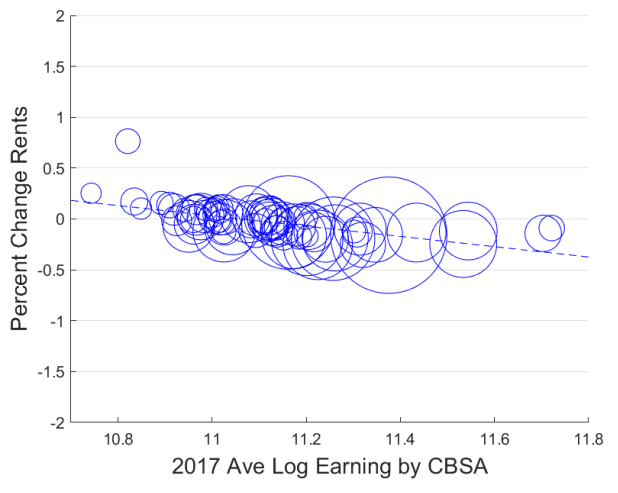

(b) Rent Changes

Figure 5: Earnings Distortion with Baseline Transfer Programs: Counterfactual price relative to lump-sum transfers for baseline transfer programs across cities. Each dot represents a CBSA. The horizontal axis is the $2017 \log$ mean earnings for all households. Panel (a) presents change in wages and Panel (b) presents changes in rents.

However, as we reveal below, the incentive to move towards locations with generous transfers is slightly muted by the positive correlation between local earnings and transfer generosity that we highlighted in Figure 3; while the differences in transfer generosity reward households for locating in states with more generous transfer programs, this effect is mitigated by the fact that locations with more generous transfers also tend to have higher income levels.

General Equilibrium Effects To get a better sense of the general equilibrium effects caused by the current transfer programs, Figure 5 shows equilibrium changes in prices compared to the efficient equilibrium. Panel A shows the change in unskilled and skilled wages as a result of the current transfer programs. Unskilled wages decrease in low-income cities, reflecting the increase in the ratio of unskilled to skilled workers.

Panel B shows the change in equilibrium rents. The transfer programs lead to an increase in rents in low-income cities, as transfer program increase demand for living in those cities. As we have seen above, these general equilibrium price changes can lead to "crowding out" of low-skilled households who are unlikely to receive large transfers, such as married households without children; these households are less likely to live in low-productivity locations as a result of the increase in rents and decrease in low-skilled wages. 
Deadweight Loss To measure the efficiency cost of the current transfer program, we calculate deadweight loss as the total equivalent variation of switching from this equilibrium with lump-sum transfers to the equilibrium in question. ${ }^{64}$ As shown in Panel III of Table 1, the current social transfer programs lead to a deadweight loss equal to 4.38 percent of total transfer payments; for each dollar spent on transfers, there is a locational inefficiency of over 4 cents.

\subsection{Alternative Transfer Programs}

We have argued that the current transfer system distorts household choices and leads to deadweight loss by both by incentivizing households to locate in cities where they receive lower income and in states with more generous transfer programs. Therefore, programs aimed at reducing the efficiency costs of the transfers system can do so either by removing differences in transfer generosity across states or by removing the dependence of transfers on local productivity levels. In what follows, we first consider dealing with the earnings distortion by indexing household earnings to local average earnings levels. ${ }^{65}$ Next, we consider a program which harmonizes TANF and SNAP programs across states. Finally, we consider a combined program in which we both harmonize transfer programs and index household earnings to local average earnings levels.

Indexing Household Earnings to Average Local Earnings Social transfers incentivize households to live in low-productivity cities because a household's income, and therefore the transfers they would receive, depend on where they live. If a household locates in a high-productivity city, they increase their income and therefore receive fewer transfers. One possibility is to adjust the earnings used to calculated transfers such that households are not penalized for living in high-productivity cities.

To this end, we consider indexing the earnings used to calculate transfer ben-

\footnotetext{
${ }^{64}$ This is the classic definition of deadweight loss as suggested by Mohring (1971) and Kay (1980).

${ }^{65}$ In Appendix D.8 we consider a program where we index earnings to local rent levels. The results are qualitatively similar to those in which we index earnings to local earnings levels. However, the deadweight loss is larger than when we index to local earnings levels.
} 
efits to local average earnings levels. ${ }^{66}$ In this case, household earnings are measured against average earning level in a city, and therefore households are not penalized for living in cities where average earnings are higher. Formally, let $\hat{I}_{d j}=\frac{I_{d j}}{I_{U j}}$ be local average earnings-adjusted household earnings, where $\bar{I}_{U j}$ is the average earnings of unskilled households in city $j$. Then transfers are calculated as $\tau_{d j}\left(\kappa \hat{I}_{d j}, U_{d}, 0\right)$, where $\kappa$ is a parameter we choose to keep total transfers equal to their baseline levels, and " 0 " as the final argument denotes that we eliminate the excess-shelter deduction in this program. As $\hat{I}_{d j}$, local average earnings-adjusted household earnings, are what determines transfer receipt, households are not penalized for choosing locations where average earnings are high.

The results are displayed in Column B of Tables 1, 2, and 3, and in Figure $6{ }^{67}$ The local earnings adjustment significantly reduces the distortion towards low-income cities, as it essentially removes the incentive to locate in cities where average earnings are low. As a result, earnings inequality decreases: from Table 3 we can see that average earnings of high school dropouts are higher than in the lump-sum equilibrium. However, the generosity distortion is exacerbated: the number of high school dropout households in generous-transfer locations is $6.56 \%$ higher than in the efficient case compared to only $2.42 \%$ higher in the baseline. The fact that this is higher than the baseline case reflects the positive correlation between state-level earnings and transfer generosity documented in Figure 3: locations with lower earnings also tend to have less generous transfer programs. Therefore, within the current transfer system, the earnings distortion slightly mitigates the generosity distortion by incentivizing households to live in lower wage, and generally lower transfer generosity, locations. Once this earnings distortion is removed, households become more likely to choose locations with more generous transfer programs. The total deadweight loss with the earnings index is equal to $1.22 \%$ of total transfer payments, roughly $70 \%$ less than the baseline case.

Harmonizing Transfer Program We remove the differences across locations in transfer generosity by standardizing the SNAP and TANF benefit functions

\footnotetext{
${ }^{66}$ In Appendix D.8 we consider a cost-of-living adjustment, in which household earnings are indexed to local rent levels.

${ }^{67}$ We show additional figures in Appendix D.7.
} 


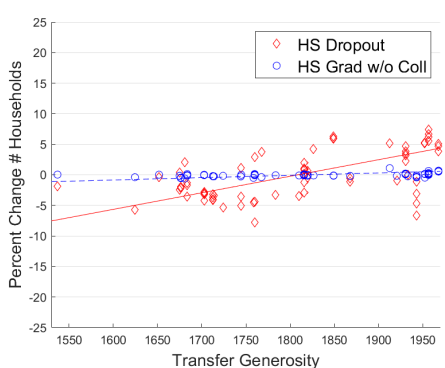

(a) Education Groups

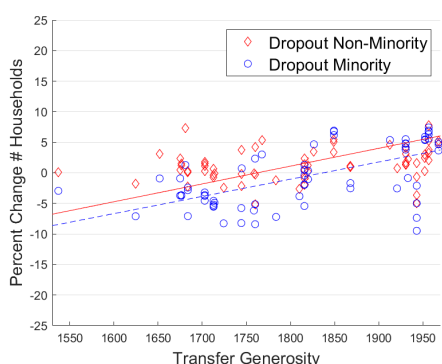

(b) Minority vs. Non-Minority

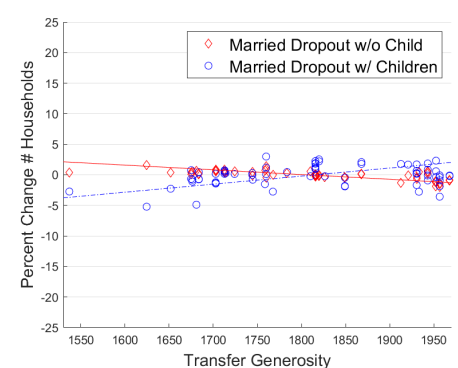

(c) Children vs. Without

Figure 6: Generosity Distortion with Local Earnings Adjustment: Counterfactual population relative to lump-sum transfers for program with local earnings adjustments. Each dot represents a CBSA. The horizontal axis is the average transfers received by a household with 0 income. Panel (a) presents results for high school dropouts and high school graduates, Panel (b) presents results for non-minority high school dropout households compared to minority dropout households, and Panel (c) presents results for married high school dropouts with children and without children.

across all states and setting $o_{d j}^{T}$ and $o_{d j}^{F}$, TANF and SNAP accessibility, to the population-weighted average across states. ${ }^{68}$ To keep total transfer spending constant, we additionally add lump-sum transfers so that the total transfers paid to each demographic group are the same as under the current transfer program.

The main results are displayed in Column $\mathrm{C}$ of Table 1 and in Figure 7. Panel A of Table 1 shows the earnings distortion given the harmonized transfer programs. Household location choices are distorted towards low-income cities $-2.26 \%$ more high school dropout households locate in low-income cities compared to the efficient case. Panel B of Table 1 shows the generosity distortion. The distortion towards generous states is effectively eliminated, and the proportions of household who locate in originally generous locations is lower than in the equilibrium with lump-sum transfers. This again occurs because of the positive state-level correlation between transfer generosity and earnings.

All together, we find a deadweight loss of $3.95 \%$ of transfer spending with the harmonized transfer system, only 10 percent less than the current system. Harmonizing transfers is significantly less effective than the earnings index at reducing deadweight loss. Taken together, these previous two counterfactuals suggest that most of the locational efficiency arising from the current transfer

\footnotetext{
${ }^{68}$ Specifically, we set all TANF benefit formulas to the formula used in California, the largest state by population. Recall that Hawaii and Alaska have different parameters in their SNAP benefit function. These are standardized as well in this counterfactual.
} 


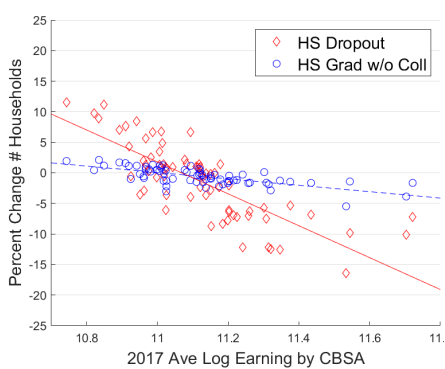

Panel A

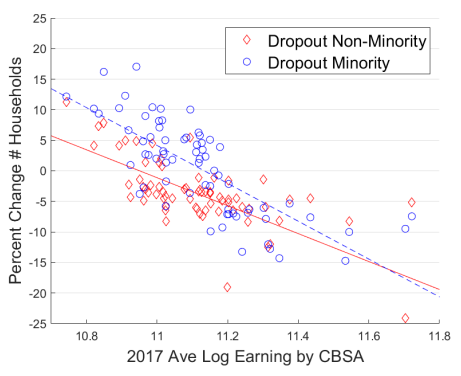

Panel B

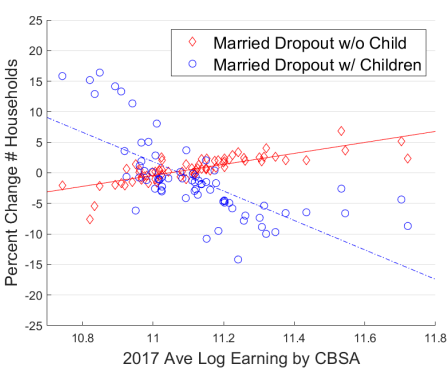

Panel C

Figure 7: Earnings Distortion with Harmonized Transfer Programs: Counterfactual population relative to lump-sum transfers for harmonizing transfer programs across cities. Each dot represents a CBSA. The horizontal axis is the $2017 \log$ mean earnings for all households. Panel (a) presents results for high school dropouts and high school graduates, Panel (b) presents results for non-minority high school dropout households compared to minority dropout households, and Panel (c) presents results for married high-school dropouts with children and without children.

system is due to the fact that transfer programs reward living in low-productivity cities, with a much smaller proportion due to the differences in transfer generosity across locations.

Combined Program Finally, we consider a program which targets both distortions by harmonizing transfer functions across states and indexing household earnings to local average earnings levels. The results are presented in the Column $\mathrm{D}$ in Tables 1 and 3. We can see that the number of households in low-income cities and generous-benefit locations are relatively similar to the efficient equilibrium, suggesting both the earnings distortion and generosity distortions are small. Further, average earnings across education groups are similar to those in the efficient equilibrium, implying that this policy intervention would lead to a decrease in earnings inequality compared to current programs. Overall, we find a deadweight loss of $0.60 \%$ of total transfer spending, a reduction of over $85 \%$ from the baseline case. ${ }^{69}$

We can see that efficiency gains from the combined program are greater than the sum of the gains from the individual programs. ${ }^{70}$ This highlights the in-

\footnotetext{
${ }^{69}$ We find that SNAP's excess-shelter deduction reduces deadweight loss by a small amount. While the excess-shelter deduction increases the amount of benefits households receive in highrent cities, it also subsidies the consumption of housing, thereby distorting the household's housing decision.

${ }^{70}$ Harmonizing transfer programs alone leads to a $4.38-3.95=0.43$ percentage point reduction in deadweight loss while applying only the earnings adjustment leads to a $4.38-1.22=3.16$
} 
teraction between the two distortions: applying the earnings index in a vacuum can potentially exacerbate the generosity distortion because earnings and transfer generosity are positively correlated. In order to effectively reduce the spatial inefficiencies caused by these programs, the policy maker must target both the distortions towards low-productivity cities and the distortions towards cities with generous transfer programs.

\subsection{Decomposition: TANF vs. SNAP}

In the previous subsection we analyzed the distortions caused by the current social transfer programs and considered several alternative programs aimed at minimizing these distortions. In this subsection, we decompose the distortions into those caused by TANF and those caused by SNAP.

The results are displayed in Table 4. As before, Column A shows the distortions caused by the combination of the current TANF and SNAP programs. In the column B, we remove the SNAP program and analyze the distortions caused by TANF alone. In both counterfactuals we provide demographic-specific lumpsum transfers such that total spending on transfer programs is the same as in the baseline case. When we remove SNAP, the earnings distortion is reduced substantially but there is still a generosity distortion: high school dropout households are $4.09 \%$ more likely to locate in states with generous benefits compared to the efficient equilibrium with lump-sum transfers. However, the efficiency costs are relatively small, as total deadweight loss is only $0.29 \%$ of total spending on transfer programs.

The following column $(\mathrm{C})$ instead removes the TANF program and analyzes the distortion caused by SNAP. There is still a substantial earning distortion in this case. However, households are less likely than the baseline case to choose states with generous transfers, reflecting that much of the differences in transfer generosity across locations are driven by TANF. The deadweight loss is only slightly less than the baseline case, at $4.17 \%$ of total transfer spending. We conclude that the majority of the deadweight loss from the current transfer programs is caused by SNAP, and only a small proportion is caused by TANF.

percentage point reduction in deadweight loss. The combined program leads to $4.38-.60=$ 


\begin{tabular}{lccc}
\hline & $\begin{array}{c}\mathrm{A} \\
\text { Baseline }\end{array}$ & $\begin{array}{c}\mathrm{B} \\
\text { No } \\
\text { SNAP }\end{array}$ & $\begin{array}{c}\mathrm{C} \\
\text { TANF }\end{array}$ \\
\hline \multicolumn{2}{l}{ I. \% $\Delta$ Low-Earning Locations } \\
HS Dropout & 3.37 & 1.75 & 1.76 \\
HS Grad & 0.49 & 0.00 & 0.52 \\
College & 0.45 & -0.03 & 0.49 \\
Post College & -0.36 & -0.03 & -0.34 \\
II. \% $\Delta$ Generous-Benefit Locations \\
HS Dropout & 2.42 & 4.09 & -0.72 \\
HS Grad & -0.96 & -0.06 & -0.90 \\
College & -0.83 & -0.06 & -0.78 \\
Post College & 0.07 & -0.05 & 0.10 \\
III. Deadweight Loss & 4.38 & 0.29 & 4.17 \\
\hline
\end{tabular}

Table 4: Spatial distortions caused by SNAP and by TANF. Total transfer spending is held constant across counterfactuals. See Table 1 for details.

\section{Robustness}

\subsection{Alternative Parameter Values}

In our main results above, we calibrated $\sigma_{e}$, the parameter dictating the variance of the idiosyncratic preference draw, and $\alpha_{e}$, the parameter dictating the budget share of housing, based on the parameter estimates from Colas and Hutchinson (2021). To better understand the importance of these parameter values in our results, we repeat our main analysis using values of these parameters based on the estimates form Notowidigdo (2020), who calibrates parameters analogous to $\alpha_{e}$ and estimates parameters analogous to $\sigma_{e}$ via GMM using a model which accounts for how social transfers affect a household's decision to locate in a city. ${ }^{71}$

The results with these alternative parameters values are displayed in Table 5, which mirrors Table 1. Qualitatively, the results are fairly similar to the main results: the current transfer programs leads to a large increase in high school dropouts in low-income cities and introducing an earnings index and harmoniz-

$3.78>(.43+3.16)$ reduction in deadweight loss.

${ }^{71} \mathrm{We}$ therefore set $\sigma_{e}=0.066$ and $\alpha_{e}=0.30$ for high-skill households and $\sigma_{e}=0.065$ and $\alpha_{e}=0.34$ for low-skilled households based on the baseline GMM estimates and calibration of housing share parameters from Notowidigdo (2020). 


\begin{tabular}{lcccc}
\hline & $\begin{array}{c}\mathrm{A} \\
\text { Baseline }\end{array}$ & $\begin{array}{c}\mathrm{B} \\
\text { Earnings } \\
\text { Adjustments }\end{array}$ & $\begin{array}{c}\mathrm{C} \\
\text { Harmonize }\end{array}$ & $\begin{array}{c}\mathrm{D} \\
\text { Earn Adj+ } \\
\text { Harmonize }\end{array}$ \\
\hline I. \% $\Delta$ Low-Earning Locations & & & \\
HS Dropout & 7.34 & 3.63 & 5.39 & 0.80 \\
HS Grad & 0.30 & -0.08 & 0.66 & 0.20 \\
College & 0.22 & 0.09 & 0.22 & -0.03 \\
Post College & -0.51 & -0.03 & -0.54 & -0.03 \\
II. \% $\Delta$ Generous-Benefit Locations & & & \\
HS Dropout & 3.09 & 11.44 & -4.83 & 1.52 \\
HS Grad & -1.32 & 0.77 & -1.04 & 0.09 \\
College & -1.00 & -0.35 & -0.89 & -0.78 \\
Post College & -0.05 & 0.02 & 0.00 & 0.15 \\
III. Deadweight Loss & 9.87 & 2.06 & 9.18 & 0.73 \\
\hline
\end{tabular}

Table 5: Spatial distortions caused by current transfer programs and by alternative transfer programs using parameter estimates based on Notowidigdo (2020). Total transfer spending is held constant across counterfactuals. See Table 1 for details.

ing transfer programs leads to large decreases in deadweight loss. However, the results are larger in magnitude than our baseline results. For example, using estimates based on Notowidigdo (2020), we find that the current transfer scheme leads to a deadweight loss of $9.87 \%$ of total transfer spending, compared to $4.38 \%$ in our baseline results. This occurs for two reasons. First, the estimates from Notowidigdo (2020) imply lower values for $\sigma_{e}$, the parameter governing the variance of the idiosyncratic shock. Idiosyncratic factors play a less important role in determining households location choices and therefore households are more responsive to differences in transfers across locations. Second, in this section we also use lower values $\alpha_{e}$, the parameter which determines the weight of housing relative to the consumption good in household utility. A lower value of $\alpha_{e}$ implies households spend less on housing and therefore are less sensitive to general equilibrium changes in rents. ${ }^{72}$ Therefore, if transfers lead to an influx of low-skilled households in a particular location, a low value of $\alpha_{e}$ implies that other households will be less affected by the resulting increasing in rents.

\footnotetext{
${ }^{72}$ In the simple case without transfers, $\alpha_{e}$ is equal to the optimal budget share of housing.
} 


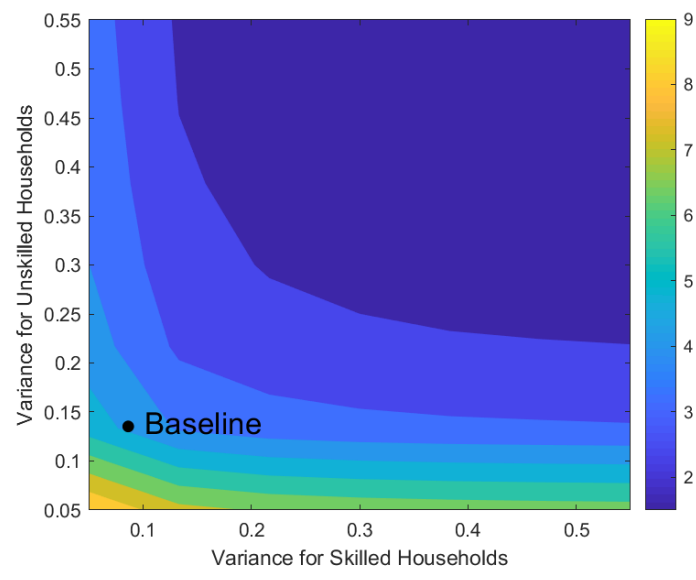

(a) Variance of Preference Draw

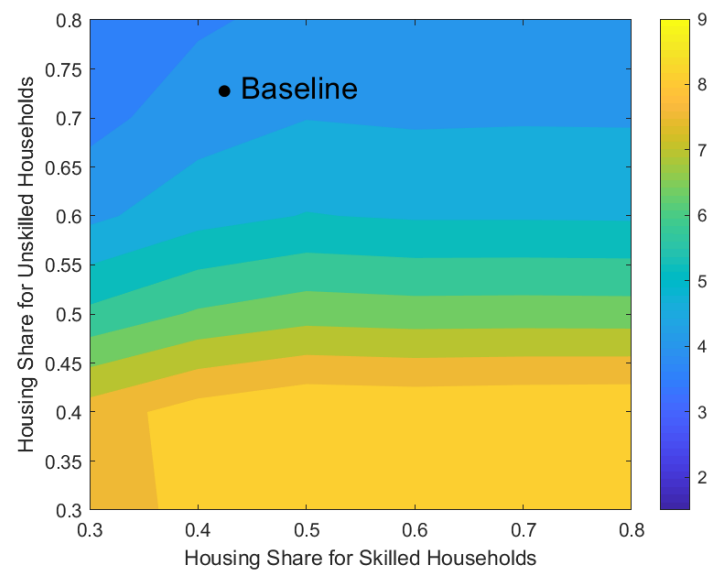

(b) Housing Expenditure Share

Figure 8: Deadweight loss caused by current transfer programs. Both figures show the deadweight loss resulting from the current SNAP and TANF programs. In Panel (a), we display $\sigma_{e}$ for low-skilled households on the $\mathrm{Y}$ (vertical) axis, and $\sigma_{e}$ for high-skilled households on the $\mathrm{X}$ (horizontal) axis. In Panel (b), we display $\alpha_{e}$ for low-skilled households on the Y (vertical) axis, and $\alpha_{e}$ for high-skilled households on the $\mathrm{X}$ (horizontal) axis.

To get a more complete picture of the importance of these two parameters in our results, Figure 8 shows the deadweight loss resulting from the current transfer programs for different values of $\sigma_{e}$ and $\alpha_{e}$. In Panel (a), we vary $\sigma_{e}$ for low-skilled households on the $\mathrm{Y}$ (vertical) axis, and $\sigma_{e}$ for high-skilled households on the X (horizontal) axis. We can see that deadweight loss is strongly decreasing in $\sigma_{e}$ for low-skilled households - lower values of $\sigma_{e}$ imply greater mobility for low-skilled households and therefore larger distortions. $\sigma_{e}$ for high-skilled households plays a smaller role, as these households are much less likely to be eligible for transfers.

In Panel (b) we vary $\alpha_{e}$, with the $\mathrm{Y}$ axis showing difference values for lowskilled households, and the $\mathrm{X}$ axis showing difference values for high-skilled households. Deadweight loss is strongly decreasing in $\alpha_{e}$ for low-skilled households higher values of $\alpha_{e}$ for low-skilled households imply that the rent increase resulting from an influx of low-skilled households into a location will discourage other low-skilled households from choosing this location. ${ }^{73}$

\footnotetext{
${ }^{73}$ Deadweight loss is slightly decreasing in $\alpha_{e}$ for high-skilled households. Higher values of $\alpha_{e}$ for high-skilled households imply that influxes of low-skilled households into a location with high transfers will lead to the exit of high-skilled households, thereby decreasing rents and leading to more influxes of low-skilled households.
} 


\subsection{Elastic Labor Supply}

Throughout, we have assumed that households inelastically supply $\ell_{d}$ units of labor regardless of where they live. How would allowing for elastic labor supply affect our main conclusions? First, allowing for elastic labor supply would likely increase the total efficiency cost of the current transfer programs, as transfers would lead to distortions of both location choice and labor supply.

Perhaps a more important question is: how would allowing for elastic labor supply change our results on spatial distortions? Note that the returns to labor supply are generally lower in low-productivity cities, both because of low wages and because households in low-productivity cities will on average face higher phase-out rates of social transfers than households in high-productivity cities, who are more likely to be ineligible for transfers. If labor supply were elastic, households would therefore have lower labor supply in low-productivity relative to high-productivity cities. This would increase the differences in earnings and thus transfers received between low- and high-productivity cities. These larger differences in transfers across cities would create an even larger incentive to locate in low-productivity cities relative to high-productivity cities. Therefore, allowing for elastic labor supply would likely increase the size of the earnings distortion on location choice.

\section{Conclusion}

In this paper, we used combined a spatial equilibrium model with a detailed model of the United States social transfer system to quantify the locational inefficiency caused by these programs. We found that the current transfer program leads to deadweight loss mostly by incentivizing households to locate in cities where they have lower earnings. We also showed that simultaneously harmonizing transfer programs across state and indexing household earnings to local average earnings could reduce the locational inefficiency caused by these programs by over $85 \%$ while still providing mean-tested transfers.

For a number of reasons, we view our results as conservative and believe our results may understate the spatial distortions caused by social transfer programs. 
First, while we consider a fairly rich set of demographic types, we assume that within each demographic group all households have the same income conditional on location. In reality, there may be considerable heterogeneity in earnings even within these demographic groups. Some highly educated households, for example, may earn low income and therefore be eligible for transfers in some locations. These highly educated households with low income levels could therefore also have their location decisions distorted by social transfer programs. Further, we employ a static model, and therefore are unable to account for monthly fluctuations in income. Households who, on average, have relatively high income may experience months of unemployment and therefore be eligible for social transfers for short periods of time. Future work could potentially make progress on these issues by using a dynamic spatial equilibrium model, in the spirit of Almagro and Dominguez-Iino (2019), Colas (2019), Greaney (2019), Caliendo, Dvorkin, and Parro (2019), or Giannone et al. (2020).

Future work could also utilize this framework to analyze other means-tested programs. Analyzing the distortions caused by Medicaid would be interesting, as the Medicaid schedules are highly progressive and the Medicaid schedule and eligibility varies across states. It would also be interesting to use our framework to analyze the distortions caused by tax credits, such that the Earned Income Tax Credit or the Child Tax Credit. We leave these questions for future research. 


\section{References}

Albouy, David. 2009. "The unequal geographic burden of federal taxation." Journal of Political Economy, 117(4): 635-667.

Almagro, Milena, and Tomás Domınguez-Iino. 2019. "Location sorting and endogenous amenities: Evidence from amsterdam." NYU, mimeograph.

Baum-Snow, Nathaniel, and Ronni Pavan. 2012. "Understanding the city size wage gap." The Review of economic studies, 79(1): 88-127.

Baum-Snow, Nathaniel, Matthew Freedman, and Ronni Pavan. 2018. "Why has urban inequality increased?" American Economic Journal: Applied Economics, 10(4): $1-42$.

Berry, Steven. 1994. "Estimating Discrete-Choice Models of Product Differentiation." RAND Journal of Economics, 25(2): 242-262.

Berry, Steven, James Levinsohn, and Ariel Pakes. 2004. "Differentiated Product Demand Systems from a Combination of Micro and Macro Data: The New Car Market." Journal of Political Economy, 112(1): 68-105.

Bilal, Adrien. 2020. "The geography of unemployment." mimeo, Princeton University.

Bitler, Marianne, and Hilary W Hoynes. 2010. "The state of the safety net in the post-welfare reform era." National Bureau of Economic Research.

Blank, Rebecca M. 1988. "The effect of welfare and wage levels on the location decisions of female-headed households." Journal of Urban Economics, 24(2): 186211.

Blundell, Richard, Monica Costa Dias, Costas Meghir, and Jonathan Shaw. 2016. "Female labor supply, human capital, and welfare reform." Econometrica, 84(5): 1705-1753.

Borjas, George J. 1999. "Immigration and welfare magnets." Journal of labor economics, 17(4): 607-637.

Caliendo, Lorenzo, Maximiliano Dvorkin, and Fernando Parro. 2019. "Trade and labor market dynamics: General equilibrium analysis of the china trade shock." Econometrica, 87(3): 741-835.

Card, David. 2009. "Immigration and Inequality." American Economic Review: Papers and Proceedings, 99(2): 1-21.

Chan, Marc K. 2013. "A dynamic model of welfare reform.” Econometrica, 81(3): 9411001. 
Coen-Pirani, Daniele. 2021. "Geographic mobility and redistribution." International Economic Review, 62(3): 921-952.

Colas, Mark. 2019. "Dynamic responses to immigration." Opportunity and Inclusive Growth Institute.

Colas, Mark, and John M Morehouse. 2021. "The Environmental Cost of Land Use Restrictions." Quantitative Economics, (Forthcoming).

Colas, Mark, and Kevin Hutchinson. 2021. "Heterogeneous workers and federal income taxes in a spatial equilibrium." American Economic Journal: Economic Policy, 13(2): 100-134.

Currie, Janet. 2004. "The take up of social benefits." National Bureau of Economic Research.

Currie, Janet, and Jeffrey Grogger. 2001. "Explaining recent declines in food stamp program participation." Brookings-Wharton papers on urban affairs, 203-244.

Diamond, Rebecca. 2016. "The determinants and welfare implications of US workers' diverging location choices by skill: 1980-2000." American Economic Review, 106(3): 479-524.

Dickert-Conlin, Stacy, Katie Fitzpatrick, Brian Stacy, and Laura Tiehen. 2010. "The Downs and Ups of the SNAP Caseload: What Matters?" Applied Economic Perspectives and Policy.

Economic Research Service, U.S. Department of Agriculture. 2019. "SNAP Policy Database." data retrieved from U.S. Department of Agriculture (USDA), https://www.ers.usda.gov/data-products/snap-policy-data-sets/.

Enchautegui, Maria E. 1997. "Welfare payments and other economic determinants of female migration." Journal of Labor Economics, 15(3): 529-554.

Fajgelbaum, Pablo D, and Cecile Gaubert. 2020. "Optimal spatial policies, geography, and sorting." The Quarterly Journal of Economics, 135(2): 959-1036.

Fajgelbaum, Pablo D, Eduardo Morales, Juan Carlos Suárez Serrato, and Owen Zidar. 2019. "State taxes and spatial misallocation." The Review of Economic Studies, 86(1): 333-376.

Ganong, Peter, and Jeffrey B Liebman. 2018. "The decline, rebound, and further rise in SNAP enrollment: Disentangling business cycle fluctuations and policy changes." American Economic Journal: Economic Policy, 10(4): 153-76.

Gelbach, Jonah B. 2004. "Migration, the life cycle, and state benefits: How low is the bottom?" Journal of Political Economy, 112(5): 1091-1130. 
Giannone, Elisa, Qi Li, Nuno Paixao, and Xinle Pang. 2020. "Unpacking Moving." Working Paper.

Glaeser, Edward L, and David C Mare. 2001. "Cities and skills." Journal of labor economics, 19(2): 316-342.

Glaeser, Edward L., and Joshua D. Gottlieb. 2009. "The Wealth of Cities: Agglomeration Economies and Spatial Equilibrium in the United States." Journal of Economic Literature, 47(4): 983-1028.

Greaney, Brian. 2019. "The Distributional Effects of Uneven Regional Growth." Working Paper.[5].

Greenwood, Jeremy, Nezih Guner, and John A Knowles. 2000. "Women on welfare: A macroeconomic analysis." American Economic Review, 90(2): 383-388.

Guner, Nezih, Remzi Kaygusuz, and Gustavo Ventura. 2020. "Child-related transfers, household labour supply, and welfare." The Review of Economic Studies, 87(5): 2290-2321.

Gyourko, Joseph, Albert Saiz, and Anita A. Summers. 2008. "A New Measure of the Local Regulatory Environment for Housing Markets: The Wharton Residential Land Use Regulatory Index." Urban Studies, 45(3): 693-729.

Heffernan, Christine, Benjamin Goehring, Ian Hecker, Linda Giannarelli, and Sarah Minton. 2018. "Welfare Rules Databook: State TANF Policies as of July 2017." The Urban Institute.

Kabbani, Nader S, and Parke E Wilde. 2003. "Short recertification periods in the US Food Stamp Program." Journal of Human Resources, 1112-1138.

Kay, John A. 1980. "The deadweight loss from a tax system." Journal of Public Economics, 13(1): 111-119.

Keane, Michael P, and Kenneth I Wolpin. 2010. "The role of labor and marriage markets, preference heterogeneity, and the welfare system in the life cycle decisions of black, hispanic, and white women." International Economic Review, 51(3): 851-892.

Kennan, John, and James R Walker. 2010. "Wages, welfare benefits and migration." Journal of Econometrics, 156(1): 229-238.

Kline, Patrick, and Enrico Moretti. 2014. "People, places, and public policy: Some simple welfare economics of local economic development programs." Annual Review of Economics, 6(1): 629-662.

Levine, Phillip B, and David J Zimmerman. 1999. "An empirical analysis of the welfare magnet debate using the NLSY." Journal of Population Economics, 12(3): 391-409. 
Low, Hamish, Costas Meghir, Luigi Pistaferri, and Alessandra Voena. 2018. "Marriage, labor supply and the dynamics of the social safety net." National Bureau of Economic Research.

Meyer, Bruce D. 1998. Do the poor move to receive higher welfare benefits? Institute for Policy Research, Northwestern University.

Meyer, Bruce D, Wallace KC Mok, and James X Sullivan. 2009. "The underreporting of transfers in household surveys: its nature and consequences." National Bureau of Economic Research.

Mohring, Herbert. 1971. "Alternative welfare gain and loss measures." Economic Inquiry, 9(4): 349 .

Moretti, Enrico. 2011. "Local labor markets." In Handbook of Labor Economics. Vol. 4, , ed. Orley Ashenfelter, and D. Card, 1237-1313. Amsterdam:Elsevier.

Moretti, Enrico. 2013. "Real wage inequality." American Economic Journal: Applied Economics, 5(1): 65-103.

Notowidigdo, Matthew J. 2020. "The incidence of local labor demand shocks." Journal of Labor Economics, 38(3): 000-000.

on Budget, Center, and Policy Priorities. 2017. "A Quick Guide to SNAP Eligibility and Benefits." ", https://www.cbpp.org/research/a-quickguide-to-snap-eligibilityand-benefits".

Ortigueira, Salvador, and Nawid Siassi. 2021. "The US tax-transfer system and low-income households: Savings, labor supply, and household formation." Review of Economic Dynamics.

Piyapromdee, Suphanit. 2019. "The impact of immigration on wages, internal migration and welfare." Working paper.

Ratcliffe, Caroline, Signe-Mary McKernan, and Kenneth Finegold. 2008. "Effects of food stamp and TANF policies on food stamp receipt." Social Service Review, 82(2): 291-334.

Roback, Jennifer. 1982. "Wages, Rents, and the Quality of Life." Journal of Political Economy, 90(6): 1257-1278.

Roca, Jorge De La, and Diego Puga. 2017. "Learning by working in big cities." The Review of Economic Studies, 84(1): 106-142.

Rosen, Sherwin. 1979. "Wage-based Indexes of Urban Quality of Life." In Current Issues in Urban Economics., ed. Peter Mieszkowski, and Mahlon Straszheim. Baltimore, MD:John Hopkins Univ. Press. 
Ruggles, Steven, J. Trent Alexander, Katie Genadek, Ronald Goeken, Matthew B. Schroeder, and Matthew Sobek. 2010. "Integrated Public Use Microdata Series: Version 5.0 [Machine-readable database]." Minneapolis: University of Minnesota.

The Urban Institute. 2019. "Welfare Rules Database." https://wrd.urban.org/.

Walker, James R. 1994. Migration among low-income households: Helping the witch doctors reach consensus. Institute for Research on Poverty, University of WisconsinMadison. 


\section{A Data Appendix: For Online Publication Only B Theoretical Appendix: For Online Publica- tion Only}

\section{B.1 Institutional Details: Transfer Programs}

In this section we give further details on the eligibility criteria and benefits formulas for SNAP and TANF. We also give more details on how we model these programs.

\section{B.1.1 SNAP}

Eligibility There are three eligibility criteria for SNAP: a gross income test, a net income test, and an assets test. Gross income is the sum of earned and unearned income, including income from other transfer programs, such as TANF. In the context of our model, this includes earnings, $I_{d j}$, unearned income, $U_{d}$, and TANF transfers, $\tau_{d j}^{T}$. Gross income as measured for SNAP, $G I_{d j}^{F}$, in our model is therefore given by

$$
G I_{d j}^{F}=I_{d j}+U_{d}+\tau_{d j}^{T}
$$

A household passes the gross income test if gross income is less than 1.3 times the federal poverty level. Note that the federal poverty level depends on household size and is higher for households in Hawaii and Alaska.

Net income is given by gross income less deductions. There is a deduction for a portion of earned income, a standard deduction, an excess-shelter deduction, and deductions for dependent care, medical expenses, and child support. As we do not model dependent care, medical expenses, or child support, and because these three deductions are not widely taken, ${ }^{74}$ we set these last three deductions to 0 .

In order to calculate the excess-shelter deduction, we must first define countable income (sometimes referred to as "net income for shelter deduction"). This is

\footnotetext{
${ }^{74}$ Only 3 percent of SNAP households claim the dependent care deduction, 2 percent claim the child support deduction, and 6\% claim the medical expense deduction (on Budget and Priorities, 2017).
} 
given by gross income minus all deductions except for the excess-shelter deduction. Therefore, countable income, $C I$, in our model is given by

$$
C I_{d j}=G I_{d j}^{F}-\text { StandardDeduction }_{d j}-{\text { Disregard } \times I_{d j} .}
$$

StandardDeduction $_{d j}$ is a standard deduction. It is indexed by $d$ to reflect that the standard deduction is increasing in family size, and by $j$ to reflect that the standard deduction is larger for households living in Hawaii and Alaska. Disregard is a parameter and is equal to .2 .

The excess-shelter deduction is given by housing costs, $r_{j} h_{j}$, minus half of countable income, and is capped at the maximum shelter deduction:

$$
\text { ShelterDeduct }_{d j}=\max \left\{0, \min \left\{\text { MaxShelter }_{j}, r_{j} h_{j}-.5 C I_{d j}\right\}\right\} \text {. }
$$

Net income as calculated for SNAP, $N I^{F}$, is then given by

$$
N I_{d j}^{F}=\max \left\{0, C I_{d j}-\text { ShelterDeduct }_{d j}\right\} .
$$

A household passes the net income test if net income is less than the federal poverty level.

The asset test requires that household assets fall below a certain limit. The details of how the asset test is implemented, such as whether vehicles are included in the asset calculation, varies across states. We do not model assets directly and therefore do not include the asset test in our eligibility criteria. We can think of our SNAP accessibility measures, $o_{d j}^{F}$, as capturing the probability at which a household of a given demographic group will pass the asset test. Note that our vector of SNAP implementation policies in (7) includes variables describing how assets are calculated and an indicator for whether or not the state relaxes the asset test through broad based categorical eligibility.

Some states also include a three-month time limit for able-bodied adults without dependents. This time limit is not modeled directly and is therefore captured by the SNAP accessibility estimates. The SNAP policy implementation vector includes a dummy for whether the household is an able-bodied adult without dependents and an indicator for whether the state waives this three-month time 
limit.

Benefits Benefits are calculated as a "maximum allotment" minus a constant times net income. We therefore can write:

$$
\tilde{\tau}_{d j}^{F}=\text { MaxAllotment }_{d j}-\text { NetIncWeight }^{F} \times N I_{d j}^{F} \text {, }
$$

where we index the maximum allotment by $d$ to reflect that the maximum allotment is increasing in household size, and by $j$ to reflect that the maximum allotment is higher in Hawaii and Alaska. NetIncWeight ${ }^{F}$ is a parameter which is equal to 0.3. We include an $F$ superscript to distinguish between the net income weight for SNAP denoted here, and the net income weight for TANF.

There is a minimum benefit amount for households with one or two members who are eligible for SNAP. As these minimum benefit amounts are very small $(\$ 16$ per month for households in the continental US), they are ignored here.

\section{B.1.2 TANF}

In what follows, we first describe the general TANF structure that applies in most states. We then describe alternative TANF structures that have been implemented which do not follow this structure.

Eligibility Similar to SNAP, most states have three eligibility criteria for TANF: a gross income test, a net income test, and an assets test. As with SNAP, these tests compare some measure of income or assets against a threshold, which can vary by state and household characteristics. Unlike SNAP, though, households can be subject to two different versions of the gross and net income test: one version used for the initial application for TANF benefits, and one version used to determine continuing eligibility. ${ }^{75}$ Both versions of these tests, though, simply compare the pertinent income measure to some threshold. We implement the more restrictive test (i.e., the lower threshold) in each location. This is based on the fact that if a household were to move between states, they would almost always have

\footnotetext{
${ }^{75}$ Generally speaking, households are required to report any substantive change in monthly income which could affect their TANF benefit. As with SNAP, states also have the ability to implement recurring reporting requirements.
} 
to re-apply for TANF. Since income is static in our model once households choose location, a family passing the more restrictive test implies also passing the test with the higher threshold. While uncommon, some states have also implemented tests comparing gross and net earnings alone to some threshold. Only the gross earnings test on recipients is used in the states included in our model.

We calculate gross income for TANF as the sum of unearned and earned income:

$$
G I_{d j}^{T}=I_{d j}+U_{d}
$$

Net income is given by earnings minus deductions, plus unearned income. In most states, there are two deductions to earned income. The first is a deduction given in dollars, which is fixed conditional on family composition. This "dollar deduction" in most states will vary only with the number of adult workers in the household, as most states apply a portion of this deduction twice for families with two adult earners. The second deduction is a percentage of the household's remaining gross earned income after the dollar deduction is applied. This "percentage deduction" is standard across household characteristics. As with SNAP, net income cannot be negative for the purposes of TANF benefit calculation or eligibility testing. Net income can be represented then as:

$$
N I_{d j}^{T}=\max \left\{0,\left(1-\text { PctDeduction }_{j}\right)\left(I_{d j}-\text { DollarDeduction }_{d j}\right)+U_{d}\right\} .
$$

In some states, the deduction vary in size based on how long a household has received TANF. For instance, some states deduct the entirety of a household's earnings in the first month of TANF receipt and then deduct a fixed portion of earnings for all future months. More rarely, several states decrease the percentage deduction periodically as a household continues to receive TANF. Because our model does not account for time in this way, we use the modal deduction in all cases: that deduction which would apply in the most months of a household's TANF receipt.

In order to pass the asset test, household assets must fall below a certain limit. States vary in how assets of calculated. We do not model assets directly 
and therefore do not include the asset test in our eligibility criteria. Similar to SNAP, we can think of our TANF accessibility measures, $o_{d j}^{T}$, as capturing the probability at which a household of a given demographic group will pass the asset test.

States have also implemented work requirements for TANF households. In most cases, each adult parent in a TANF-eligible household must be actively working, actively seeking work, or engaged with a state-facilitated work-training program. These requirements are generally written so as to require parents to work or search for work for some minimum number of hours per week. States also have extensive rules for the number of months that a household may claim TANF. As a baseline, heads-of-household may only receive federal TANF payments for 60 months over a lifetime, by federal statute. However, most states have added additional structure around this 60-month cap. Some states have legislated shorter lifetime limits on TANF receipt. Other states have left the 60-month cap alone, but have implemented rules which allow families to claim TANF only intermittently. ${ }^{76}$ On the other hand, some states have chosen to extend TANF benefits to families for more than 60 months using state funds.

To respond to the diverse circumstances that lead a family to be in need, each state has also formalized a large set of exceptions to both work rules and time limits. For instance, most states exempt from work requirements those parents with children under the age of two, and those parents who are physically or mentally dependent, or who care for another dependent adult in the household. A variety of circumstances will lead to the suspension of the 60-month TANF clock. For instance, the Family Violence Option provides each state with the option to stop counting months of TANF use against the 60-month cap in situations involving domestic violence. ${ }^{77}$

Most of the parameters which govern how work rules and time-limits impact

\footnotetext{
${ }^{76}$ Most commonly, a household may claim TANF benefits for 12 months, but is then ineligible until the household has went without TANF benefits for some period of time.

${ }^{77}$ Specifically, states may suspend the 60 -month clock in situations "where compliance with such requirements would make it more difficult for individuals receiving assistance under this part to escape domestic violence or unfairly penalize such individuals who are or have been victimized by such violence, or individuals who are at risk of further domestic violence." 42 U.S.C. $\S$ 602(a)(7)(A)(iii).(http://www.ncdsv.org/images/LM_FamilyViolenceOptionStateByStateSummary_updated7-2004.pdf)
} 
a household's TANF eligibility fall entirely outside the scope of our modeling. As such, we capture the probability that a household would be ineligible for TANF due to work or time rules in our TANF accessibility measures.

Benefits In the standard structure, benefits are calculated as a "standard of need" minus a constant times net income. ${ }^{78}$ Benefits cannot exceed a "maximum grant" amount. ${ }^{79}$ We therefore can write:

$$
\tilde{\tau}_{d j}^{T}=\min \left\{\operatorname{MaxGrant}_{d j}, \operatorname{StandardNeed}_{d j}-\operatorname{NetIncWeight}_{d j}^{T} \times N I_{d j}^{T}\right\},
$$

where MaxGrant dj $_{j}$ gives the maximum grant, StandardNeed ${ }_{d j}$ is the standard of need, and NetIncWeight ${ }_{d j}^{T}$ gives the rate at which benefits decrease with net income. Note that all parameters are indexed by demographic $d$ and location $j$ to reflect that states may choose different values for these parameters within this general structure.

Exceptions Most state TANF systems follow the above standard for calculating benefits, but there are several states that have adopted alternative TANF benefit calculations that do not fit into the framework above. Note that there are other states that are not included as locations in our model which also differ from this standard TANF structure.

1. Flat Benefits: A handful of states have chosen to eliminate the progressive benefit structure above entirely, and instead pay flat benefits to all eligible TANF recipients, regardless of household income. The states represented in our model that have made this change are Wisconsin and Arkansas. In Arkansas, TANF benefits are flat conditional on family size, but benefits do

\footnotetext{
${ }^{78}$ Many states use the term "standard of need," but terminology varies considerably between states. The term "benefit standard" has also been widely adopted. Note that some states refer to the standard of need as a "maximum benefit." This is relevant since other states have a separately codified maximum benefit in addition to the standard of need, as per the formula below.

${ }^{79}$ This maximum grant is set explicitely in some states, such as Delaware. In states with no separately codified maximum grant, the standard of need can be thought of as the maximum grant. This allows us to write the TANF benefit formula for most states using one equation.
} 
still increase as family size increases. In Wisconsin, every eligible family receives the same TANF payment, which was $\$ 608$ in 2017 . These states have also implemented several alternatives to the payment of traditional TANF benefits, such as state employment and work-training programs, which frequently fall under the authority of the same state agency that administers TANF. ${ }^{80}$ Such forms of assistance and subsidized employment fall outside of our model, so we limit our formalization of TANF in these states to the flat benefit payments, since these are most comparable to TANF payments in general. ${ }^{81}$

2. Less than $\mathbf{1 0 0 \%}$ benefits: Several states use the standard TANF formula above to calculate a benefit payment, but then pay less than $100 \%$ of those benefits. For instance, North Carolina pays only $50 \%$ of what the above TANF schedule would indicate.

3. Treatment of Unearned Income: Among those states with explicitely coded maximum benefit amounts, some will subtract unearned income from that maximum benefit amount when determining the maximum TANF payment. This matters, for instance, for families with little or no earned income but some unearned income.

4. Intra-state Standard of Need Differences: A handful of states have different standards of need depending on the recipient's county of residence. These seem to generally reflect cost of living differences, but are not large in size.

5. Virginia: In addition to the common standard of need minus net income formulation, Virginia has also established two distinct maximum grant amounts for TANF benefits, each of which is binding for a distinct set of households. The first is a set of maximum grants for different counties that are independent of household size. The second, Virginia's "standard of assistance" (SOA), does vary with household size. For households with fewer

\footnotetext{
${ }^{80}$ E.g., Wisconsin's Community Service Jobs program.

${ }^{81}$ Specifically, these flat benefits are paid out under the "W-2 Transition" program, which replaced AFDC in Wisconsin.
} 
than 5 members, the state-wide maximums are larger than the appropriate SOA, meaning that the only binding maximum grant for these families is the SOA. For households with more than 5 members, the state-wide maximums are smaller than the appropriate standard of assistance. However, unearned income is subtracted from the SOA. This means that both maximums must be taken into account for larger assistance units in Virginia. If a household with more than 5 members has no unearned income, the SOA minus unearned income will be larger than the absolute maximum; if the unit has a high level of unearned income, the SOA minus that unearned income may be smaller than the absolute maximum.

6. Minnesota: Minnesota's TANF program is actually a combined cash and food aid program, in which households receive a single cash transfer every month, but a portion of that transfer may only be spent on food items. ${ }^{82}$ Families receiving TANF in Minnesota are thus ineligible for separate SNAP benefits. The food benefits provided under this combined program are of a similar magnitude to SNAP payments in Minnesota and other states, but are not identical. To account for the fact that households do not receive SNAP when they receive TANF, we subtract TANF accessibility from SNAP accessibility in Minnesota. This solution reflects the notion that, for every portion of the year that a family receives TANF, they are ineligible to receive SNAP.

Outside Option Locations Since we include the nine census divisions as aggregate location options for households, we must also make some simplification regarding the TANF schedule for households locating there. We model TANF in these areas using the program details of the state with the largest remaining population after subtracting the 2017 population figures from each CBSA included in the model. We do the same for our measures of TANF and SNAP accessibility.

\footnotetext{
${ }^{82}$ This is accomplished using an electronic benefit transfer (EBT) card, as is the case with SNAP.
} 


\section{B.2 Budget Constraint and Optimal Housing and Con- sumption}

In Section B.2.1, we show how the excess-shelter deduction can lead to kinks in the budget constraint. In Section B.2.2 then show how we solve for $h_{d j}^{\star}$ and $c_{d j}^{\star}$ given this budget constraint.

\section{B.2.1 Full Household Problem}

Recall that household utility is given by Cobb-Douglas utility function

$$
U_{i j}=c^{1-\alpha_{e}} h_{j}^{\alpha_{e}} \Gamma_{i j}
$$

where $\alpha_{e}$ is a skill level specific utility parameter and $\Gamma_{i j}$ represents the amenity utility household $i$ receives when they live in location $j$. Households face the following budget constraint

$$
I_{d j}+U_{d}+\tau_{d j}\left(I_{d j}, U_{d}, \tau_{d j}^{T}, r_{j} h_{j}\right)=c+r_{j} h_{j}
$$

We can rewrite transfers as the sum of TANF and SNAP as:

$$
\tau_{d j}\left(I_{d j}, U_{d}, r_{j} h_{j}\right)=\tilde{\tau}_{d j}^{T}\left(I_{d j}, U_{d}\right) o_{d j}^{T}\left(I_{d j}, U_{d}\right)+\tilde{\tau}_{d j}^{F}\left(I_{d j}, U_{d}, r_{j} h_{j}\right) o_{d j}^{F}\left(I_{d j}, U_{d}\right)
$$

Given income, we can think of SNAP benefits as a piece-wise linear function in housing costs: for households in the phase-out region of SNAP whose shelter deduction does not exceed the maximum excess-shelter deduction, an increase in housing cost implies an increase in SNAP. However, if the household is not in the phase-out region of SNAP or if the household has exceeded the max shelter deduction, then an increase in housing costs does not change the amount of SNAP benefits. Let $X_{d j}=\left[I_{d j}, U_{d}, \tau_{d j}^{T}\right]$ denote the vector of household variables besides housing cost which affect SNAP benefits We express this formally as 


$$
\begin{aligned}
& \tilde{\tau}_{d j}^{F}\left(X_{d j}, r_{j} h_{j}\right)=\mathbb{I}\left[\operatorname{Elig}_{d j}\left(X_{d j}\right)\right] \times \\
& \left\{\begin{array}{lr}
\hat{t}_{d j}^{0}\left(X_{d j}\right), & \text { for } r_{j} h_{j}<\underline{r h} d j\left(X_{d j}\right) \\
t_{d j}^{0}\left(X_{d j}\right)+\operatorname{NetIncW}\left(r_{j} h_{j}-\underline{r h}\left(X_{d j}\right)\right), & \text { for } \underline{r h} d j\left(X_{d j}\right) \leq r_{j} h_{j} \leq \overline{r h}_{d j}\left(X_{d j}\right) \\
t_{d j}^{0}\left(X_{d j}\right)+\operatorname{NetIncW}\left(\overline{r h}_{d j}\left(X_{d j}\right)-\underline{r h}\left(X_{d j}\right)\right), & \text { for } \overline{r h}_{d j}\left(X_{d j}\right)<r_{j} h_{j}
\end{array}\right\}
\end{aligned}
$$

where

- $\mathbb{I}\left[\operatorname{Elig}_{d j}\left(X_{d j}\right)\right]$ is a function indicating that the household has income such that (i) the income test is passed and (ii) the net income test can be passed for some value of housing costs. If either of these conditions do not hold, then the household receives 0 benefits, regardless of their housing cost. $^{83}$

- $\hat{t}_{d j}^{0}$ is the amount of SNAP benefits the household will receive if they do not take an excess-shelter deduction. Note that this can be a positive amount if their net income without a shelter deduction qualifies them for positive benefits, or can be 0 if their net income without the shelter deduction does not pass the net income test or does not qualify them for positive benefits. We can write this as $\hat{t}^{0}\left(X_{d j}\right)=\tilde{\tau}_{d j}^{F}\left(X_{d j}, 0\right)$.

- $t_{d j}^{0}$ gives the amount of SNAP benefits at the lowest level of housing costs at which increases in housing cost lead to increases in benefits. This can be either

1. The benefits received once the household has shelter costs such that net income is equal to the federal poverty live and therefore the household passes the net income test.

2. $\hat{t}_{d j}^{0}$.

- $\overline{r h_{d j}}$ is the maximum amount of housing cost for which a household which increases in housing cost lead to increases in SNAP benefits. This is given by the minimum of the following two thresholds:

\footnotetext{
${ }^{83}$ Also recall that the asset test is included in the SNAP accessibility measure, $o_{d j}^{F}$.
} 
1. Housing costs such that the excess-shelter cost is equal to the maximum excess-shelter deduction. In this case $\overline{r h_{d j}}=.5 C I_{d j}+$ MaxShelter $_{j}$.

2. Housing cost such that net income is equal to 0 .

- $r h_{d j}$ is the minimum amount of house cost for which decreases in housing cost lead to decreases in SNAP benefits. This is given by the maximum of the following thresholds:

1. Housing costs such that the household receives an excess-shelter deduction of 0 . In this case $r h_{d j}=.5 C I_{d j}$.

2. Housing cost such that net income leads to households receiving 0 SNAP benefits, either via the benefits formula or failing the net income test.

\section{B.2.2 Optimal Housing and Consumption}

If a household cannot be eligible for SNAP given their income $\left(\mathbb{I}\left[\operatorname{Elig}\left(X_{d j}\right)\right]=0\right)$, then optimal housing cost is simply given by:

$$
h_{j}^{\star} r_{j}=\alpha_{e}\left(I_{d j}+U_{d}+\tau_{d j}^{T}\left(X_{j d}\right)\right) .
$$

If the households may be eligible for SNAP, these two kinks in the SNAP benefits formula imply that the household's budget constraint has two kinks as well. Therefore, there are five possible solutions for the optimal choice of housing:

1. A tangency solution such that $r_{j} h_{j}<\underline{r h_{d j}}\left(X_{j d}\right)$

2. A solution at the kink where $r_{j} h_{j}=r h_{d j}\left(X_{j d}\right)$.

3. A tangency solution such that $r h_{d j}\left(X_{j d}\right) \leq r_{j} h_{j} \leq \overline{r h_{d j}}\left(X_{j d}\right)$

4. A solution at the kink where $r_{j} h_{j}=\overline{r h_{d j}}\left(X_{j d}\right)$

5. A tangency solution such that $\overline{r h_{d j}}\left(X_{j d}\right)>r_{j} h_{j}$

We now categorize the optimal choice of housing in each possible solution. Optimal consumption is simply given by total income minus spending on housing:

$$
c_{d j}^{\star}=I_{d j}+U_{d}+\tau_{d j}(\cdot)-r_{j} h_{d j}^{\star}
$$


Possible solution 1: Tangency condition with $r_{j} h_{j}<r h_{d j}\left(X_{j d}\right)$ Solving the household's problem yields the following optimal housing cost

$$
\tilde{h}_{d j}^{\star 1} r_{j}=\alpha\left(I_{d j}+U_{d}+\tau_{d j}^{T}\left(X_{j d}\right)+o_{d j}^{F}\left(X_{d j}\right) \hat{t}_{d j}^{0}\left(X_{j d}\right)\right)
$$

This possible solution is only feasible is the tangency condition occurs at the appropriate region of the budget constraint such that

$$
\tilde{h}_{d j}^{\star 1} r_{j}<\underline{r h_{d j}}\left(X_{j d}\right) .
$$

Possible solution 2: Kink solution with $r_{j} h_{j}=r h_{d j}\left(X_{j d}\right)$ In this case housing cost is simply given by

$$
\tilde{h}_{d j}^{\star 2} r_{j}=\underline{r h_{d j}}\left(X_{j d}\right) .
$$

Possible solution 3: Tangency Condition with $r h_{d j} \leq r_{j} h_{j} \leq \overline{r h_{d j}} \quad$ Solving the household's problem yields the following optimal housing cost

$$
\begin{aligned}
& \tilde{h}_{d j}^{\star 3} r_{j}= \\
& \quad \alpha_{e} \frac{\left(I_{d j}+U_{d}+\tau_{d j}^{T}\left(X_{j d}\right)+o_{d j}^{F}\left(X_{d j}\right)\left(t_{d j}^{0}\left(X_{j d}\right)-\operatorname{NetIncWeightrh_{dj}}\left(X_{j d}\right)\right)\right)}{1-o_{d j}^{F}\left(X_{j d}\right) \text { NetIncWeight }} .
\end{aligned}
$$

This solution is possible only if tangency occurs in the phase-out region of the budget constraint such that

$$
\underline{r h_{d j}}\left(X_{j d}\right) \leq \tilde{h}_{d j}^{\star 3} r_{j} \leq \overline{r h_{d j}}\left(X_{j d}\right)
$$

Possible Solution 4: Kink solution with $r_{j} h_{j}=\overline{r h_{d j}}\left(X_{j d}\right) \quad$ In this solution, housing cost is given by

$$
\tilde{h}_{d j}^{\star 4} r_{j}=\overline{r h_{d j}}\left(X_{j d}\right) .
$$


Possible solution 5: Tangency condition with $r_{j} h_{j} \geq \overline{r h_{d j}}\left(X_{j d}\right)$. Optimal housing cost is given by

$$
\begin{aligned}
& \tilde{h}_{d j}^{\star 5} r_{j}= \\
& \quad \alpha_{e}\left(I_{d j}+U_{d}+\tau_{d j}^{T}\left(X_{j d}\right)+o_{d j}^{F}\left(X_{d j}\right)\left(t_{d j}^{0}\left(X_{j d}\right)+\left(\overline{r h_{d j}}\left(X_{j d}\right)-\underline{r h_{d j}}\left(X_{j d}\right)\right)\right)\right) .
\end{aligned}
$$

This solution is possible if

$$
\tilde{h}_{d j}^{\star 5} r_{j}>\overline{r h_{d j}}\left(X_{j d}\right)
$$

Optimal Solution Given the kinks in the budget constraint, it is possible that multiple tangency conditions can hold simultaneously. Therefore, we choose optimal housing, and therefore optimal consumption, by comparing the utility generated given each of the possible solutions. The housing and consumption choices which maximize utility among the possible alternatives give us $c_{d j}^{\star}$ and $h_{d j}^{\star}$.

\section{Estimation and Simulation Appendix: For On- line Publication Only}

\section{C.1 Hedonic Rents}

In order to generate comparable measures of housing rents across cities, we estimate hedonic regressions of rents on housing characteristics and CBSA fixed effects. This allows us to generate the predicted rent of a house in each city, holding housing characteristics constant.

Specifically, we estimate hedonic regressions of log gross rent on CBSA fixed effects and a vector of housing characteristics using data on renters. The vector of housing characteristics consists of the number of units in the structure containing the household, number of bedrooms, number of total rooms, and household members per room. The rent index is given by the predicted rent from the hedonic regressions using the mean values of the elements of the housing characteristics vector. This gives the predicted value of housing in each CBSA, holding housing characteristics constant. 


\section{C.2 Estimation: Production Function}

Recall from (12), that the production function in location $j$ is given by

$$
Y_{j}=A_{j}\left[\left(1-\theta_{j}\right) L_{U j}^{\frac{\varsigma-1}{\varsigma}}+\theta_{j} L_{S j}^{\frac{\varsigma-1}{\varsigma}}\right]^{\frac{\varsigma}{\varsigma-1}} .
$$

The parameters to estimate are the city-specific productivity and skilled labor intensities, $A_{j}$ and $\sigma_{j}$, and the elasticity of substitution between skilled and unskilled labor $\varsigma$. We calibrate the elasticity of substitution, $\varsigma=2$.

We can rewrite the labor wage ratio in city $j$ as

$$
\log \left(\frac{W_{j s}}{W_{j u}}\right)=-\frac{1}{\varsigma} \log \left(\frac{L_{S j}}{L_{U j}}\right)+\log \left(\frac{\theta_{j}}{1-\theta_{j}}\right),
$$

which allows us to solve for the parameter $\theta_{j}$ given data on wages, labor supply and the elasticity of substitution $\varsigma$. Finally, we can back out $A_{j}$ in each city as such that the simulated wage level are equal to the wage levels we observe in the data.

\section{C.3 Calibration: Housing Supply}

The parameters of the housing supply functions in each city are $z_{j}$ for each city, and $\nu_{1}$ and $\nu_{2}$. We calibrate these parameters using the estimates from Colas and Hutchinson (2021). Specifically, we us estimates of $\nu_{1}$ and $\nu_{2}$ from this paper, which estimates housing supply elasticities using the ethnic-enclave instruments for immigrant inflows proposed by Card (2009) to instrument for housing demand. We can therefore write housing demand in city $j$ as

$$
H_{j}=\sum_{d} N_{d j} h_{d j}^{\star}
$$

where $N_{d j}$ is the total number of households of demographic $d$ living in city $j$. Given estimates of $\nu_{1}, \nu_{2}$, local housing rents $r_{j}$, and housing demand, we can back out the parameter $z_{j}$ in each city. 


\section{Results Appendix: For Online Publication Only D.1 SNAP Generosity Regressions}

Table 6 presents our estimates of (7). We regress the fraction of months each household receives SNAP on a vector of demographic controls and the following 6 policy variables: (i) whether the state uses broad-based categorical eligibility, (ii) whether one vehicle can be excluded from asset test, (iii) whether all vehicles can be excluded from the asset test, (iv) whether the state has an online application, (v) how often a household must re-certify their SNAP eligibility, (vi) whether the state has time limit waivers for Able-Bodied Adults without Dependents (interacted with the household in question being less than 60 years old and having no children). We use SNAP Policy Database from October of 2015, the latest date with no missing data on all variables. 


\begin{tabular}{|c|c|}
\hline VARIABLES & $\begin{array}{c}(1) \\
\text { part_snap }\end{array}$ \\
\hline Broad Based Categorical Eligibility & $\begin{array}{c}0.0370^{* *} \\
(0.0148)\end{array}$ \\
\hline Can Deduct One Vehicle from Assets & $\begin{array}{c}0.0541 \\
(0.0476)\end{array}$ \\
\hline Can Deduct All Vehicles from Assets & $\begin{array}{c}0.0559 \\
(0.0488)\end{array}$ \\
\hline Has Online Application & $\begin{array}{c}0.0462 \\
(0.0300)\end{array}$ \\
\hline Average Time to Recertify & $\begin{array}{c}0.00765^{* * *} \\
(0.00200)\end{array}$ \\
\hline ABAWD Waiver & $\begin{array}{c}0.0439^{* *} \\
(0.0186)\end{array}$ \\
\hline Constant & $\begin{array}{c}0.482^{* * *} \\
(0.0655)\end{array}$ \\
\hline Observations & 12,385 \\
\hline R-squared & 0.141 \\
\hline Demographic Controls & YES \\
\hline
\end{tabular}

Standard errors in parentheses

*** $\mathrm{p}<0.01, * * \mathrm{p}<0.05,{ }^{*} \mathrm{p}<0.1$

Table 6: SNAP take-up regression

To get a sense of these SNAP accessibility varies across locations, Figure 9 shows the SNAP accessibility of a single household with zero income and two children, and a with a high school dropout, white, non-immigrant head of household. We can see there is are substantial differences across states in these accessibility measures. 


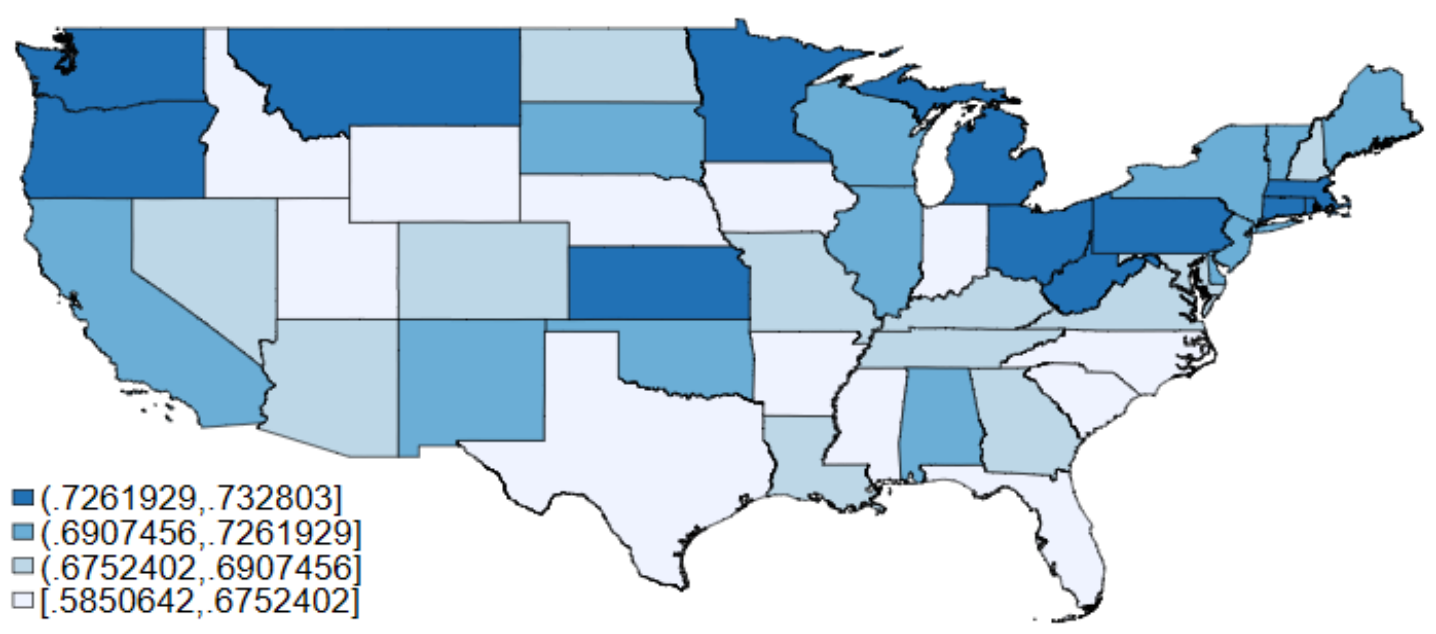

Figure 9: Estimated SNAP accessibility across states as measured by take-up rates predicted by state level policy variables. Measures predicted receipt rates of high school dropout with no children and single with 0 income.

\section{D.2 Productivity Regressions}

Table 7 presents the estimates of (6") (Column 1) and (5") (Column 2). Robust standard errors are displayed in parenthesis. Each regression includes a dummy for whether the household is married, has greater than 25 years of potential experience (High Exp), is a non-minority, and a dummy for narrow education group. Both regressions include CBSA fixed effects. 


\begin{tabular}{lcc}
\hline & $(1)$ & $(2)$ \\
& Unskilled & Skilled \\
\hline Married & $0.632^{* * *}$ & $0.775^{* * *}$ \\
& $(0.00206)$ & $(0.00133)$ \\
High Experience & $0.143^{* * *}$ & $0.0735^{* * *}$ \\
& $(0.00212)$ & $(0.00130)$ \\
Non-minority & $0.267^{* * *}$ & $0.227^{* * *}$ \\
& $(0.00247)$ & $(0.00151)$ \\
HS Graduate & $0.317^{* * *}$ & \\
& $(0.00273)$ & \\
Post College & & $0.452^{* * *}$ \\
& & $(0.00152)$ \\
Constant & $9.634^{* * *}$ & $10.23^{* * *}$ \\
& $(0.00987)$ & $(0.00596)$ \\
& & \\
Observations & $1,144,706$ & $2,888,259$ \\
R-squared & 0.195 & 0.262 \\
CBSA FE & YES & YES \\
\hline
\end{tabular}

Robust standard errors in parentheses ${ }^{* * *} \mathrm{p}<0.01,{ }^{* *} \mathrm{p}<0.05,{ }^{*} \mathrm{p}<0.1$ Table 7: Estimates of 5" and 6".

\section{D.3 Estimates of Birth State Premium Function}

Tables 8 and 9 shows our estimates of $\gamma_{d}^{h p} \mathbb{I}\left(j \in\right.$ Bstate $\left._{i}\right), \gamma_{d}^{\text {dist }} \phi\left(j\right.$, Bstate $\left._{i}\right)$, and $\gamma_{d}^{\text {dist2 }} \phi^{2}\left(j\right.$, Bstate $\left._{i}\right)$, the parameters governing the utility of location close to the household head's birth state, for all demographic groups. 


\begin{tabular}{|c|c|c|c|c|c|c|c|c|c|c|}
\hline Education & Marital Status & \# Children & Experience & Minority & $\gamma_{d}^{h p}$ & Standard Error & $\gamma_{d}^{\text {dist }}$ & Standard Error & $\gamma_{d}^{\text {dist2 }}$ & Standard Error \\
\hline Dropout & Single & 0 & Not Experienced & Minority & 3.01 & 0.03 & -1.78 & 0.03 & 0.33 & 0.01 \\
\hline Dropout & Single & 0 & Not Experienced & Non-Minority & 3.1 & 0.03 & -1.85 & 0.03 & 0.44 & 0.01 \\
\hline Dropout & Single & 1 & Not Experienced & Minority & 3.2 & 0.05 & -2.28 & 0.06 & 0.47 & 0.02 \\
\hline Dropout & Single & 1 & Not Experienced & Non-Minority & 3.21 & 0.04 & -1.7 & 0.05 & 0.38 & 0.02 \\
\hline Dropout & Single & 2 & Not Experienced & Minority & 3.01 & 0.05 & -2.22 & 0.05 & 0.37 & 0.02 \\
\hline Dropout & Single & 2 & Not Experienced & Non-Minority & 3.11 & 0.04 & -1.73 & 0.05 & 0.34 & 0.02 \\
\hline Dropout & Single & 3 & Not Experienced & Minority & 2.93 & 0.04 & -2.42 & 0.05 & 0.41 & 0.02 \\
\hline Dropout & Single & 3 & Not Experienced & Non-Minority & 3.03 & 0.05 & -1.69 & 0.06 & 0.22 & 0.03 \\
\hline Dropout & Single & 0 & Experienced & Minority & 2.92 & 0.02 & -1.96 & 0.02 & 0.3 & 0.01 \\
\hline Dropout & Single & 0 & Experienced & Non-Minority & 2.74 & 0.01 & -2.3 & 0.01 & 0.62 & 0.01 \\
\hline Dropout & Single & 1 & Experienced & Minority & 3.05 & 0.03 & -1.86 & 0.04 & 0.24 & 0.02 \\
\hline Dropout & Single & 1 & Experienced & Non-Minority & 2.72 & 0.03 & -2.68 & 0.03 & 0.75 & 0.01 \\
\hline Dropout & Single & 2 & Experienced & Minority & 3.01 & 0.05 & -1.84 & 0.05 & 0.25 & 0.03 \\
\hline Dropout & Single & 2 & Experienced & Non-Minority & 3.13 & 0.05 & -1.28 & 0.05 & 0.24 & 0.02 \\
\hline Dropout & Single & 3 & Experienced & Minority & 3.35 & 0.07 & -1.15 & 0.05 & 0.19 & 0.02 \\
\hline Dropout & Single & 3 & Experienced & Non-Minority & 2.94 & 0.08 & -1.56 & 0.09 & 0.26 & 0.04 \\
\hline Dropout & Married & 0 & Not Experienced & Minority & 2.43 & 0.09 & -1.79 & 0.08 & 0.36 & 0.03 \\
\hline Dropout & Married & 0 & Not Experienced & Non-Minority & 3.16 & 0.06 & -1.24 & 0.06 & 0.25 & 0.03 \\
\hline Dropout & Married & 1 & Not Experienced & Minority & 2.32 & 0.08 & -1.84 & 0.08 & 0.32 & 0.04 \\
\hline Dropout & Married & 1 & Not Experienced & Non-Minority & 2.68 & 0.05 & -2.39 & 0.05 & 0.62 & 0.02 \\
\hline Dropout & Married & 2 & Not Experienced & Minority & 2.63 & 0.07 & -1.4 & 0.06 & 0.24 & 0.02 \\
\hline Dropout & Married & 2 & Not Experienced & Non-Minority & 2.76 & 0.04 & -2.23 & 0.05 & 0.5 & 0.02 \\
\hline Dropout & Married & 3 & Not Experienced & Minority & 2.45 & 0.05 & -1.12 & 0.05 & 0.09 & 0.02 \\
\hline Dropout & Married & 3 & Not Experienced & Non-Minority & 2.36 & 0.03 & -2.82 & 0.04 & 0.67 & 0.02 \\
\hline Dropout & Married & 0 & Experienced & Minority & 2.83 & 0.03 & -1.78 & 0.03 & 0.26 & 0.01 \\
\hline Dropout & Married & 0 & Experienced & Non-Minority & 2.67 & 0.02 & -2.63 & 0.02 & 0.74 & 0.01 \\
\hline Dropout & Married & 1 & Experienced & Minority & 3.22 & 0.05 & -1.09 & 0.04 & 0.19 & 0.01 \\
\hline Dropout & Married & 1 & Experienced & Non-Minority & 2.74 & 0.03 & -2.63 & 0.03 & 0.77 & 0.01 \\
\hline Dropout & Married & 2 & Experienced & Minority & 2.95 & 0.06 & -0.91 & 0.05 & 0.03 & 0.02 \\
\hline Dropout & Married & 2 & Experienced & Non-Minority & 2.78 & 0.04 & -2.41 & 0.04 & 0.72 & 0.02 \\
\hline Dropout & Married & 3 & Experienced & Minority & 3.04 & 0.07 & -0.96 & 0.05 & 0.21 & 0.02 \\
\hline Dropout & Married & 3 & Experienced & Non-Minority & 2.04 & 0.04 & -2.98 & 0.05 & 0.75 & 0.02 \\
\hline HS Grad & Single & 0 & Not Experienced & Minority & 2.97 & 0.01 & -1.63 & 0.01 & 0.26 & 0.01 \\
\hline HS Grad & Single & 0 & Not Experienced & Non-Minority & 3.12 & 0.01 & -1.59 & 0.01 & 0.37 & 0.01 \\
\hline HS Grad & Single & 1 & Not Experienced & Minority & 3.18 & 0.02 & -1.85 & 0.02 & 0.31 & 0.01 \\
\hline HS Grad & Single & 1 & Not Experienced & Non-Minority & 3.19 & 0.02 & -1.86 & 0.02 & 0.44 & 0.01 \\
\hline HS Grad & Single & 2 & Not Experienced & Minority & 3.15 & 0.02 & -1.87 & 0.03 & 0.31 & 0.01 \\
\hline HS Grad & Single & 2 & Not Experienced & Non-Minority & 3.15 & 0.02 & -1.89 & 0.02 & 0.47 & 0.01 \\
\hline HS Grad & Single & 3 & Not Experienced & Minority & 3.04 & 0.03 & -2.05 & 0.03 & 0.32 & 0.01 \\
\hline HS Grad & Single & 3 & Not Experienced & Non-Minority & 2.99 & 0.03 & -2.25 & 0.03 & 0.6 & 0.01 \\
\hline HS Grad & Single & 0 & Experienced & Minority & 3.02 & 0.01 & -1.65 & 0.01 & 0.24 & 0 \\
\hline HS Grad & Single & 0 & Experienced & Non-Minority & 2.95 & 0.01 & -2.13 & 0.01 & 0.58 & 0 \\
\hline HS Grad & Single & 1 & Experienced & Minority & 3.04 & 0.02 & -1.51 & 0.02 & 0.15 & 0.01 \\
\hline HS Grad & Single & 1 & Experienced & Non-Minority & 2.93 & 0.01 & -2.18 & 0.01 & 0.58 & 0.01 \\
\hline HS Grad & Single & 2 & Experienced & Minority & 3.1 & 0.03 & -1.76 & 0.04 & 0.22 & 0.01 \\
\hline HS Grad & Single & 2 & Experienced & Non-Minority & 3.01 & 0.02 & -2.15 & 0.03 & 0.56 & 0.03 \\
\hline HS Grad & Single & 3 & Experienced & Minority & 3.35 & 0.05 & -1.16 & 0.05 & 0.12 & 0.02 \\
\hline HS Grad & Single & 3 & Experienced & Non-Minority & 2.98 & 0.05 & -2.14 & 0.05 & 0.6 & 0.02 \\
\hline HS Grad & Married & 0 & Not Experienced & Minority & 2.52 & 0.03 & -1.18 & 0.03 & 0.22 & 0.01 \\
\hline HS Grad & Married & 0 & Not Experienced & Non-Minority & 3.2 & 0.02 & -1.12 & 0.02 & 0.25 & 0.01 \\
\hline HS Grad & Married & 1 & Not Experienced & Minority & 2.7 & 0.03 & -1.33 & 0.03 & 0.21 & 0.01 \\
\hline HS Grad & Married & 1 & Not Experienced & Non-Minority & 3.24 & 0.02 & -1.09 & 0.02 & 0.2 & 0.01 \\
\hline HS Grad & Married & 2 & Not Experienced & Minority & 2.72 & 0.03 & -1.15 & 0.02 & 0.13 & 0.01 \\
\hline HS Grad & Married & 2 & Not Experienced & Non-Minority & 3.15 & 0.01 & -1.92 & 0.02 & 0.46 & 0.01 \\
\hline HS Grad & Married & 3 & Not Experienced & Minority & 2.74 & 0.03 & -1.06 & 0.02 & 0.07 & 0.01 \\
\hline HS Grad & Married & 3 & Not Experienced & Non-Minority & 2.93 & 0.02 & -2.02 & 0.02 & 0.48 & 0.01 \\
\hline HS Grad & Married & 0 & Experienced & Minority & 3.13 & 0.02 & -1.05 & 0.02 & 0.11 & 0.01 \\
\hline HS Grad & Married & 0 & Experienced & Non-Minority & 2.77 & 0.01 & -2.48 & 0.01 & 0.65 & 0 \\
\hline HS Grad & Married & 1 & Experienced & Minority & 2.95 & 0.02 & -1.57 & 0.02 & 0.19 & 0.01 \\
\hline HS Grad & Married & 1 & Experienced & Non-Minority & 2.84 & 0.01 & -2.56 & 0.01 & 0.71 & 0.01 \\
\hline HS Grad & Married & 2 & Experienced & Minority & 2.92 & 0.03 & -1.32 & 0.03 & 0.12 & 0.01 \\
\hline HS Grad & Married & 2 & Experienced & Non-Minority & 3.11 & 0.01 & -1.89 & 0.01 & 0.5 & 0.01 \\
\hline HS Grad & Married & 3 & Experienced & Minority & 2.92 & 0.04 & -1.13 & 0.04 & 0.07 & 0.01 \\
\hline HS Grad & Married & 3 & Experienced & Non-Minority & 3.04 & 0.02 & -1.84 & 0.02 & 0.48 & 0.01 \\
\hline
\end{tabular}

Table 8: Estimates of birth state premium parameters for all demographic groups with less than college education. 


\begin{tabular}{|c|c|c|c|c|c|c|c|c|c|c|}
\hline Education & Marital Status & \# Children & Experience & Minority & $\gamma_{d}^{h p}$ & Standard Error & $\gamma_{d}^{\text {dist }}$ & Standard Error & $\gamma_{d}^{\text {dist2 }}$ & Standard Error \\
\hline College & Single & 0 & Not Experienced & Minority & 2.65 & 0.01 & -0.89 & 0.01 & 0.12 & 0 \\
\hline College & Single & 0 & Not Experienced & Non-Minority & 2.55 & 0 & -1.81 & 0 & 0.5 & 0 \\
\hline College & Single & 1 & Not Experienced & Minority & 2.92 & 0.01 & -1.57 & 0.01 & 0.26 & 0 \\
\hline College & Single & 1 & Not Experienced & Non-Minority & 2.9 & 0.01 & -1.67 & 0.01 & 0.41 & 0.01 \\
\hline College & Single & 2 & Not Experienced & Minority & 2.9 & 0.02 & -1.65 & 0.02 & 0.27 & 0.01 \\
\hline College & Single & 2 & Not Experienced & Non-Minority & 2.75 & 0.01 & -2.15 & 0.01 & 0.58 & 0.01 \\
\hline College & Single & 3 & Not Experienced & Minority & 2.91 & 0.02 & -1.73 & 0.02 & 0.28 & 0.01 \\
\hline College & Single & 3 & Not Experienced & Non-Minority & 2.74 & 0.02 & -1.85 & 0.02 & 0.46 & 0.01 \\
\hline College & Single & 0 & Experienced & Minority & 2.76 & 0.01 & -1.16 & 0.01 & 0.15 & 0 \\
\hline College & Single & 0 & Experienced & Non-Minority & 2.59 & 0 & -1.67 & 0 & 0.43 & 0 \\
\hline College & Single & 1 & Experienced & Minority & 2.78 & 0.02 & -1.41 & 0.01 & 0.19 & 0.01 \\
\hline College & Single & 1 & Experienced & Non-Minority & 2.51 & 0.01 & -1.95 & 0.01 & 0.5 & 0 \\
\hline College & Single & 2 & Experienced & Minority & 2.73 & 0.03 & -1.43 & 0.02 & 0.18 & 0.01 \\
\hline College & Single & 2 & Experienced & Non-Minority & 2.57 & 0.02 & -1.9 & 0.02 & 0.49 & 0.01 \\
\hline College & Single & 3 & Experienced & Minority & 2.85 & 0.05 & -1.06 & 0.04 & 0.1 & 0.02 \\
\hline College & Single & 3 & Experienced & Non-Minority & 2.53 & 0.03 & -1.8 & 0.03 & 0.46 & 0.01 \\
\hline College & Married & 0 & Not Experienced & Minority & 2.17 & 0.02 & -1.25 & 0.01 & 0.2 & 0 \\
\hline College & Married & 0 & Not Experienced & Non-Minority & 2.64 & 0.01 & -1.33 & 0.01 & 0.3 & 0 \\
\hline College & Married & 1 & Not Experienced & Minority & 2.35 & 0.02 & -1.24 & 0.01 & 0.18 & 0 \\
\hline College & Married & 1 & Not Experienced & Non-Minority & 2.54 & 0.01 & -2.01 & 0.01 & 0.53 & 0.01 \\
\hline College & Married & 2 & Not Experienced & Minority & 2.42 & 0.01 & -1.24 & 0.01 & 0.17 & 0 \\
\hline College & Married & 2 & Not Experienced & Non-Minority & 2.69 & 0.01 & -1.8 & 0.01 & 0.44 & 0 \\
\hline College & Married & 3 & Not Experienced & Minority & 2.46 & 0.02 & -1.17 & 0.01 & 0.15 & 0 \\
\hline College & Married & 3 & Not Experienced & Non-Minority & 2.48 & 0.01 & -2.19 & 0.01 & 0.57 & 0 \\
\hline College & Married & 0 & Experienced & Minority & 2.38 & 0.01 & -1.35 & 0.01 & 0.17 & 0 \\
\hline College & Married & 0 & Experienced & Non-Minority & 2.38 & 0 & -2.08 & 0 & 0.54 & 0 \\
\hline College & Married & 1 & Experienced & Minority & 2.45 & 0.02 & -1.27 & 0.01 & 0.14 & 0 \\
\hline College & Married & 1 & Experienced & Non-Minority & 2.43 & 0.01 & -2.14 & 0.01 & 0.57 & 0 \\
\hline College & Married & 2 & Experienced & Minority & 2.44 & 0.02 & -1.17 & 0.02 & 0.14 & 0.01 \\
\hline College & Married & 2 & Experienced & Non-Minority & 2.49 & 0.01 & -2.18 & 0.01 & 0.6 & 0 \\
\hline College & Married & 3 & Experienced & Minority & 2.35 & 0.03 & -1.15 & 0.03 & 0.12 & 0.01 \\
\hline College & Married & 3 & Experienced & Non-Minority & 2.52 & 0.01 & -1.97 & 0.01 & 0.53 & 0.01 \\
\hline Post-College & Single & 0 & Not Experienced & Minority & 2 & 0.02 & -0.99 & 0.01 & 0.16 & 0 \\
\hline Post-College & Single & 0 & Not Experienced & Non-Minority & 2 & 0.01 & -1.88 & 0.01 & 0.55 & 0 \\
\hline Post-College & Single & 1 & Not Experienced & Minority & 2.47 & 0.04 & -1.49 & 0.03 & 0.26 & 0.01 \\
\hline Post-College & Single & 1 & Not Experienced & Non-Minority & 2.33 & 0.02 & -1.82 & 0.02 & 0.51 & 0.01 \\
\hline Post-College & Single & 2 & Not Experienced & Minority & 2.51 & 0.05 & -1.33 & 0.04 & 0.19 & 0.01 \\
\hline Post-College & Single & 2 & Not Experienced & Non-Minority & 2.27 & 0.03 & -2.06 & 0.02 & 0.6 & 0.01 \\
\hline Post-College & Single & 3 & Not Experienced & Minority & 2.86 & 0.07 & -0.95 & 0.06 & 0.13 & 0.02 \\
\hline Post-College & Single & 3 & Not Experienced & Non-Minority & 2.23 & 0.04 & -2.32 & 0.04 & 0.68 & 0.02 \\
\hline Post-College & Single & 0 & Experienced & Minority & 2.27 & 0.02 & -1.34 & 0.02 & 0.2 & 0.01 \\
\hline Post-College & Single & 0 & Experienced & Non-Minority & 2.07 & 0.01 & -1.96 & 0.01 & 0.55 & 0 \\
\hline Post-College & Single & 1 & Experienced & Minority & 2.38 & 0.05 & -1.4 & 0.04 & 0.21 & 0.01 \\
\hline Post-College & Single & 1 & Experienced & Non-Minority & 2.18 & 0.02 & -1.66 & 0.02 & 0.44 & 0.01 \\
\hline Post-College & Single & 2 & Experienced & Minority & 2.61 & 0.09 & -1.11 & 0.07 & 0.15 & 0.02 \\
\hline Post-College & Single & 2 & Experienced & Non-Minority & 2.15 & 0.04 & -1.77 & 0.04 & 0.49 & 0.02 \\
\hline Post-College & Single & 3 & Experienced & Minority & 2.61 & 0.18 & -0.91 & 0.15 & 0.05 & 0.05 \\
\hline Post-College & Single & 3 & Experienced & Non-Minority & 1.94 & 0.1 & -2.06 & 0.09 & 0.43 & 0.03 \\
\hline Post-College & Married & 0 & Not Experienced & Minority & 1.89 & 0.03 & -0.88 & 0.02 & 0.12 & 0.01 \\
\hline Post-College & Married & 0 & Not Experienced & Non-Minority & 2 & 0.01 & -1.94 & 0.01 & 0.56 & 0 \\
\hline Post-College & Married & 1 & Not Experienced & Minority & 1.98 & 0.03 & -1.17 & 0.02 & 0.16 & 0.01 \\
\hline Post-College & Married & 1 & Not Experienced & Non-Minority & 2.1 & 0.01 & -2.15 & 0.01 & 0.62 & 0.01 \\
\hline Post-College & Married & 2 & Not Experienced & Minority & 2.06 & 0.02 & -0.99 & 0.02 & 0.13 & 0.01 \\
\hline Post-College & Married & 2 & Not Experienced & Non-Minority & 2.1 & 0.01 & -2.26 & 0.01 & 0.66 & 0 \\
\hline Post-College & Married & 3 & Not Experienced & Minority & 1.97 & 0.03 & -1.18 & 0.03 & 0.15 & 0.01 \\
\hline Post-College & Married & 3 & Not Experienced & Non-Minority & 2.06 & 0.01 & -2.25 & 0.01 & 0.62 & 0.01 \\
\hline Post-College & Married & 0 & Experienced & Minority & 2.01 & 0.03 & -1.14 & 0.02 & 0.14 & 0.01 \\
\hline Post-College & Married & 0 & Experienced & Non-Minority & 1.92 & 0.01 & -2.12 & 0.01 & 0.59 & 0 \\
\hline Post-College & Married & 1 & Experienced & Minority & 1.99 & 0.04 & -1.18 & 0.03 & 0.12 & 0.01 \\
\hline Post-College & Married & 1 & Experienced & Non-Minority & 1.9 & 0.01 & -2.24 & 0.01 & 0.66 & 0.01 \\
\hline Post-College & Married & 2 & Experienced & Minority & 1.77 & 0.06 & -1.09 & 0.04 & 0.09 & 0.01 \\
\hline Post-College & Married & 2 & Experienced & Non-Minority & 1.9 & 0.02 & -2.13 & 0.02 & 0.6 & 0.01 \\
\hline Post-College & Married & 3 & Experienced & Minority & 1.83 & 0.1 & -1.01 & 0.08 & 0.08 & 0.02 \\
\hline Post-College & Married & 3 & Experienced & Non-Minority & 1.98 & 0.03 & -1.88 & 0.03 & 0.51 & 0.01 \\
\hline
\end{tabular}

Table 9: Estimates of birth state premium parameters for all demographic groups with college and greater education. 

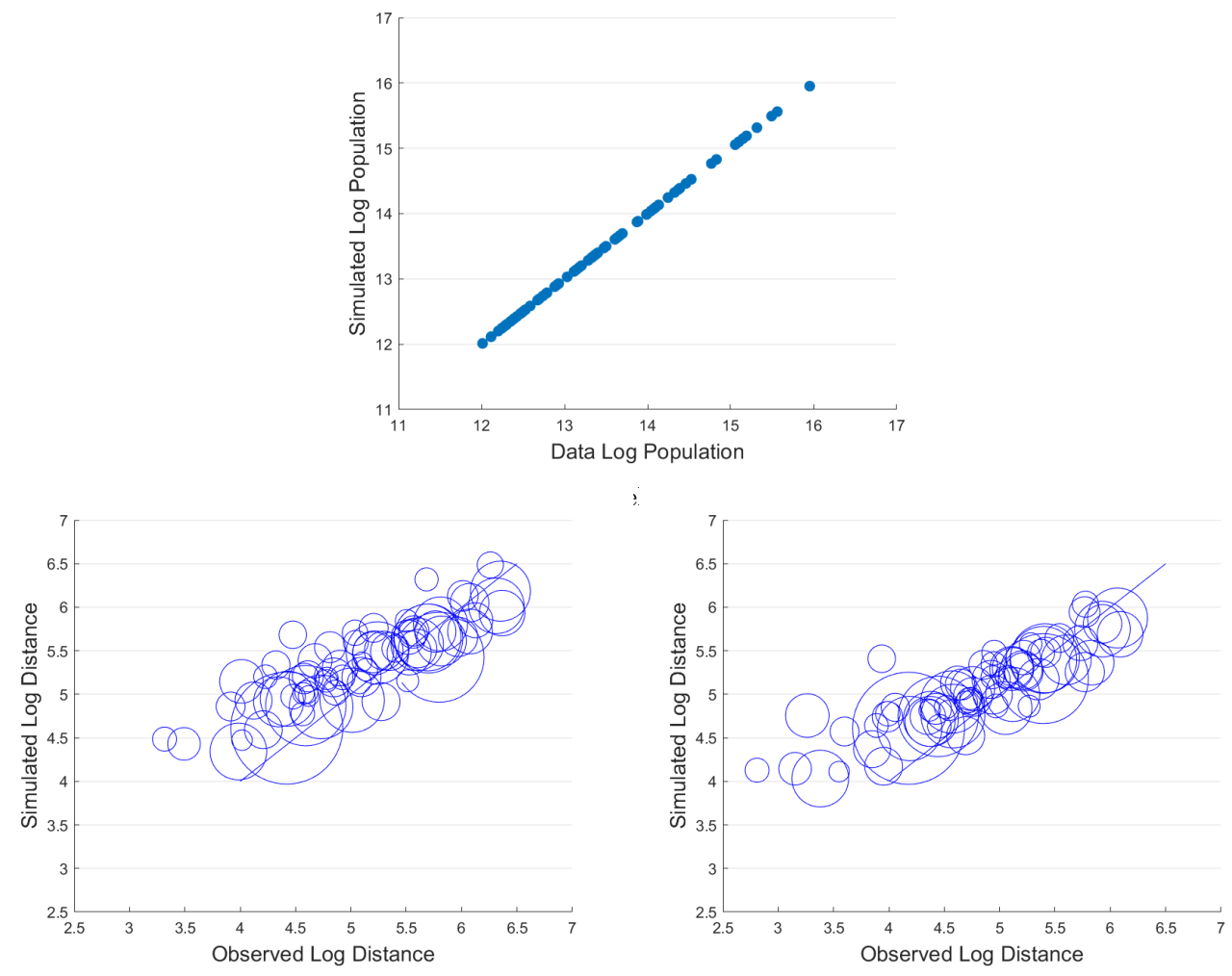

Panel A

Panel B

Figure 10: A) Skilled B) Unskilled

\section{D.4 Model Fit}

Panel A of Figure 10 shows the population in each city in the data and predicted by the model. Panels B and C of Figure 10 display the distance from home state in the data ( $\mathrm{X}$ axis) and simulated by the model ( $\mathrm{Y}$ axis) for skilled and unskilled households, respectively.

\section{D.5 Simulated Elasticities of Location Choice w.r.t. Social Transfers}

To understand what our quantification implies for the responsiveness of household location choice with respect transfers, we now simulate the effect of a ten percent increase in transfer generosity in a given city. Specifically, we simulate an equilibrium in which we increase transfers in a given city $j$ by ten percent, such that households who live in $j$ receive $1.1 \times \tau_{j d}(\cdot)$. We then calculate the 
percentage change in location $j$ 's population relative to the equilibrium with the baseline transfer function. We calculate the elasticity with respect to transfers as the percent change in population divided by the percent change in benefits $(10 \%)$. We repeat this exercise for all 79 locations in our model. Note that this represents a general equilibrium elasticity, and therefore includes not only the direct effect of the transfer itself, but also the effect of general equilibrium changes in wages in rents. In fact, for some household who do not receive benefits, the elasticities are negative - reflecting that these general equilibrium price changes effectively crowd them out of a location when transfers become more generous.

We present the simulated elasticities of selected demographic groups in Figure 11. Panel (a) presents the distribution of elasticities across the 79 simulations for high school dropout households who vary in their number of children. We find that the migration elasticities are strongly increasing in number of children, reflecting that households with children receive larger transfer amounts, all else equal. Panel (b) presents the distribution of elasticities across the 79 simulations for high school dropout households who vary in their marital status. A single, high school dropout household with children has an elasticity of 0.086 .

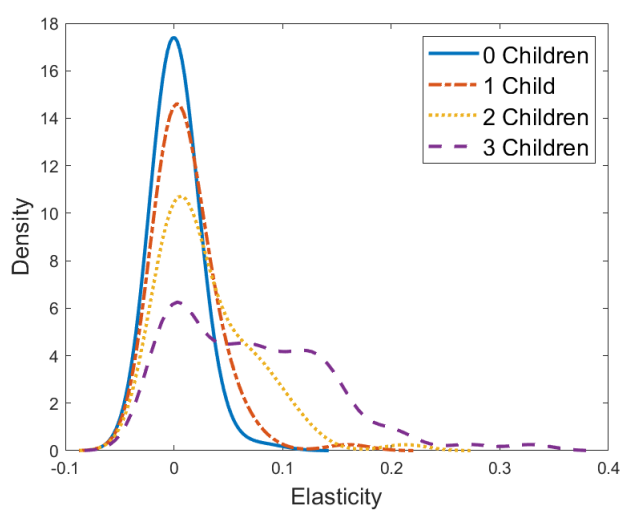

(a) HS Dropouts by Number of Children

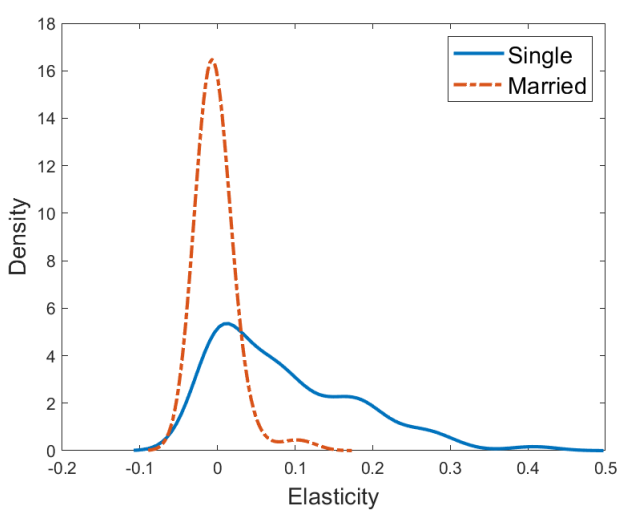

(b) HS Dropouts by Marital Status

Figure 11: Simulated elasticities of location choice with respect to social transfers for high school dropout households. We simulated increasing social transfers in a given location $j$ by one percent and calculate the percentage increase in location $j$ 's population. We repeat the exercise for all 79 locations in the model. The histogram shows the density of elasticities over all 79 simulations. Panel (a) shows the density for high school dropout households who vary in number of children. Panel (b) shows the density for high school dropout households who vary in their marital status. 


\section{D.6 Comparison of Location Choice Elasticities with Gel- bach (2004)}

Gelbach (2004) estimates the effects of local transfers 5-year out-migration rates for women with young children. The paper finds that a $\$ 100$ increase of local transfers reduces the probability of out-migration by 0.5 to 2.4 percentage points, depending on whether the women is a high school dropout or graduate and whether she has ever been married. ${ }^{84}$ To compare our simulated elasticities to these semi-elasticities, we re-scale our simulated elasticities such that they measure the percent change in population associated with an increase in local transfers of 100 real dollars. ${ }^{85}$ These re-scaled elasticities imply that an increase of local transfers of $\$ 100$ real dollars is associated with a $0.15 \%$ increase in the population of a high-school dropout households with children, on average.

As a back-of-the-envelope way to compare our estimates our estimates of population with changes in out-migration rates, consider a baseline city in which out-migration equals in-migration. If transfers decrease the probability of outmigration by 0.5 to 2.4 percentage point and have no effect on in-migration, then the city's population will be $0.5 \%$ to $2.4 \%$ smaller by the end of the period. ${ }^{86}$ Therefore, our simulated elasticities are smaller than those implied by Gelbach (2004).

\section{D.7 Additional Counterfactual Results}

In this Appendix, we display additional results for the counterfactuals from Section 5. In particular, while our main counterfactual results focused on differential sorting patterns by education, race, and the presence of children, this Appendix also explores different dimensions of heterogeneity and shows equilibrium price

\footnotetext{
${ }^{84}$ This refers to the marginal effects of increasing the maximum welfare benefits on outmigration probabilities for the regression with full controls. We refer to Gelbach (2004)'s results from the 1980 sample (Table 3), which the author argues are more reliable than the results from the 1990 sample.

${ }^{85}$ The estimates in Gelbach (2004) are measured in 1997 dollars. We therefore re-scale our elasticities to measure the change in location choice probabilities associated with an increase in transfers of 100 dollars, measured in 1997 dollars.

${ }^{86}$ Of course the effects will be larger over multiple periods and transfers affect in-migration as well.
} 


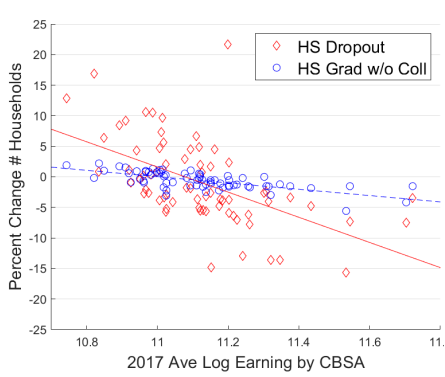

Panel A

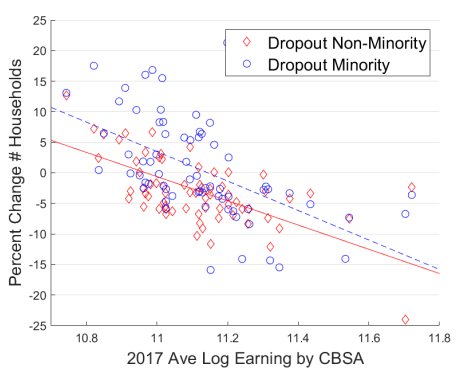

Panel B

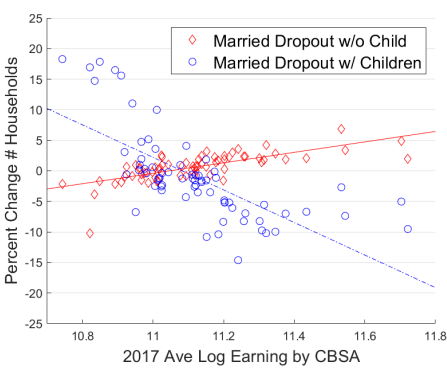

Panel C

Figure 12: Earnings distortion with baseline transfer programs: Counterfactual population relative to lump-sum transfers for baseline transfer programs across cities. Each dot represents a CBSA. The horizontal axis is the $2017 \log$ mean earnings for all households. Panel (a) presents results for high school dropouts and high school graduates, Panel (b) presents results for nonminority high-school dropout households compared to minority dropout households, and Panel (c) presents results for married high-school dropouts with children and without children.

changes.

Baseline Figure 12 shows changes in sorting patterns going from the efficient equilibrium with lump-sum transfers, to the equilibrium given the current SNAP and TANF schedules. Panel A shows sorting patterns of high school dropougs compared to high school graduate households, Panel B show shows minority compared to non-minority households, and Panel $\mathrm{C}$ shows households with children versus households with no children. In all graphs, the $\mathrm{X}$ axis gives the log average earnings of the CBSA in question.

Figure 13 additional degrees of heterogeneity. Panel A shows sorting patterns of College Educated compared to post college Educated households, Panel show shows experienced compared to less-experienced households, and Panel C shows single households compared to married households.

Figure 14 explores the general equilibrium effects caused by the current transfer programs. Panel A displays the change in college share, Panel B displays the change in equilibrium wages across cities, and Panel $\mathrm{C}$ displays the change in equilibrium rents.

Harmonized Transfer Programs Figures 15 through 16 present additional results for the counterfactual in which we harmonize transfer schedules across all states. 


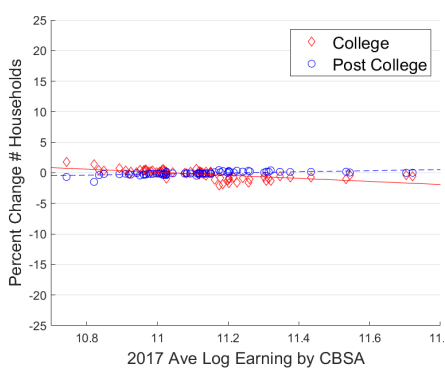

Panel A

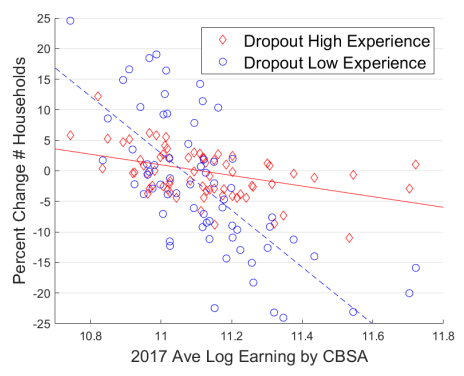

Panel B

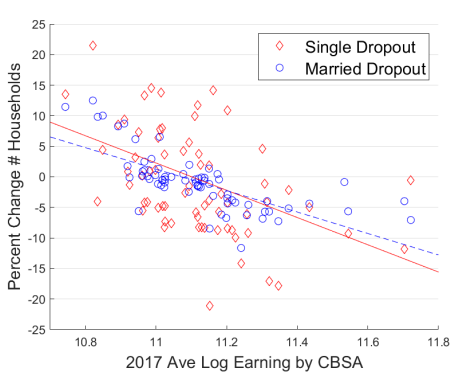

Panel C

Figure 13: Earnings distortion with baseline transfer programs: Counterfactual population relative to lump-sum transfers for baseline transfer programs across cities. Each dot represents a CBSA. The horizontal axis is the $2017 \log$ mean earnings for all households. Panel A presents results for college and post-college educated, Panel B presents results for experience and less experienced dropouts households, and Panel C presents results for single dropout households compared to married dropout households.

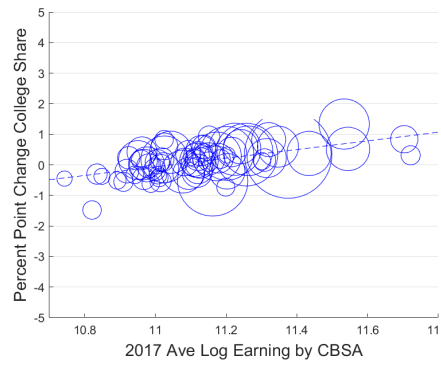

Panel A

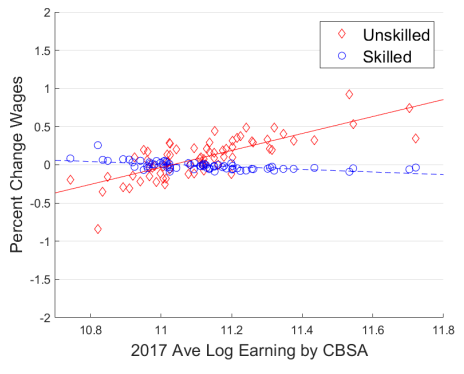

Panel B

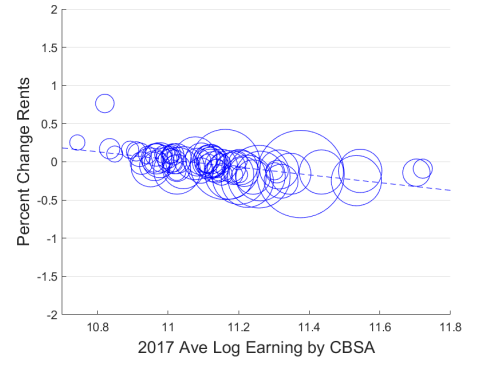

Panel C

Figure 14: Earnings distortion with baseline transfer programs: Counterfactual population relative to lump-sum transfers for baseline transfer programs across cities. Each dot represents a CBSA. The horizontal axis is the $2017 \log$ mean earnings for all households. Panel A presents change in college share, Panel B presents change in wages, and Panel C presents changes in rents.

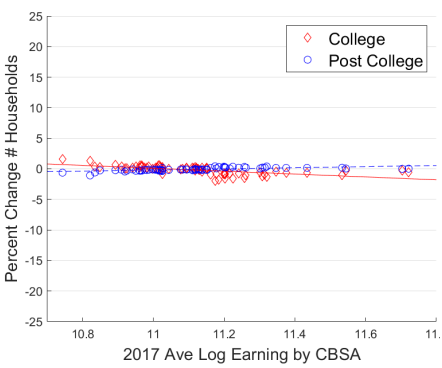

Panel A

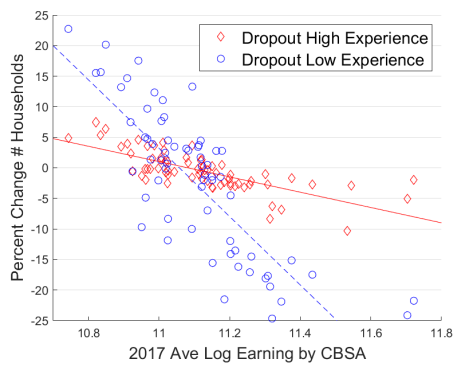

Panel B

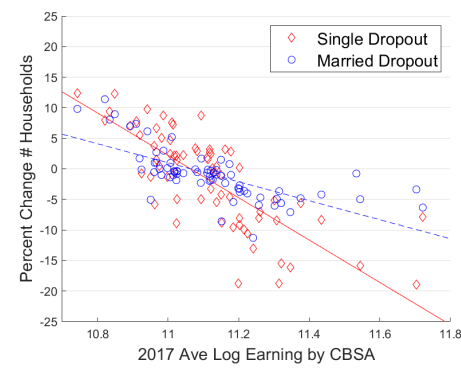

Panel C

Figure 15: Earnings distortion with harmonized transfer programs: Counterfactual population relative to lump-sum transfers for harmonized transfer programs across cities. Each dot represents a CBSA. The horizontal axis is the $2017 \log$ mean earnings for all households. Panel A presents results for college and post-college educated, Panel B presents results for experience and less experienced dropouts households, and Panel C presents results for single dropout households compared to married dropout households. 


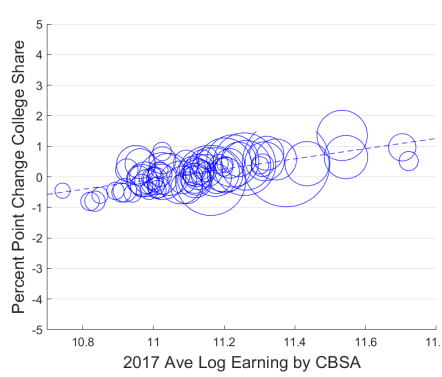

Panel A

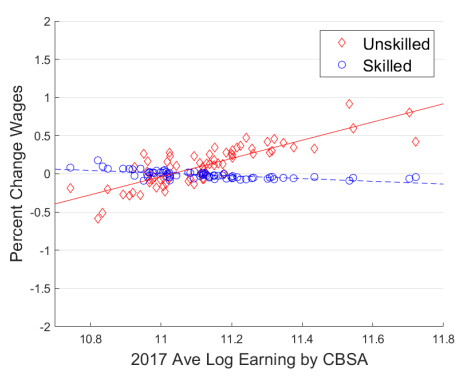

Panel B

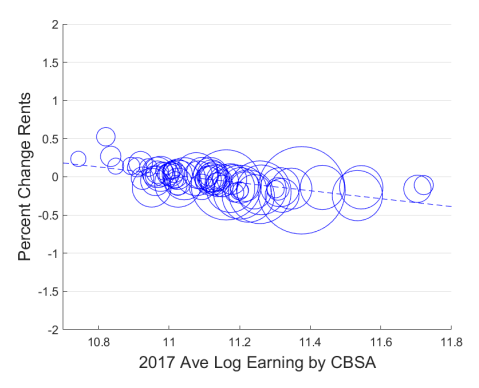

Panel C

Figure 16: Earnings distortion with harmonized transfer programs: Counterfactual population relative to lump-sum transfers for harmonized transfer programs across cities. Each dot represents a CBSA. The horizontal axis is the 2017 log mean earnings for all households. Panel A presents change in college share, Panel B presents change in wages, and Panel C presents changes in rents.

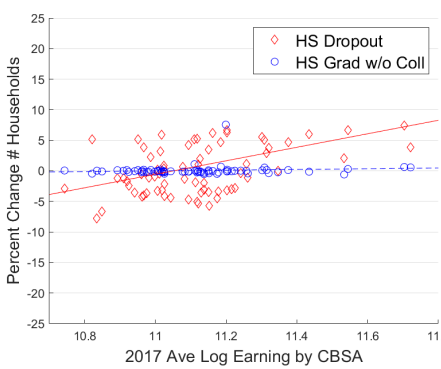

Panel A

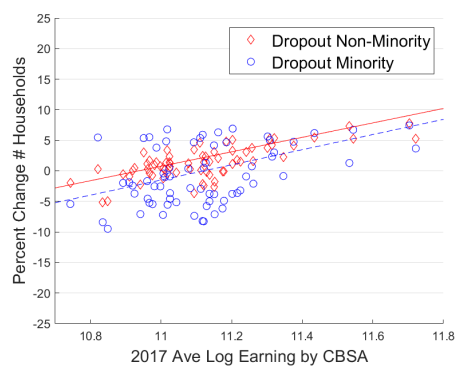

Panel B

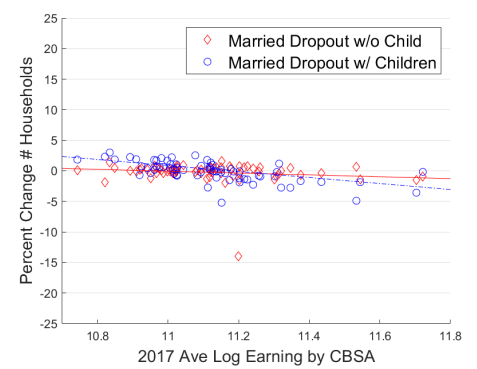

Panel C

Figure 17: Earnings distortion with earnings index: Counterfactual population relative to lumpsum transfers with earnings index. Each dot represents a CBSA. The horizontal axis is the 2017 log mean earnings for all households. Panel (a) presents results for high school dropouts and high school graduates, Panel (b) presents results for non-minority high-school dropout households compared to minority dropout households, and Panel (c) presents results for married high-school dropouts with children and without children.

Earnings Index Figures 17 through 19 present additional results for the counterfactual in which we index earnings to local average earnings levels.

Earnings Index and Harmonized Transfer Programs Figures 20 through 22 present additional results for the counterfactual in which we both index earnings to local average earnings levels and harmonize transfer programs across states. As we can see, the distribution of households across locations are similar to those in the efficient equilibrium with lump-sum transfers. 


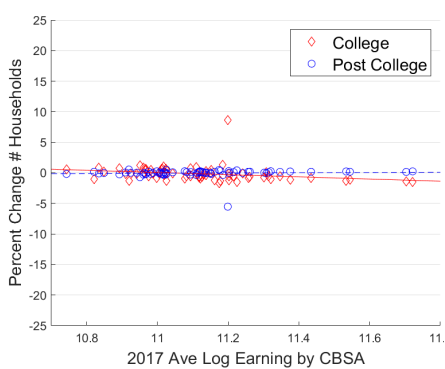

Panel A

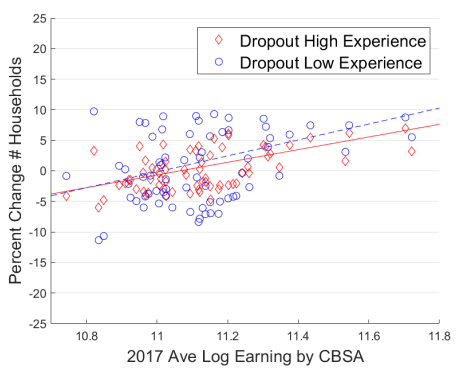

Panel B

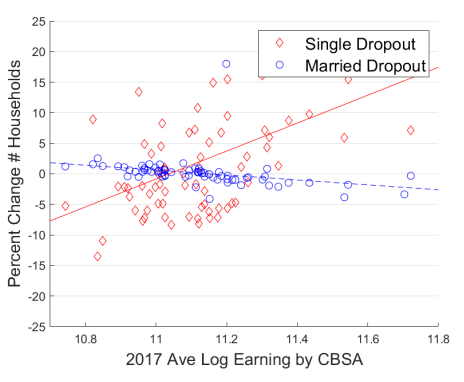

Panel C

Figure 18: Earnings distortion with earnings index: Counterfactual population relative to lumpsum transfers with earnings index. Each dot represents a CBSA. The horizontal axis is the $2017 \log$ mean earnings for all households. Panel A presents results for college and post-college educated, Panel B presents results for experience and less experienced dropouts households, and Panel C presents results for single dropout households compared to married dropout households.

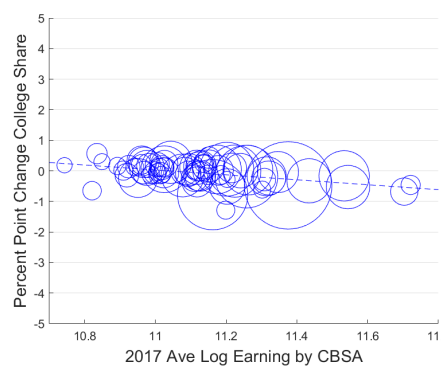

Panel A

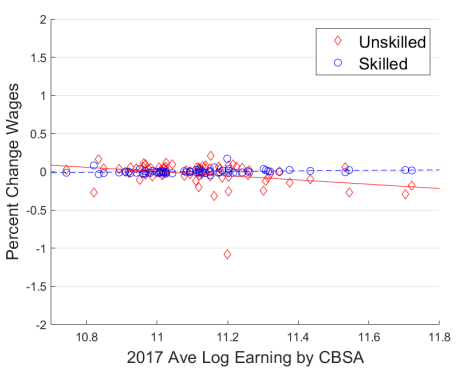

Panel B

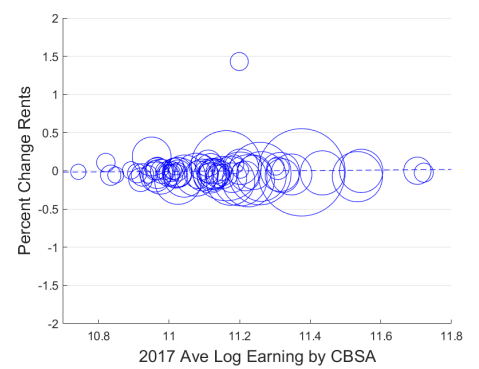

Panel C

Figure 19: Earnings distortion with earnings index: Counterfactual population relative to lumpsum transfers with earnings index. Each dot represents a CBSA. The horizontal axis is the 2017 log mean earnings for all households. Panel A presents change in college share, Panel B presents change in wages, and Panel $\mathrm{C}$ presents changes in rents.

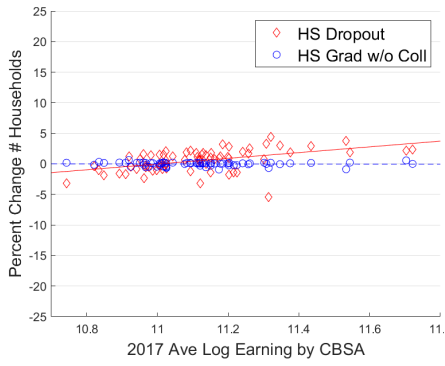

Panel A

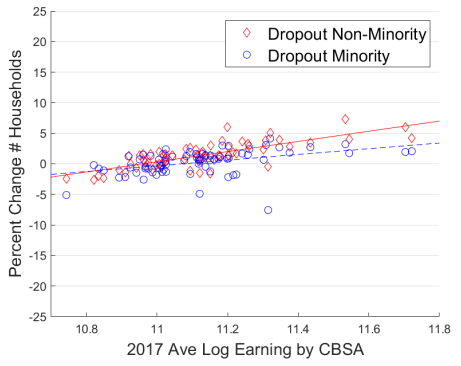

Panel B

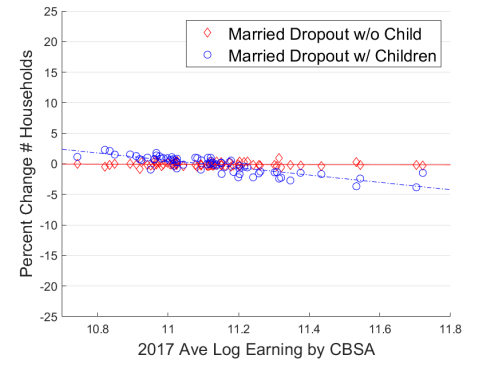

Panel C

Figure 20: Earnings distortion with earnings index and harmonized transfer programs: Counterfactual population relative to lump-sum transfers with earnings index and harmonized transfer programs. Each dot represents a CBSA. The horizontal axis is the 2017 log mean earnings for all households. Panel (a) presents results for high school dropouts and high school graduates, Panel (b) presents results for non-minority high-school dropout households compared to minority dropout households, and Panel (c) presents results for married high-school dropouts with children and without children. 


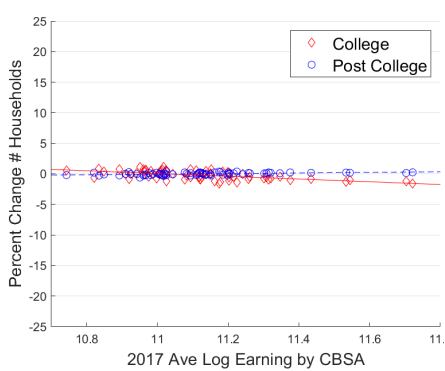

Panel A

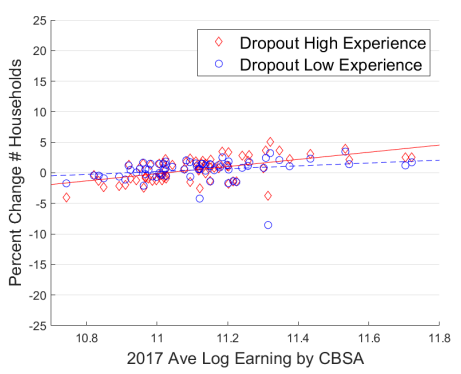

Panel B

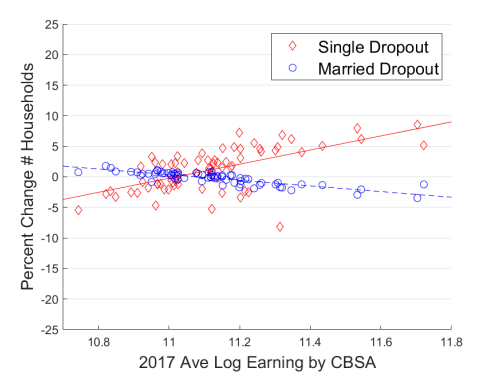

Panel C

Figure 21: Earnings distortion with earnings index and harmonized transfer programs: Counterfactual population relative to lump-sum transfers with earnings index and harmonized transfer programs. Each dot represents a CBSA. The horizontal axis is the 2017 log mean earnings for all households. Panel A presents results for college and post-college educated, Panel B presents results for experience and less experienced dropouts households, and Panel C presents results for single dropout households compared to married dropout households.

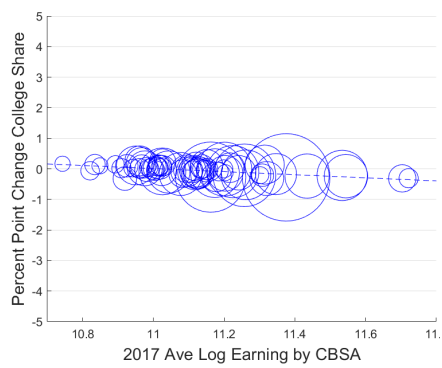

Panel A

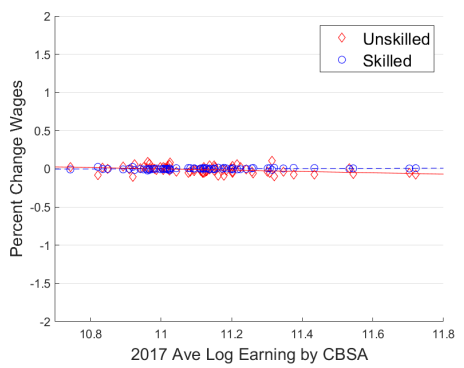

Panel B

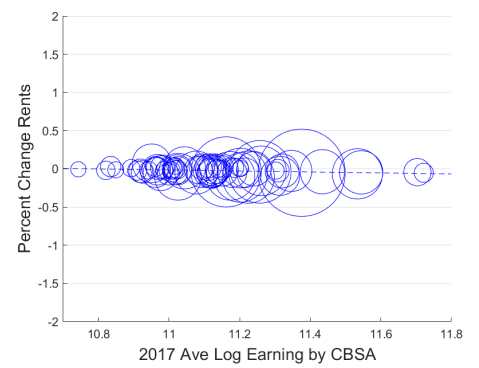

Panel C

Figure 22: Earnings distortion with earnings index and harmonized transfer programs: Counterfactual population relative to lump-sum transfers with earnings index and harmonized transfer programs. Each dot represents a CBSA. The horizontal axis is the 2017 log mean earnings for all households. Panel A presents change in college share, Panel B presents change in wages, and Panel C presents changes in rents.

\section{D.8 Cost-of-living Adjustments}

In this section, we consider indexing earnings to local cost-of-living, such that benefits are based on real income, rather than nominal income. ${ }^{87}$ As prices are generally higher in high wage cities, this increases the amount of transfer households receive if they live in high rent, high wage cities and potentially reduces the distortion towards low-wage cities.

Let $\tilde{I}_{j}^{d}=\frac{I_{d j}}{\kappa_{j}}$ be cost-of-living adjusted household earnings, where $\kappa_{j}$ is the price of a market basket in city $j$. We calculate the cost of the market basket as $\kappa_{j}=\bar{h} r_{j}+\bar{c}$, where $\bar{h}$ and $\bar{c}$ are the average quantities of housing and the

\footnotetext{
${ }^{87}$ This adjustment was suggested by Albouy (2009) to reduce the spatial distortion caused by the federal income tax program.
} 


\begin{tabular}{lccc}
\hline & $\begin{array}{c}\mathrm{A} \\
\text { Baseline }\end{array}$ & $\begin{array}{c}\mathrm{B} \\
\text { COLA } \\
\text { Adjustments }\end{array}$ & $\begin{array}{c}\mathrm{C} \\
\text { COLA+ } \\
\text { Harmonize }\end{array}$ \\
\hline I. \% $\Delta$ Low-Earning Locations & & \\
HS Dropout & 3.37 & 0.83 & 0.74 \\
HS Grad & 0.49 & 0.00 & 0.08 \\
College & 0.45 & 0.03 & 0.25 \\
Post College & -0.36 & -0.04 & -0.16 \\
II. \% $\Delta$ Generous-Benefit Locations & & \\
HS Dropout & 2.42 & 13.42 & 7.80 \\
HS Grad & -0.96 & 0.68 & 0.37 \\
College & -0.83 & 0.10 & -0.35 \\
Post College & 0.07 & -0.19 & 0.02 \\
III. Deadweight Loss & 4.38 & 1.67 & 0.88 \\
\hline
\end{tabular}

Table 10: Spatial distortions caused by current transfer programs and by alternative programs with cost-of-living adjustments. Panel I gives the percentage difference the number of households location in low-income cities compared to the equilibrium with lump-sum transfers. Low-earning locations are defined as the ten cities with the lowest average income in the data. Panel II gives the percentage difference the number of households locating in generous-benefit locations compared to the equilibrium with lump-sum transfers. Generous benefit locations are defined as the ten cities which provide the highest transfers to households with zero income. Deadweight loss is measured as a percent of total spending on transfer programs. See text for details on each counterfactual.

consumption good consumed across all households. Transfers are calculated as $\tau_{d j}\left(\kappa \hat{I}_{j}^{d}, U_{d}, 0\right)$, where again $\kappa$ is a parameter we choose to keep total transfers equal to their baseline levels, and we again set " 0 " as the final argument to denote that we eliminate the excess-shelter deduction in this program.

The results are displayed in Table 10. The first column shows the distortion caused by the current transfer programs, for reference. ${ }^{88}$ The next column shows the results with only the cost-of-living adjustments, and the final column shows the effects of both the cost-of-living adjustment and harmonizing transfer programs across states. Overall, the results are fairly similar to those with the local earnings indexing, as average rents and earnings are strongly correlated in the data. However, the deadweight loss with the cost-of-living adjustment is larger than that with the earnings index.

\footnotetext{
${ }^{88}$ This is the same information that is included in the "Baseline" column of Table 1.
} 